UNIVERSIDADE DE SÃO PAULO

ESCOLA DE ENFERMAGEM DE RIBEIRÃO PRETO

CLODIS MARIA TAVARES

A SAÚDE REPRODUTIVA DE MULHERES PORTADORAS E EX-PORTADORAS

DE HANSENÍASE EM UMA CAPITAL DO NORDESTE - BRASIL

Ribeirão Preto 
CLODIS MARIA TAVARES

\title{
A SAÚDE REPRODUTIVA DE MULHERES PORTADORAS E EX-PORTADORAS DE HANSENÍASE EM UMA CAPITAL DO NORDESTE - BRASIL
}

\author{
VERSÃO CORRIGIDA
}

Tese apresentada ao Programa Interunidades de Doutoramento em Enfermagem da Escola de Enfermagem da Universidade de São Paulo e Escola de Enfermagem de Ribeirão Preto da Universidade de São Paulo - Curso Doutorado Interinstitucional entre a Universidade de São Paulo e Universidade Federal de Sergipe tendo como associada à Universidade Federal de Alagoas, para obtenção do título de Doutor em Ciências.

Área de Concentração: Enfermagem

Linha de Pesquisa: Fundamentos Teóricos e Filosóficos do Cuidar

Orientadora: Prof. ${ }^{\text {a }}$ Dr. ${ }^{\text {a }}$ Ana Maria de Almeida

\section{Ribeirão Preto}


Autorizo a reprodução e a divulgação total ou parcial deste trabalho, por qualquer meio convencional ou eletrônico, para fins de estudo e pesquisa, desde que citada a fonte.

\section{FICHA CATALOGRÁFICA}

Tavares, Clodis Maria

A saúde reprodutiva de mulheres portadoras e ex-portadoras de hanseníase em uma capital do Nordeste - Brasil Ribeirão Preto, 2014.

124p.: il.; $30 \mathrm{~cm}$.

Tese de Doutorado apresentada à Escola de Enfermagem de Ribeirão Preto/USP - Área de Concentração: Enfermagem

Orientadora: Almeida, Ana Maria.

1. Hanseníase. 2. Epidemiologia. 3. Anticoncepção. 4. Saúde da Mulher.

5. Gestantes. 
TAVARES, C. M. A saúde reprodutiva de mulheres portadoras e ex-portadoras de hanseníase em uma capital do Nordeste - Brasil.

Tese apresentada ao Programa de Doutorado Interinstitucional (DINTER) de Doutoramento em Enfermagem da Escola de Enfermagem de Ribeirão Preto da Universidade de São Paulo para obtenção do título de Doutor em Ciências.

Aprovado em

Banca Examinadora

Prof. Dr. Instituição:

Julgamento: Assinatura:

Prof. Dr. ${ }^{\mathrm{a}}$ Instituição:

Julgamento: Assinatura:

Prof. Dr. ${ }^{\mathrm{a}}$ Instituição:

Julgamento: Assinatura:

Prof. Dr. ${ }^{\mathrm{a}}$ Instituição:

Julgamento: Assinatura:

Prof. Dr. ${ }^{\mathrm{a}}$ Instituição:

Julgamento: Assinatura: 
A hanseníase é um dos mais sérios problemas de saúde pública do país. O Brasil ocupa o $1^{\circ}$ lugar da América Latina e o $2^{\circ}$ do mundo em número de doentes. (Ministério da Saúde) 
"Perdemos a nossa identidade e somos forçados a carregar uma outra, cujo peso estigmatizante foge às dimensões descritíveis.

De fato, não dá para descrever o que sentimos quando alguém nos chama de leproso, hanseniano ou nos trata como tal. Nada dói mais do que ser tratado como algo que dá nojo, que causa piedade, que desperta medo"

(BACURAU, Uma liderança confirmada, 1988. MORHAN Movimento de Reintegração das Pessoas atingidas pela Hanseníase) 
DEDICATÓRIA

A Deus, por ter me dado saúde e força para superar as dificuldades;

À minha família, de modo especial, à minha mãe Zeneida, meus irmãos Everton, Edson e Najla, minha filha Karine e meu companheiro Dáfines;

Aos meus sobrinhos, em especial Pedro Tavares;

Ao meu saudoso pai Francisco Teodonísio Tavares, carinhosamente conhecido por Boris. (In memorian) 


\section{AGRADECIMENTOS}

Meu apreço aos professores, minha família, amigos e colegas que, estiveram ao meu lado de várias formas, apoiando este trabalho.

De modo especial à:

Prof. ${ }^{\text {a }}$ Dr. ${ }^{\text {a }}$ Ana Maria de Almeida - Minha orientadora - EERP-USP

Prof. ${ }^{a}$ Dr. ${ }^{a}$ Cláudia Benedita dos Santos - EERP/USP

Prof. ${ }^{a}$ Dr. ${ }^{a}$ Dulce Maria Rosa Gualda - Ex-Coordenadora do DINTER/EESP/USP

Prof. ${ }^{a}$ Dr. ${ }^{a}$ Isília Aparecida Silva - Atual Coordenadora - USP

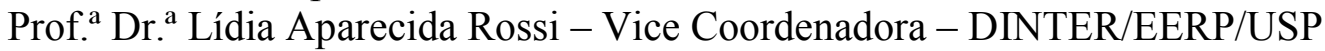

Prof. a Dr. ${ }^{\text {a }}$ Renata Man - Coordenadora do DINTER/UFS

Prof. Dr. João Xavier de Araújo Júnior - Diretor da Esc. Enf. e Farmácia ESENFAR/ UFAL

Prof. ${ }^{\text {a Dr. }}{ }^{\text {a }}$ Regina Maria dos Santos - Coordenadora do DINTER - ESENFAR/UFAL

Prof. ${ }^{\text {a Dr. }}$. Ruth França Cizino da Trindade - Coordenadora do Grupo de Pesquisa

Enfermagem Saúde e Sociedade - ESENFAR/UFAL

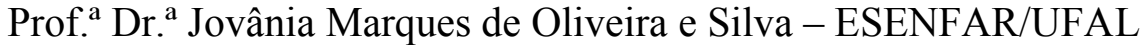

Prof. ${ }^{a}$ Dr. ${ }^{a}$ Vera Grácia Neumann Monteiro - Ex-Coordenadora do curso de

Enfermagem - ESENFAR/UFAL

Prof. ${ }^{a}$ Dr. ${ }^{\text {a }}$ Leila Pacheco Ferreira Cavalcante - Coordenadora do curso de

Enfermagem - ESENFAR/UFAL

Agradeço também aos colegas professores da Escola de Enfermagem e Farmácia ESENFAR/UFAL, pelo apoio e incentivo para a realização desta nova etapa de minha vida.

Minha gratidão a todos os funcionários da Escola de Enfermagem e FarmáciaESENFAR/UFAL

Ao grupo de Extensão e Pesquisa Hanseníase na Comunidade - ESENFAR-UFAL, que tanto contribuiu para realização deste trabalho.

A todos que colaboraram durante minha trajetória de 13 anos no controle da hanseníase na Secretaria de Estado da Saúde (SESAU/AL), que me inspirou para elaboração deste estudo.

Agradeço de modo especial aos Enfermeiros Maria Antonieta Spinoso Prado, Daniele Teodósio, Tâmyssa Simões dos Santos, Carla Islowa da Costa Pereira, Emiliana Bomfim, Michell Ângelo Marques Araújo, Luís Carlos Lopes Júnior, Dione Santos; ao Odontólogo Raony Môlim; aos Estatísticos Paulo César de Almeida e Lúcio Wagner Torres de Carvalho; aos discentes monitores de Maceió/AL Fernanda Goes, Pedro Tavares, Khennia Tarciana Correia, José Manuel Ângelo, Michael Rocha, Cristiano Melo, as discentes da EERP-USP Priscila Galo Farnocchi e Karen Santos. 


\section{RESUMO}

TAVARES, C. M. A saúde reprodutiva de mulheres portadoras e ex-portadoras de hanseníase em uma capital do Nordeste - Brasil. 2014. 124f. Tese (Doutorado) - Escola de Enfermagem de Ribeirão Preto, Universidade de São Paulo, Ribeirão Preto, 2014.

A detecção de casos novos de hanseníase permanece elevada no mundo, no Brasil e em Alagoas. Trata-se de uma importante morbidade que leva a incapacidades físicas, preconceito e estigma. A ênfase dada à saúde reprodutiva de mulheres portadoras e ex-portadoras de hanseníase deve-se ao fato de a gestação induzir recidivas, exacerbar lesões pré-existentes e aumentar a evolução da forma indeterminada para outras formas clínicas, o que exige um acompanhamento para uma prática anticonceptiva segura. O objetivo geral foi conhecer a situação da saúde reprodutiva das mulheres portadoras e ex-portadoras de hanseníase na rede de atenção básica do município de Maceió. Trata-se de um estudo descritivo de corte transversal com abordagem quantitativa. O estudo foi realizado em 14 Unidades Básicas de Saúde (UBS) dos 07 Distritos Sanitários do município de Maceió/Alagoas. A população foi constituída por 60 mulheres. Os dados nos revelam que a maioria das mulheres se encontrava na faixa etária de 30 a 49 anos (75\%), tinham companheiro (70\%), eram analfabetas ou com o ensino fundamental incompleto (53,3\%). Em relação à ocupação, $45 \%$ eram do lar e 55\% desempenhavam outras ocupações remuneradas. Essas mulheres coabitavam com uma a três pessoas $(36,7 \%)$ ou com seis a quatorze pessoas $(28,3 \%)$. Quanto à religião, $61,7 \%$ eram católicas. A maioria buscou detecção por demanda espontânea $(30,0 \%)$. Quanto à forma clínica, 30,0\% era Dimorfa, 20\% Tuberculóide, 15\% Indeterminada, 10\% Virchowiana e $25,0 \%$ formas clínicas não classificadas. Eram multibacilares 56,7\%. Quanto às reações hansênicas, $16,7 \%$ informaram tê-las antes do diagnóstico, $28,3 \%$ durante o tratamento e $21,7 \%$ no pós-tratamento; $8,3 \%$ das reações eram do tipo I e $66,7 \%$, do tipo II. Das mulheres, $5 \%$ estavam grávidas no diagnóstico, $1,7 \%$ no período puerperal e 1,7\% amamentando. Em relação à história reprodutiva, $63,3 \%$ engravidou de uma a três vezes e $26,6 \%$ de quatro a dez vezes e $75 \%$ tiveram de um a três partos. Três mulheres estavam grávidas no momento do diagnóstico. Conheciam métodos contraceptivos, como condom masculino (98,3\%), pílula $(88,3 \%)$, laqueadura tubária $(86,7 \%)$ e outros; os utilizavam, em maior índice, pílula $(73,3 \%)$, condom masculino $(70,0 \%)$, laqueadura tubária $(53,3 \%)$ e outros. Quanto ao conhecimento dos métodos anticoncepcionais e características sociodemográficas, os maiores percentuais foram: condom masculino $(100 \%)$, pílula $(87,8 \%)$, laqueadura tubária $(85,7 \%)$, injeção $(75,6 \%)$, tabela $(71,4 \%)$, DIU $(64,3 \%)$. Realizando uma análise inferencial os dados denotam relação significativa com associação entre temperatura e ocupação, aleitamento materno e número de pessoas na família, pílula e número de pessoas, injeção e escolaridade, injeção e ocupação, diafragma e número de pessoas, espermicida e número de pessoas, vasectomia e se estudava, com $p>0,05$. Médicos e enfermeiros contribuíram mais na oferta de informações sobre contraceptivos, meios midiáticos exerceram grande influência. $\mathrm{O}$ principal local de recebimento dos contraceptivos foi a UBS. Concluímos que as mulheres em idade fértil portadoras e ex-portadoras de hanseníase estão sendo pouco aconselhadas para a anticoncepção, tornando-se susceptíveis ao risco de uma gravidez indesejável, levando-as a apresentar reações imunológicas graves.

Palavras chave: Hanseníase. Epidemiologia. Anticoncepção. Saúde da Mulher. Gestantes. 


\begin{abstract}
The reproductive health of women suffering and former carriers of leprosy in a capital Northeast - Brazil. 2014. 124p. Thesis (Ph.D.) - School of Nursing of Ribeirão Preto, University of São Paulo, Ribeirão Preto, 2014.

The detection of new leprosy cases in the world remains high in Brazil and Alagoas. This is an important morbidity that leads to physical disability, prejudice and stigma. The emphasis on reproductive health of women suffering and former carriers of leprosy is due to the fact pregnancy induce relapses, exacerbate pre-existing injuries and increase the evolution of indeterminate form for other clinical forms, which requires monitoring for a safe contraceptive practice. The overall objective was to know the situation of reproductive health of women suffering and former carriers of leprosy in primary health care in the city of Maceió network. This is a descriptive cross-sectional study with a quantitative approach. The study was conducted in 14 Basic Health Units (BHU) of the 07 health districts of the city of Maceió / Alagoas. The study population consisted of 60 women. The data reveal that a majority of women in the age group $30-49$ years $(75 \%)$ had a partner $(70 \%)$ were illiterate or with incomplete primary education (53.3\%). In terms of occupation, $45 \%$ were housewives and $55 \%$ played other paid occupations. These women lived with one to three people $(36.7 \%)$ or six to fourteen people (28.3\%). As for religion, $61.7 \%$ were Catholic. Most searched detection by spontaneous demand (30.0\%). Clinical forms, 30.0\% were borderline, 20\% Tuberculoid, Indefinite $15 \%, 10 \%$ and $25.0 \%$ Lepromatous clinical forms not classified. $56.7 \%$ were multibacillary. As for leprosy reactions, $16.7 \%$ reported having them before diagnosis, during treatment $28.3 \%$ and $21.7 \%$ after treatment; $8.3 \%$ of the reactions were of type I and $66.7 \%$ type II. Among women, 5\% were pregnant at diagnosis, $1.7 \%$ in the postpartum period and $1.7 \%$ breastfeeding. Regarding reproductive history, $63.3 \%$ of pregnant once to three times, and $26.6 \%$ for four to ten times, and $75 \%$ had one to three deliveries. Three women were pregnant at the time of diagnosis. Knew contraception, and male condom $(98.3 \%)$, pill $(88.3 \%)$, female sterilization $(86.7 \%)$ and others; used them in highest pill $(73.3 \%)$, male condom $(70.0 \%)$, female sterilization $(53.3 \%)$ and others. Regarding knowledge of contraceptive methods and sociodemographic characteristics, the highest percentages were male condom (100\%), pill (87.8\%), female sterilization (85.7\%), injection (75.6\%), table (71, $4 \%)$, IUD (64.3\%). Performing an inferential data analysis showed a significant relationship with association between temperature and occupation, breastfeeding and number of family members, and number of people pill, injection and education, and occupation injection, diaphragm and number of people, number of people and spermicide, vasectomy and studied with $\mathrm{p}>0.05$. Doctors and nurses have contributed more to offer information about contraceptives, exerted great influence from the media. The principal place of receipt of contraceptives was BHU. We conclude that women of childbearing age bearers and former carriers of leprosy are being advised to little contraception, making it susceptible to the risk of an unwanted pregnancy, leading them to develop severe immune reactions.
\end{abstract}

Keywords: Leprosy. Epidemiology. Contraception. Women's Health. Pregnant women. 


\section{RESUMEN}

TAVARES, C. M. La salud reproductiva de las mujeres que portadoras y ex portadoras de lepra en una capítal del Nordeste - Brasil. 2014. 124h. Tesis (Doctorado) - Escuela de Enfermería de Ribeirão Preto de la Universidad de São Paulo, Ribeirão Preto, 2014.

La detección de nuevos casos de lepra en el mundo sigue siendo alto en Brasil y Alagoas. Se trata de una morbilidad importante que conduce a la discapacidad física, el preconcepto y el estigma. El énfasis en la salud reproductiva de las mujeres que sufren y los ex portadores de lepra, se debe al hecho de inducir el embarazo recaídas, exagerar las lesiones pre-existentes y aumentar la evolución de la forma indeterminada de otras formas clínicas, lo que requiere la supervisión de una práctica anticonceptiva segura. El objetivo general fue conocer la situación de la salud reproductiva de las mujeres que sufren y los ex portadores de lepra en atención primaria en la ciudad de Maceió. Se trata de un estudio transversal descriptivo con abordaje cuantitativo. El estudio se realizó en 14 Unidades Básicas de Salud (UBS) de los 07 distritos de salud de la ciudad de Maceió/Alagoas. La población de estudio estuvo constituida por 60 mujeres. Los datos revelan que la mayoría de las mujeres en el grupo de edad de 30-49 años (75\%) tenían su compañero de vida $(70 \%)$ eran analfabetas o con educación primaria incompleta (53.3\%). En términos de ocupación, el 45\% eran amas de casa y el 55\% jugó otras ocupaciones remuneradas. Estas mujeres vivían con uno a tres personas $(36,7 \%)$ o de seis a catorce personas $(28,3 \%)$. En cuanto a la religión, el 61,7\% eran católicos. La detección la detección más buscada fue por demanda espontánea (30,0\%). Formas clínicas, el 30,0\% estaban en el límite, el 20\% tuberculoide, Indefinida 15\%, 10\% Virchowiana y 25,0\% formas clínicas lepromatosa no clasificados. 56,7\% eran multibacilares. En cuanto a las reacciones leprosas, $16.7 \%$ reportó tenerlas antes del diagnóstico, durante el tratamiento el $28,3 \%$ y el $21,7 \%$ después del tratamiento; $8,3 \%$ de las reacciones fueron de tipo I y el $66,7 \%$ de tipo II. Las mujeres, el 5\% estaban embarazadas al momento del diagnóstico, el 1,7\% en el período post-parto y el 1,7\% en la lactancia materna. En cuanto a la historia reproductiva, $63,3 \%$ de las mujeres quedaron embarazadas de una a tres veces, y $26,6 \%$ de cuatro a diez veces, y $75 \%$ tuvieron de uno a tres alumbramientos. Tres mujeres que estaban embarazadas en el momento del diagnóstico. Sabía de los métodos anticonceptivos y del condón masculino $(98,3 \%)$, la píldora $(88,3 \%)$, la esterilización femenina $(86,7 \%)$ y otros; ellos utilizaban en mayor cantidad, la píldora $(73,3 \%)$, el condón masculino $(70,0 \%)$, la esterilización femenina $(53,3 \%)$ y otros. Respecto al conocimiento de los métodos anticonceptivos y las características sociodemográficas, los mayores porcentajes fueron condón masculino (100\%), la píldora $(87,8 \%)$, la esterilización femenina $(85,7 \%)$, inyección $(75,6 \%)$ método de abstinencia periódica $(71,4 \%)$, DIU $(64,3 \%)$. La realización de un análisis de datos inferencial mostró una relación significativa con la asociación entre la temperatura y la ocupación, la lactancia materna y el número de miembros de la familia, y el número de personas y la píldora, la inyección y la educación, la inyección y la ocupación, el diafragma y el número de personas, el número de personas y el espermicida, la vasectomía y estudió con $p>0,05$. Los médicos y enfermeras han contribuido más en la oferta de información sobre los anticonceptivos, los medios de comunicación hicieron un buen papel. El principal lugar de recepción de los anticonceptivos fue la UBS. Llegamos a la conclusión de que las mujeres de edad fértil y antiguas portadoras de lepra no están recibiendo la debida información para la anticoncepción, por lo que es susceptible al riesgo de un embarazo no deseado, lo que lleva a desarrollar reacciones inmunes severas.

Palabras clave: Lepra. Epidemiología. Anticoncepción. Salud de la Mujer. Mujeres embarazadas. 


\section{LISTA DE ILUSTRAÇÕES}

Figura 1 - Objetivos de Desenvolvimento do Milênio. Fonte: Programa das Nações Unidas para o Desenvolvimento (PNUD) - ONU, 2000 


\section{LISTA DE TABELAS}

Tabela 1 - Distribuição das mulheres portadoras e ex-portadoras de Hanseníase, em idade fértil, segundo características sociodemográficas, Maceió-Alagoas, 2006 a 2011

Tabela 2 - Distribuição das mulheres portadoras e ex-portadoras de Hanseníase, em idade fértil, segundo modo de detecção e modo de entrada no sistema de saúde, MaceióAlagoas, 2006 a 2011.

Tabela 3 - Distribuição das mulheres portadoras e ex-portadoras de Hanseníase, em idade fértil, segundo forma clínica, classificação operacional, baciloscopia e número de lesões, Maceió-Alagoas, 2006 a 2011.

Tabela 4 - Distribuição das mulheres portadoras e ex-portadoras de Hanseníase, em idade fértil, segundo o grau de incapacidade física no diagnóstico e na alta, Maceió-Alagoas, 2006 a 2011 . $(n=60)$.

Tabela 5 - Distribuição das mulheres portadoras e ex-portadoras de Hanseníase, em idade fértil, segundo número de contatos registrados e contatos examinados no momento do diagnóstico, Maceió-Alagoas 2006 a 2011. $(\mathrm{n}=60)$.

Tabela 6 - Distribuição das mulheres portadoras e ex-portadoras de Hanseníase, em idade fértil, segundo reações hansênicas e história reprodutiva no momento do diagnóstico, Maceió-Alagoas 2006 a 2011. $(\mathrm{n}=60)$.

Tabela 7 - Distribuição das mulheres portadoras e ex-portadoras de Hanseníase, em idade fértil, segundo número de gestações, partos, número de filhos e abortos, Maceió-Alagoas 2006 a $2011 .$.

Tabela 8 - Distribuição das mulheres portadoras e ex-portadoras de Hanseníase, em idade fértil, segundo idade do primeiro parto e último parto, Maceió-Alagoas 2006 a 2011.

Tabela 9 - Distribuição do número de mulheres grávidas no momento do diagnóstico segundo características sociodemográficas, Maceió-Alagoas 2006 a 2011

Tabela 10 - Distribuição do número de mulheres, em idade fértil, portadoras e exportadoras de Hanseníase, segundo o conhecimento espontâneo e o uso de método contraceptivo, Maceió-Alagoas 2006 a 2011.

Tabela 11 - Distribuição do número de mulheres em idade fértil, portadoras e exportadoras com Hanseníase, segundo gravidez no percurso da doença e conhecimento espontâneo sobre método anticoncepcional, Maceió-AL, 2006 a 2011

Tabela 12 - Distribuição do percentual de mulheres portadoras e ex-portadoras de hanseníase, com conhecimento espontâneo sobre métodos anticoncepcionais e características sociodemográficas, Maceió-Alagoas 2006, a 2011. 
Tabela 13 - Distribuição do percentual de mulheres portadoras e ex-portadoras de hanseníase, segundo de quem ouviu falar sobre métodos anticoncepcionais e características, Maceió-Alagoas 2006 a 2011.

Tabela 14 - Distribuição do percentual de mulheres portadoras e ex-portadoras de hanseníase, de dados demográficos segundo o recebimento dos métodos por níveis de atenção à saúde, Maceió-Alagoas 2006 a 2011

Tabela 15 - Distribuição do percentual de mulheres portadoras e ex-portadoras de hanseníase, segundo meio de orientação / informação sobre métodos anticoncepcionais e características, Maceió-Alagoas 2006 a 2011................................................................. 7 


\section{LISTA DE SIGLAS}

ACS

CESMAC

CIPD

CNS

$\mathrm{ENH}$

ESF

HD

HI

HT

MAC

MB

MHC-II

MS

NOB/96

ODM

OMS

ONU

PAC

PAISM

PB

PNAISM

PQT/OMS

Saúde

SINAN

SMS

SPSS

SUS

TCLE

UBS
Agentes Comunitários de Saúde

Centro Universitário de Maceió

Conferência Internacional sobre População e Desenvolvimento

Conselho Nacional de Saúde

Eritema Nodoso Hansênico

Estratégia Saúde da Família

Hanseníase Dimórfica

Hanseníase Indeterminada

Hanseníase Tuberculóide

Métodos Anticoncepcionais

Hanseníase Multibacilar

Complexo de Histocompatibilidade Principal

Ministério da Saúde

Norma Operacional Básica de 1996

Objetivos de Desenvolvimento do Milênio

Organização Mundial da Saúde

Organização das Nações Unidas

Programa de Aceleração do Crescimento

Programa de Assistência Integral à Saúde da Mulher

Hanseníase Paucibacilar

Política Nacional de Atenção Integral à Saúde da Mulher

Poliquimioterapia recomendada pela Organização Mundial de

Sistema de Informação de Agravos de Notificação

Secretaria Municipal de Saúde

Statistical Package for the Social Sciences

Sistema Único de Saúde

Termo de Consentimento Livre e Esclarecido

Unidades Básicas de Saúde 


\section{SUMÁRIO}

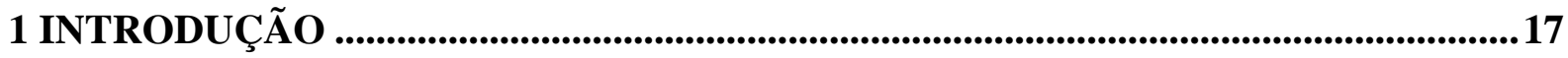

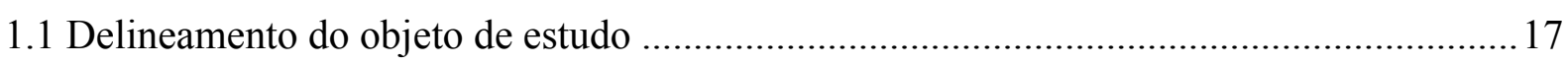

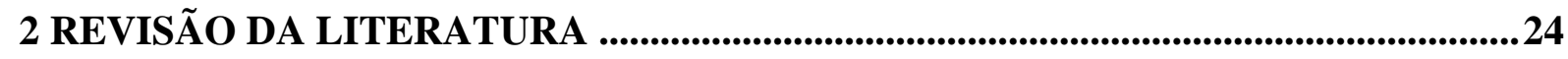

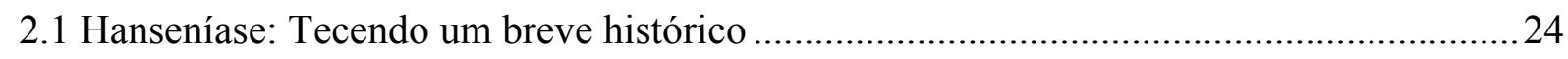

2.2 Aspectos clínicos da hanseníase: do diagnóstico ao tratamento........................................26

2.3 Políticas públicas de saúde da mulher: a integralidade em questão .................................. 35

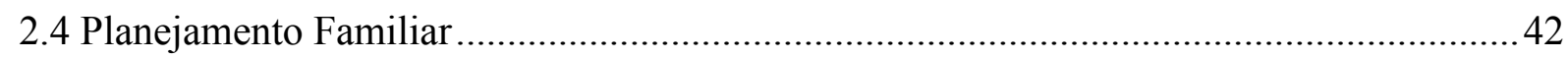

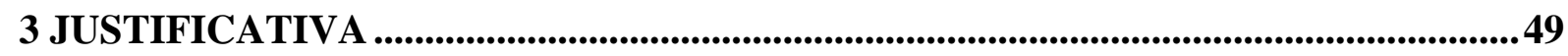

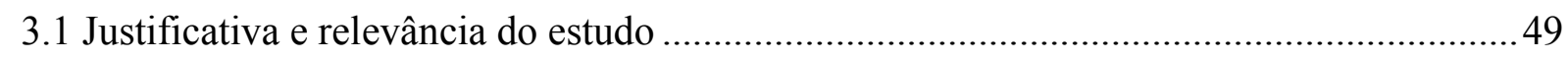

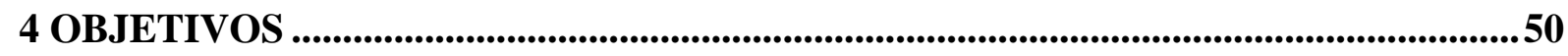

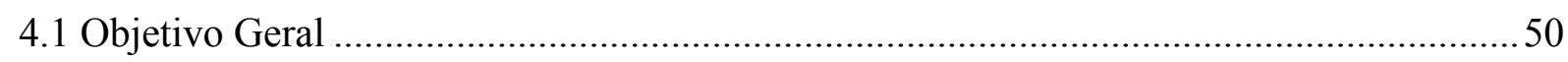

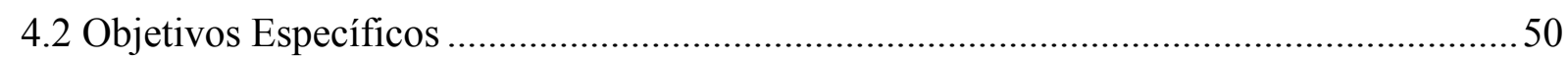

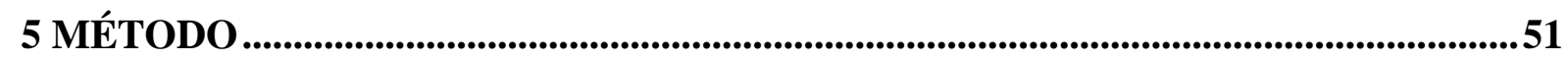

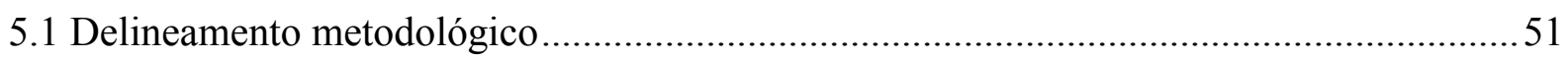

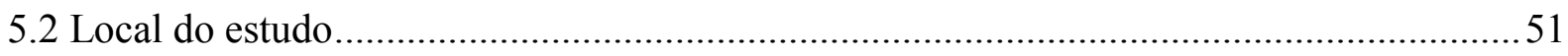

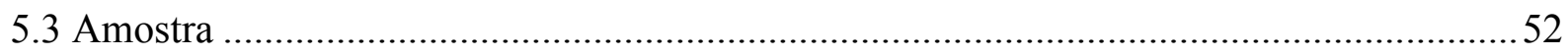

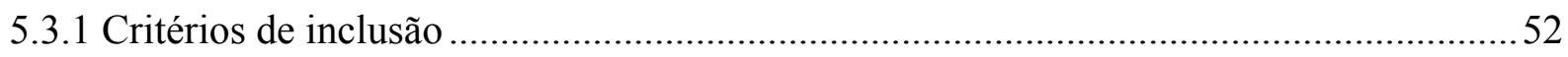

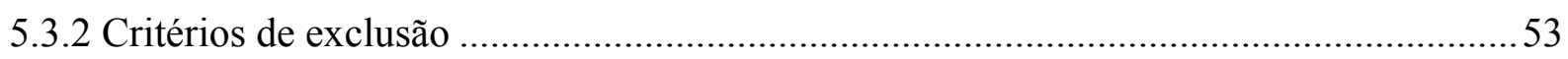

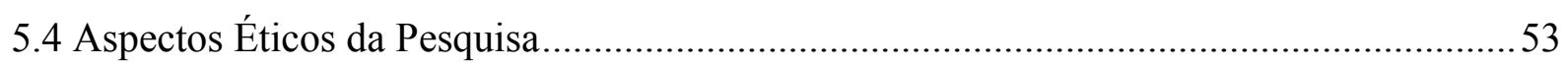

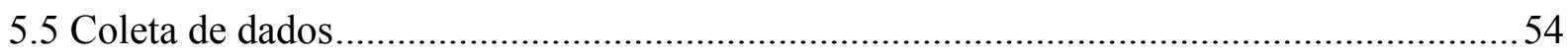

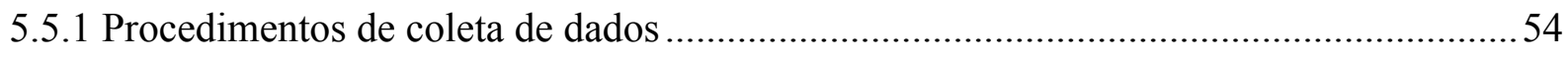

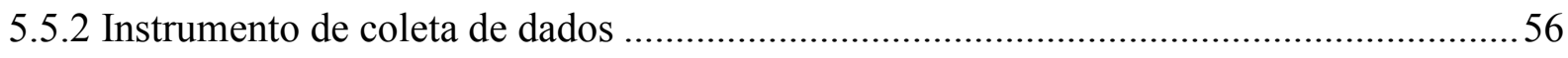

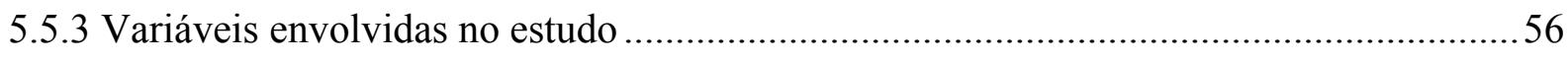

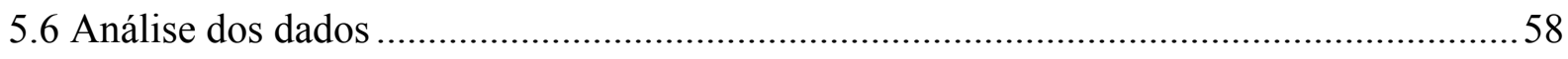

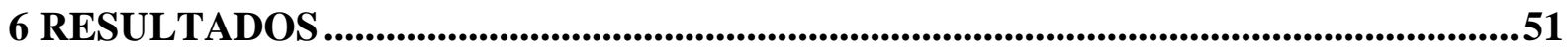

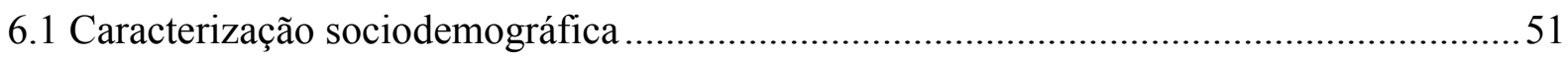




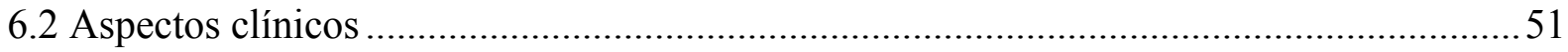

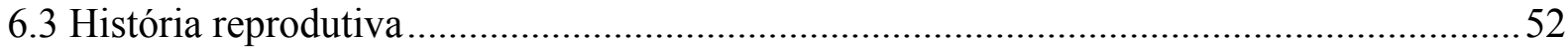

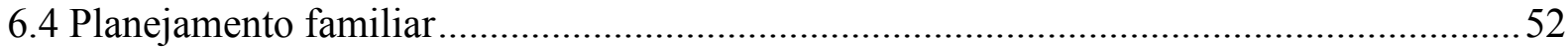

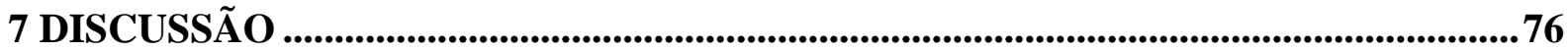

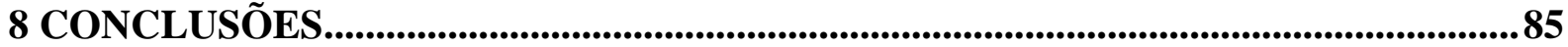

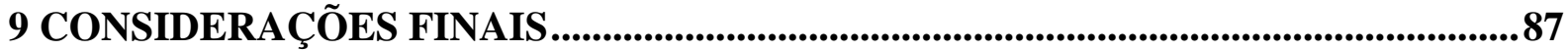

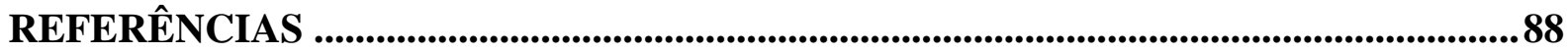

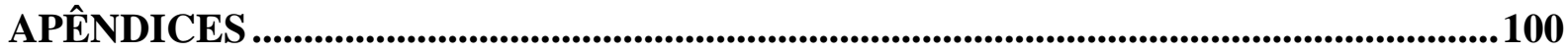

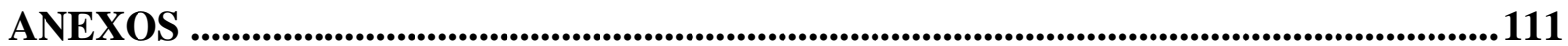




\section{INTRODUÇÃO}

\subsection{Delineamento do objeto de estudo}

Ainda no século XXI, a detecção de casos novos de hanseníase permanece elevada mundialmente, com cerca de 250 mil casos novos registrados a cada ano (MONTEIRO et al., 2013; RODRIGUES; LOCKWOOD, 2011). Trata-se de uma importante morbidade, uma vez que, pode levar a incapacidades, deformidades físicas, preconceito e estigma, embora não se apresente como causa básica frequente de óbito. No Brasil, as ações implantadas nos serviços de saúde para o controle da hanseníase não se configuraram suficientes, permitindo que a doença seja um sério problema de saúde pública (PENNA, M.; OLIVEIRA; PENNA, G., 2009). Dados da Organização Mundial da Saúde (OMS) apontam o Brasil como o segundo país com o maior número de casos em 2012, apresentando aproximadamente $93 \%$ dos casos das Américas (OMS, 2012).

A hanseníase é uma doença crônica infecciosa, causada pelo Mycobacterium leprae, um bacilo intracelular obrigatório com tropismo por células do sistema retículo-endotelial (macrófagos de pele) e de células do sistema nervoso periférico (células de Shwann) (EICHELMANN et al., 2013). Apesar do M. leprae apresentar predileção por células de Schwann devido às ligações específicas, as quais são expressas na lâmina basal dos nervos periféricos, a hanseníase também compromete a pele, articulações, olhos, testículos, gânglios e outros órgãos (BRASIL, 2007a).

$\mathrm{O}$ alto potencial incapacitante da hanseníase está diretamente relacionado à capacidade de penetração do Mycobacterium leprae na célula nervosa e devido também ao seu poder imunogênico. O M. leprae é um bacilo álcool-ácido resistente e gram-positivo, em forma de bastonete; é um parasita intracelular e contém em sua parede celular um glicolipídio fenólico (PGL-1) específico, que se liga à lâmina basal das células de Schwann e essa interação é provavelmente relevante para o fato de o $M$. leprae ser a única micobactéria a invadir os nervos periféricos. Uma vez que o agente patogênico penetra parede celular, o processo de replicação ocorre lentamente até que as células $\mathrm{T}$ reconheçam os antígenos de micobactérias e então, a reação inflamatória crônica se instala. Este bacilo não cresce em meios de cultura artificiais, ou seja, não é cultivável in vitro. Devido ao padrão de multiplicação do bacilo, a 
doença progride lentamente, sendo que o período de incubação médio é de dois a cinco anos para o aparecimento dos primeiros sinais e sintomas (EICHELMANN et al., 2013).

Considerando a magnitude da doença, seu alto potencial incapacitante e a prevalência principalmente em faixas etárias economicamente ativas, a doença torna-se de alta relevância para a saúde pública global (BRASIL, 2009a; ORGANIZAÇÃO MUNDIAL DA SAÚDE, 2012).

O boletim epidemiológico da OMS de 2010 aponta que dezesseis países no mundo notificaram mil ou mais casos em 2009. A Ásia apresentou a maior taxa de detecção, exibindo 9,39 casos por 100.000 habitantes, enquanto que as Américas apresentaram 4,58 casos por 100.000 habitantes. A grande influência nesse panorama epidemiológico foi dada pela Índia, com 133.717 casos notificados e pelo Brasil, com 37.610, alcançando o coeficiente de detecção de 19,64 para cada 100.000 habitantes, posicionando-o no segundo lugar em número de casos e primeiro lugar em coeficiente de detecção, com 40.474 casos, o que representa 93\% dos casos novos notificados nas Américas (OMS, 2010).

As estatísticas apresentadas acima ratificam a hanseníase como doença endêmica no Brasil. Registram-se em média, a cada ano, 47.000 novos casos, dos quais 23,3\% com graus de incapacidade I e II. Esta situação afeta a qualidade de vida de milhares de pessoas, uma vez que, a doença compromete o sistema imunológico, a nocicepção, a visão e o tato, tornando-os mais vulneráveis a riscos diversos tais como: acidentes, queimaduras, feridas, infecções, amputações, entre outros (BRASIL, 2008a). Nas duas últimas décadas houve redução significativa da prevalência da doença, devido à implementação da poliquimioterapia recomendada pela Organização Mundial de Saúde (PQT/OMS) em larga escala (PENNA, M.; OLIVEIRA; PENNA, G., 2009).

Nas Regiões Norte, Nordeste e Centro-Oeste verificam-se altos coeficientes de detecção da doença (IGNOTTI; DE PAULA, 2011). De acordo com o Ministério da Saúde brasileiro, a doença é mais expressiva em regiões de baixa renda, que se transpõem com ausência de recursos como saneamento básico, saúde, e educação (BRASIL, 2009a), porém, ressalta-se que a hanseníase não está totalmente relacionada com as classes desfavorecidas, mas sim à aglomeração familiar e a hiper-população doméstica (CHIRWA; FLOYD; FINE, 2013).

Em 1991, durante a 44ª Assembleia Mundial de Saúde, a eliminação da hanseníase foi estabelecida como estratégia para impactar a saúde pública nos países endêmicos até o final do ano 2000, definindo como indicador um coeficiente de prevalência de menos de um caso por 10.000 habitantes. Essa meta não foi atingida em sua totalidade, sendo projetada para o 
ano de 2005, porém, não foi alcançada. Assim, adiou-se para o ano de 2011, entretanto, também não obteve sucesso. Recentemente, representantes do Ministério da Saúde juntamente com a OMS se reuniram para tratar da Política Nacional de Eliminação da Hanseníase que prevê eliminar a hanseníase como problema de saúde pública, almeja-se atingir o coeficiente de prevalência da doença de menos de um caso a cada 10.000 habitantes até 2015 (BRASIL, 2012).

No âmbito brasileiro, reporta-se desde a década de 90, movimentos que caminhavam ao encontro da meta traçada pela OMS. Os estados brasileiros nessa ocasião, com a efetivação da descentralização dos serviços de saúde, tinham como um dos requisitos básicos, que constava da Norma Operacional Básica de 1996 (NOB/96), que as ações de Controle da Hanseníase fossem repassadas para as secretarias municipais de saúde. Essa medida foi estabelecida por meio da Portaria Ministerial N 1073/GM, que orientava sobre a implantação do Programa de Controle da Hanseníase na Atenção Básica (BRASIL, 2001). Tais ações de controle da hanseníase tinham como objetivo detectar precocemente os casos novos, evitar a transmissão da doença aos menores de 15 anos de idade e reduzir os danos causados pela doença, as incapacidades físicas e psicossociais.

Em 2006, o Ministério da Saúde, por meio da Secretaria de Vigilância em Saúde com as ações de Controle da Hanseníase, inseriu esta doença entre as prioridades do Pacto pela Saúde. Esta inclusão deveria fortalecer as ações de vigilância à saúde, desde a atenção básica até a especializada, e salientou que a maioria dos casos poderia ser diagnosticada, tratada e curada com ações do nível primário de assistência, representadas pela atenção básica à saúde. Assim, o Ministério da Saúde preconizou cinco ações programáticas, para controlar e eliminar a endemia da hanseníase no país, quais sejam: 1) detecção de casos (diagnóstico); 2) tratamento; 3) vigilância de contatos; 4) prevenção de incapacidades físicas e 5) educação em saúde (BRASIL, 2006a).

Atualmente, as estratégias de controle da doença, no país, centram-se no diagnóstico precoce dos casos, tratamento e cura, visando eliminar fontes de infecção e evitar sequelas neurológicas com o tratamento precoce por meio da PQT. Além disso, as ações de Controle da Hanseníase estão inseridas na Coordenação Nacional de Doenças Negligenciadas da Secretaria de Vigilância em Saúde (BRASIL, 2011).

Destaque para o problema da hanseníase no mundo, no Brasil e, particularmente, no estado de Alagoas, foco deste estudo, que reflete o estágio do desenvolvimento social da população, mostrando que as precárias condições de vida da maioria da população estão intimamente relacionadas a essa endemia. O Ministério da Saúde, em julho de 2007, 
recomendou o uso do coeficiente de detecção (incidência) para todas as idades e em menores de 15 anos como principal indicador para monitorar a eliminação da hanseníase como problema de saúde pública (PENNA, M.; OLIVEIRA; PENNA, G., 2009; ARAÚJO, 2003). A hanseníase ainda se mantém com uma elevada magnitude em vários países e o caráter de doença negligenciada compromete sistematicamente o seu controle, mesmo com os avanços alcançados (OMS, 2005, 2008).

No cenário brasileiro, Penna, M.; Oliveira; Penna, G. (2009), ao estudarem as séries temporais de detecção da doença no período de 1990 a 2008, encontraram uma tendência decrescente, estatisticamente significativa para as séries temporais a partir de 2004, quando considerado o Brasil como um todo. Entretanto, esse coeficiente oscilou entre 20/100.000 habitantes em 1990 a 29,4/100.000 habitantes em 2003, classificado, portanto, como "muito alto", de acordo com parâmetros oficiais, conforme ANEXOS 1 e 2. As regiões Norte, Nordeste e Centro-Oeste ainda mantêm taxas em patamares muito elevados (OMS, 2012).

No que concerne ao estado de Alagoas, a hanseníase apresenta uma elevada taxa de detecção de casos, os quais estão sendo diagnosticados tardiamente, já que apresenta uma variação de 6 a 12\% dos casos identificados, com incapacidades físicas de grau II e deformidades do tipo lagoftalmo, garras, reabsorção óssea, mãos e pés caídos, entre outras. Dados epidemiológicos de Alagoas apontaram, em 2001, um coeficiente de detecção em todas as idades de 13,26/100.000 habitantes. Em 2012, foi alcançado um coeficiente de detecção de 14,51/100.000 habitantes. Considerando-se os parâmetros da OMS e do Ministério da Saúde, os dois períodos exibem uma alta taxa de detecção. Na avaliação nacional do Ministério da Saúde, o estado de Alagoas ocupa o vigésimo lugar no país em número de casos e o oitavo da região Nordeste (BRASIL, 2011; ALAGOAS, 2010).

Em relação ao coeficiente de detecção anual de casos novos na população de 0 a 14 anos, que mede a força da transmissão recente da endemia hansênica e sua tendência, no ano de 2001, o estado de Alagoas alcançou um coeficiente de detecção de 2,59/100.000 habitantes e no ano de 2009 o coeficiente de detecção de 2,25/100.000. De acordo com os parâmetros estabelecidos internacionalmente, no primeiro ano avaliado foi classificado como sendo de alta detecção e no último ano avaliado foi observada uma pequena redução no coeficiente passando para o parâmetro de média detecção (ALAGOAS, 2010).

As principais regiões de importância epidemiológica de Alagoas são compostas por doze municípios, que foram selecionados como prioritários, por responderem por $79 \%$ da carga da doença e $78 \%$ dos residentes do estado. Esses doze municípios são: Maceió, Arapiraca, União dos Palmares, Penedo, Coruripe, Santana de Ipanema, Delmiro Gouveia, 
Pilar, Rio Largo, Teotônio Vilela, Palmeira dos Índios e São Miguel dos Campos (ALAGOAS, 2007).

O município de Maceió é referência estadual para assistências de média e alta complexidades em hanseníase, concentra mais de 37\% dos casos novos de residentes diagnosticados no período de 2003 a 2009. Em 2008, 28 unidades de saúde do município notificaram casos de hanseníase (ALAGOAS, 2010); tendo a secretaria municipal de saúde implementado ações de descentralização para diagnóstico e tratamento desta endemia nas UBS.

Um fato preocupante é que os casos novos têm ocorrido com pessoas cada vez mais jovens, o que requer ações voltadas para esse grupo, a fim de se obter a prevenção das incapacidades físicas. Para isso, a detecção e o tratamento da doença, em quaisquer grupos, precisam ocorrer o mais precocemente possível para a quebra da cadeia de transmissão. A ênfase das ações voltadas para jovens mulheres deve ser dada em seu ciclo gravídicopuerperal, a fim de se realizar o aconselhamento para o adiamento da gravidez, evitar complicações e os efeitos teratogênicos do tratamento das reações hansênicas.

Embora a associação entre a hanseníase e a gravidez pareça incomum, as complicações inerentes deste relacionamento não o são. O período gravídico e puerperal tem sido associado à elevada incidência de aparecimento dos primeiros sinais ou ao agravamento da hanseníase, sendo mais crítico o período compreendido entre o último trimestre da gestação e os três primeiros meses da lactação, por alterações hormonais, metabólicas e imunológicas. Durante a gravidez, a imunidade celular é suprimida, especialmente no último trimestre da gestação. Adicionalmente, na fase do puerpério, a imunidade humoral é depletada, o que explica também o porquê de mulheres grávidas serem mais suscetíveis a outras infecções, tais como a hepatite e a toxoplasmose nesse período (LOCKWOOD; SINHA, 1999; PALÁCIOS et al., 2013.)

Ademais, no último trimestre de gestação ocorre uma depressão da imunidade celular, o que pode resultar, em mulheres portadoras de hanseníase, em estados reacionais como o fenômeno de Lúcio (reação tipo II). O efeito aditivo do fator reacional às alterações vasculares característicos da gravidez resulta em uma maior probabilidade de vasculite necrotizante grave, tipicamente manifestada nos membros inferiores. No período pós-parto, a supressão da imunidade humoral ocorre, com intensificação de reações do tipo I, resultando em necroses nervosas irreversíveis (BRASIL, 2009b; HELMER et al., 2004; PALÁCIOS et al., 2013). 
Mulheres infectadas pelo Micobacterium leprae provavelmente mostram sinais evidentes da doença na gravidez e no início do puerpério. Nos casos em que a doença já está estabelecida, esta apresentará uma piora durante a gravidez e no puerpério, associada particularmente à deterioração da função nervosa. Primariamente, a razão pela qual estes casos ocorrem é a depressão imunológica celular, observada durante a gravidez; e secundariamente, o aumento de T4 (tiroxina) circulante durante a gestação, causando uma exacerbação da doença. Esta imunossupressão é revertida em torno da sexta semana pósparto, mesmo em lactantes, alterando novamente todo o equilíbrio orgânico, e pode levar a efeitos adversos nas doentes. Aproximadamente $45 \%$ das mulheres portadoras e ex-portadoras de hanseníase têm perda sensitiva ou motora associada à gestação ou lactação, sendo que na maioria delas as alterações da sensibilidade são mais acentuadas que o comprometimento motor (HELMER et al., 2004; OLIVEIRA et al., 2011; PALÁCIOS et al., 2013).

A abordagem dada às mulheres portadoras e ex-portadoras de hanseníase na faixa etária reprodutiva deve-se ao fato de a gestação propiciar recidivas, agravar lesões préexistentes e acentuar a evolução da forma inicial da doença para a forma virchowiana, nos grupos sem resistência imunológica, que correspondem a $10 \%$ da população mundial, e em doentes com tratamento irregular e inapropriado (LOCKWOOD; SINHA, 1999; OLIVEIRA et al., 2011).

A gravidez eleva os riscos para as reações hansênicas, contribuindo para um tratamento irregular e até mesmo seu abandono; consequentemente, aumenta a possibilidade de recidivas e complicações, que podem elevar o coeficiente de mortalidade específica de uma doença que é considerada nula ou de baixa letalidade (OLIVEIRA et al., 2011; PALÁCIOS et al., 2013).

Em relação à história reprodutiva dessas mulheres, considera-se de grande importância a temática da anticoncepção como uma prioridade na educação em saúde, devido à problemática que a gestação pode provocar. Com isso, é necessário que essas mulheres sejam acompanhadas com foco nas ações de planejamento familiar, pois estas atuam como uma potente estratégia do cuidado em saúde para que possibilite sua preparação e autonomia para uma prática contraceptiva segura, e assim prevenir uma gestação de risco (OLIVEIRA et al., 2011).

Ademais, estudos ratificam o risco de desenvolvimento de anomalias congênitas relacionadas ao uso de Talidomida ${ }^{\circledR}$ durante o tratamento de hanseníase. Uma vez que o fármaco é contra-indicado para mulheres em idade fértil, restringindo seu uso apenas nos estados graves com ameaça de óbito. Portanto, o papel da educação em saúde direcionado ao 
planejamento familiar é imprescindível. Neste sentido, mulheres em idade reprodutiva, portadoras e ex-portadoras de hanseníase, necessitam de uma maior atenção por parte dos profissionais de saúde no que diz respeito à anticoncepção, no intuito de minimizar os riscos e prevenir gravidezes indesejáveis (OLIVEIRA et al, 2011).

Mediante a contextualização supracitada, o presente estudo teve como questão de pesquisa:

Como se encontra a situação da saúde reprodutiva das mulheres portadoras e exportadoras de hanseníase, na rede de atenção básica do município de Maceió? 


\section{REVISÃO DA LITERATURA}

\subsection{Hanseníase: Tecendo um breve histórico}

A hanseníase, amplamente conhecida também pela designação de lepra, é uma das mais antigas doenças que acometem o homem. Há registros de evidências dessa enfermidade, aos sinais encontrados em fósseis descobertos no Egito no século II a.C. O registro escrito mais antigo remonta a 600 a.C. e procede da Índia que compõe juntamente com o continente africano o berço dessa morbidade (EIDT, 2004).

A doença era também conhecida pelos antigos gregos como elefantíase. Em tese, o termo lepra foi usado primeiramente por Hipócrates. Suas descrições indicavam tratar-se de uma doença de pele com lesões escamosas, entre as quais a psoríase e os eczemas crônicos, sem haver, porém, menção de manifestações neurológicas (ZAMBACO PACHA, 1914 apud Tavares, 1997).

Menções à lepra são também encontradas na Bíblia. Os capítulos 13 e 14 do Levítico trazem o termo hebreu TZARA`ATH, para designar afecções impuras (BÍBLIA SAGRADA, 1992). Este termo foi traduzido por lepra ou o seu equivalente hanseníase nos diferentes idiomas. Não se pode afirmar com certeza o significado preciso no texto bíblico referido.

A associação da hanseníase com o termo lepra, que por sua vez, está associado às imagens de deformidades, reforçadas por conceitos populares e religiosos de impurezas e/ou castigo divino, é uma das principais origens dos preconceitos e problemas psicossociais que, ainda hoje, persistem e cursam com a doença (EIDT, 2004).

$\mathrm{Na}$ Idade Média, essa enfermidade manteve alta prevalência na Europa e no Oriente Médio. A Igreja Católica, ao realizar o Concílio de Lyon na França, no ano de 583, estabeleceu regras para a profilaxia da doença (ZAMBACO PACHA, 1914 apud TAVARES, 1997). Data também da Idade Média a criação das primeiras ordens religiosas dedicadas a prestar cuidados aos doentes portadores de hanseníase, sendo estas responsáveis pela criação de centenas de asilos para abrigar os acometidos pela doença. A magnitude da hanseníase na Europa do século XIII pode ser estimada pela existência de cerca de 19.000 leprosários naquele continente (EIDT, 2004; ZAMBACO PACHA, 1914 apud Tavares, 1997). 
O declínio da endemia europeia é observado a partir do século XVII e meados do século XIX. Por volta do ano de 1870, a hanseníase já havia praticamente desaparecido de quase todos os países europeus e, mesmo na Noruega, onde ainda era considerada endêmica, sua incidência já estava declinando. Essa tendência decrescente era justificada principalmente pela melhoria das condições de vida que a população da Europa passou a gozar ao longo das idades Moderna e Contemporânea (EIDT, 2004).

Ao mesmo tempo em que a hanseníase tendia ao desaparecimento na Europa, mantinham-se focos endêmicos na Ásia e na África, e a doença surgia no Novo Mundo. As conquistas espanholas e portuguesas expandiram os espaços geográficos dessa enfermidade. Também contribuiu para o seu aparecimento nas Américas o tráfico de escravos africanos (SOUSA-ARAÚJO, 1946 apud TAVARES, 1997). Durante o período da colonização, a América Latina tornou-se, gradativamente, uma nova área endêmica mundial.

A introdução das fontes infectantes, no Brasil, segundo Sousa-Araújo, 1946 apud TAVARES, 1997 teve a seguinte trajetória: pelos portugueses (1500) e espanhóis (15801640) para a região Sudeste, pelos holandeses (1624-1654) para o Norte, e pelos franceses (1757) para a região Sudeste. Assim, os portugueses teriam sido os responsáveis pelo primeiro foco brasileiro, através das migrações colonizadoras, pelos portos das antigas colônias.

As cidades do Rio de Janeiro, Salvador e Recife, entre os séculos XIV e XVII, eram consideradas como os principais centros portuários. No Brasil, não há registro de casos de hanseníase anteriores ao ano de 1600 , pois os primeiros casos foram notificados na cidade do Rio de Janeiro, onde, anos mais tarde, seria criado o primeiro Lazareto - local destinado a abrigar os doentes de Lázaro, lazarentos ou leprosos (BRASIL, 1989 apud TAVARES, 1997).

Outros focos da doença foram identificados na Bahia e no Pará. Esse fato levou as autoridades da Colônia a solicitarem providências a Portugal, sem que estas, entretanto, fossem atendidas (BRASIL, 1989; SOUSA-ARAÚJO, 1946 apud TAVARES, 1997).

As primeiras iniciativas do Governo Colonial só foram tomadas duzentos anos depois, com a regulamentação ao combate da doença, por ordem de D. João VI. As ações de controle, entretanto, limitaram-se à assistência, de forma precária, aos doentes. $\mathrm{O}$ período compreendido entre 1912 e 1920 se constitui numa fase intermediária da história da hanseníase no Brasil. Alguns profissionais de saúde começaram a denunciar o descaso no combate à endemia e a lançar mãos de medidas isoladas em suas áreas de atuação. Entres esses profissionais, encontram-se Emílio Ribas, Oswaldo Cruz e Alfredo da Mata (SOUSAARAÚJO, 1946 apud TAVARES, 1997). 
Em 1972, no X Congresso Internacional de Lepra, realizado na Noruega, o termo lepra foi considerado inconveniente. Em 1974, durante o $1^{\circ}$ Congresso Brasileiro de Hansenologia, realizado em Juiz de Fora (MG), corroborou-se este argumento e recomendou-se a substituição do termo lepra por hanseníase. Em 1976, o Brasil adotou, oficialmente, o termo hanseníase e no ano seguinte o Ministério da Saúde empreende as reformulações necessárias a sua incorporação. Tais eventos refletiam o debate que havia se desenvolvido em São Paulo desde 1967 (CURI, 2010).

Essa medida, entretanto, não tem se mostrado suficiente para sozinha eliminar o estigma que a doença carrega. Primeiro, porque a adoção não foi universal, assim, o termo continua sendo utilizado como sinônimo de lepra. Em segundo lugar, porque essa adoção não foi acompanhada de uma ação educativa no sentido de mudar as atitudes das pessoas frente à doença (TAVARES, 1997).

\subsection{Aspectos clínicos da hanseníase: do diagnóstico ao tratamento}

Durante séculos, a inexistência de terapêutica eficaz contribuiu para a permanência da endemia hansênica. Entretanto, o controle da hanseníase foi possível nos países desenvolvidos, mesmo antes da descoberta de uma droga bactericida, em virtude das garantias de "bens sociais" que influenciaram significativamente para o decréscimo da endemia naqueles países.

Observa-se que as péssimas condições de vida, sem a garantia de moradia digna, educação, alimentação, trabalho e lazer, associadas à baixa qualidade de prestação de serviços de saúde, a permanência da endemia é uma realidade (TAVARES, 1997).

Para que haja um controle efetivo da doença e, portanto, a sua eliminação enquanto problema de saúde pública é necessário que ocorram a notificação, a busca ativa de casos e de abandonos e, principalmente, a avaliação de outras ações empregadas. Todavia, esse processo precisa acontecer sob uma perspectiva multidisciplinar e em equipe, de modo a envolver todos os atores do cuidado das diversas profissões de saúde no desenvolvimento de ações que visem à ruptura da cadeia epidemiológica da doença, na busca de fontes de contágio incluindo os contatos intradomiciliares, bem como atuar na prevenção da transmissão (BRASIL, 2007a). 
O diagnóstico de hanseníase, em grande parte do Brasil, ainda é tardio, realizado cerca de um ano e meio a dois anos aproximadamente, após o aparecimento dos sintomas. A busca tardia de atendimento nos serviços de saúde, a falta de informação sobre sinais e sintomas, a dificuldade no acesso aos serviços no atendimento e profissionais não capacitados ou com pouca capacitação para detectar a doença são fatores que influenciam o diagnóstico tardio. Assim, no Brasil, 5,7\% das pessoas que recebem o diagnóstico de hanseníase já apresentam lesões sensitivas e/ou motoras, deformidades e incapacidades que poderiam ser evitadas (ARANTES et al.,2010).

Esses fatores podem ser reduzidos quando as ações de controle da doença forem realizadas no nível primário de atenção à saúde, representado, no Brasil pela Estratégia Saúde da Família (ESF). Essas ações voltam-se, para detecção ativa e passiva dos casos, por meio de investigação epidemiológica e exames da demanda espontânea aos serviços gerais da unidade de saúde; mobilização da comunidade adstrita; monitoramento e tratamento dos casos diagnosticados bem como os comunicantes (BRASIL, 2008a).

Neste sentido, implementar mudanças na organização dos serviços de saúde para o controle da hanseníase no que diz respeito à atitude dos profissionais, se torna premente, sejam eles profissionais da assistência direta ao paciente, sejam profissionais atuantes nas gerências ou em serviços administrativos e operacionais. Assegurar a consolidação do diagnóstico e tratamento de qualidade, vigilância epidemiológica, notificação e seguimento correto da conduta de referência e contra referência é um desafio que se transpõe e compete a todos os sujeitos engajados nesse processo. Ressalta-se que frequentemente, os procedimentos de referência e contra referência não são bem compreendidos pelos pares, o que pode refletir e comprometer sobremaneira a manutenção da descentralização das ações. Enquanto não houver um entendimento amplo, por todas as categorias profissionais envolvidas, continuará havendo a concentração de casos seja nas unidades básicas ou nas especializadas (EVANGELISTA et al., 2008).

Segundo Pinto Neto et al (2002), o diagnóstico da hanseníase, que é essencialmente clínico e epidemiológico, colabora na adoção dos protocolos para o tratamento adequado a cada forma clínica segundo classificação operacional. Consideram ainda que o controle dos contatos domiciliares como ação de vigilância epidemiológica se constitui em um dos pilares para o controle da hanseníase.

Segundo definição da OMS o diagnóstico clínico de um caso de hanseníase é realizado quando uma pessoa apresenta uma ou mais das seguintes características e que requer tratamento com PQT/OMS: lesões de pele com alteração de sensibilidade; acometimento de nervo(s) com 
espessamento neural; baciloscopia positiva. O critério epidemiológico é realizado por meio da análise da história e condições de vida do paciente, do exame dermatoneurológico para identificar lesões ou áreas de pele com alteração de sensibilidade e/ou comprometimento de nervos periféricos (sensitivo motor e/ou autonômico), (OMS, 2000).

Para fins de notificação da Hanseníase, o profissional de saúde norteia-se por duas diretrizes clínicas: Madrid e Operacional/OMS. A classificação de Madrid define as formas clínicas da hanseníase em: Indeterminada (HI), Tuberculóide (HT), Dimorfa (HD) e Virchowiana (HV), (OMS, 2000).

A HI é a forma inicial da Hanseníase, que se caracteriza por uma ou poucas lesões cutâneas com alteração da sensibilidade. A HT ocorre a partir da evolução da HI não tratada, nos pacientes com boa resistência. Denomina-se Hanseníase Tuberculóide Infantil a uma variedade de HT encontrada particularmente em crianças na faixa etária de 1 a 4 anos. A HD surge em indivíduos portadores de HI com resistência superior aos portadores de HV e inferior aos portadores de HT. A HV representa a evolução da HI não tratada em paciente sem resistência ao bacilo da Hansen (TALHARI; NEVES, 2006).

A classificação operacional da Organização Mundial da Saúde define para fins de diagnóstico o número de lesões cutâneas de acordo com os seguintes critérios: Paucibacilar (PB) e Multibacilar (MB). A Hanseníase Paucibacilar (PB) é definida em casos com até cinco lesões de pele, com alteração de sensibilidade. A MB ocorre quando os casos apresentam mais de cinco lesões de pele, com alteração de sensibilidade (BRASIL, 2008a).

De acordo com Talhari e Neves (2006), os estados reacionais, também conhecidos como reações hansênicas, são manifestações agudas ocasionadas por alterações do sistema imune da pessoa atingida, que se exteriorizam por meio de inflamação aguda e subaguda, que podem ocorrer antes, durante ou depois do tratamento. Essas reações são classificadas em tipo I e tipo II. A reação tipo I ou reação reversa caracteriza-se por infiltração, alteração de cor e edemas nas lesões antigas; surgimento de novas lesões dermatológicas (manchas ou placas); comprometimento de nervos periféricos (neurite) com ou sem lesões cutâneas agudas.

Já a reação tipo II ou Eritema Nodoso Hansênico (ENH) caracteriza-se por apresentar nódulos subcutâneos dolorosos acompanhados ou não de febre, dores articulares e mal-estar generalizado; irite ou iridociclite; orquididimite; mãos e pés reacionais; glomérulo nefrite e comprometimento de nervos periféricos (neurites), (BRASIL, 2002).

No Brasil, o Fenômeno de Lúcio, variante do estado reacional hansênico tipo II, provavelmente mediado por imuno complexos, caracterizado por reação cutânea necrosante grave não nodular (PEREIRA JÚNIOR, 1993; HELMER et al., 2004). 
Clinicamente, o Fenômeno de Lúcio caracteriza-se por máculas eritemato-purpúricas, que evoluem formando escaras castanho-escuro e finas que, ao se desprenderem, em período que varia de duas a quatro semanas, deixam a área cicatricial com aspecto de papel cigarro (GILBERT et al, 1982; MOSCHELLA, 1967). Os achados laboratoriais descritos na literatura para o fenômeno de Lúcio são: anemia, velocidade de hemosedimentação elevada, hipoalbuminemia e ausência de anticorpos antinucleares, lifopenia, hipergamaglobulinemia, VDRL falsamente positivo, fator reumatóide positivo, crioglobulinas do tipo misto, imunocomplexo circulantes, hipocomplementemia e plaquetopenia (BRASIL, 2009b; ANTÔNIO et al, 2003). Para Talhari e Neves (2006) essas ocorrências deverão ser consideradas como situações de urgência e encaminhadas às unidades de referência para tratamento nas primeiras 24 horas.

Até a década de 30, não havia um tratamento específico para a hanseníase. Em 1940, as sulfonas foram descobertas e na década de 60, a Clofazimina ${ }^{\circledR}$ foi utilizada como uma nova medicação corroborando no tratamento dessa patologia. E apenas nos anos 70, com o surgimento da Rifampicina ${ }^{\circledR}$ mediante sua ação altamente bactericida, é que se encontrou o conceito de cura da hanseníase. Em 1987, a PQT/OMS foi introduzida em alguns estados brasileiros em distribuição selecionada em unidades piloto, tornando-se um instrumento fundamental para reduzir a prevalência da hanseníase, tendo em vista o alcance da meta de eliminação (1/10.000 habitantes), (BRASIL, 2009b).

O tratamento dessa endemia é fundamental como estratégia de controle, no intuito de interromper a transmissão da doença, com quebra da cadeia epidemiológica, e também no que tange a prevenção de incapacidades físicas, a reabilitação física e social do portador de hanseníase e a cura (BRASIL, 2009b).

Ressalta-se que o tratamento da hanseníase é ambulatorial, sendo que os esquemas de PQT/OMS, se cumpridos rigorosamente, levam à cura em períodos relativamente curtos (6-12 meses). Esse esquema terapêutico é constituído pela associação de Dapsona ${ }^{\circledR}$ (sulfona), Clofazimina ${ }^{\circledR}$ e Rifampicina ${ }^{\circledR}$. A administração associada desses fármacos permite evitar a resistência medicamentosa do bacilo que comumente ocorre quando se utiliza apenas um medicamento. O tratamento poliquimioterápico destrói o bacilo tornando-o inviável, evita a evolução da doença, previne as incapacidades e deformidades causadas por ela, culminando à cura. O bacilo inativo é incapaz de infectar outras pessoas, assim, rompe-se a cadeia epidemiológica da doença. Então, logo no início do tratamento, a transmissão da doença é interrompida, e, sendo realizado de forma completa e correta o tratamento garante a cura da doença (BRASIL, 2002).

A administração da PQT/OMS se dá de acordo com a classificação operacional do doente em Paucibacilar ou Multibacilar e para o tratamento de crianças com hanseníase, a 
dose dos medicamentos do esquema-padrão é ajustada, de acordo com a faixa etária e peso. No esquema Paucibacilar é utilizada uma combinação de dois fármacos: Rifampicina ${ }^{\circledR}$ e Dapsona ${ }^{\circledR}$, acondicionados em uma cartela (BRASIL, 2002). Como critério de alta por cura foi definido pelo Ministério da Saúde que o tratamento estaria concluído com seis doses supervisionadas que pode estender-se em até nove meses. $\mathrm{Na} 6^{\mathrm{a}}$ dose, os pacientes deverão ser submetidos ao exame dermatológico, avaliação neurológica simplificada e do grau de incapacidade física quando poderão receber alta do tratamento (BRASIL, 2009b).

Para os casos classificados como Multibacilar (MB), utiliza-se Rifampicina ${ }^{\circledR}$, Dapsona ${ }^{\circledR}$ e Clofazimina ${ }^{\circledR}$, acondicionados em uma cartela (BRASIL, 2002). O tratamento estará concluído com doze doses supervisionadas em até 18 meses. $\mathrm{Na} 12^{\mathrm{a}}$ dose, os pacientes deverão ser submetidos ao exame dermatológico, avaliação neurológica simplificada e do grau de incapacidade física e receber alta por cura. Os pacientes MB que não apresentarem melhora clínica ao final do tratamento preconizado de 12 doses, deverão ser encaminhados para avaliação em unidades especializadas com a finalidade de verificar a necessidade de um segundo ciclo de tratamento (BRASIL, 2009b). Em caso de indivíduos com intolerância a um dos medicamentos do esquema-padrão, são indicados esquemas alternativos (BRASIL, 2002).

Atenção especial deve ser dada à saúde da mulher portadora de hanseníase, pois o uso de fármacos pode representar riscos, em especial, o uso da Rifampicina ${ }^{\circledR}$ em mulheres em idade fértil, devido à possiblidade de interação deste fármaco com anticoncepcionais orais, o que resulta em diminuição da ação destes, como disposto na Portaria $\mathrm{N}^{\circ} 3175$ que dispõe sobre as Diretrizes para Vigilância, Atenção e Controle da Hanseníase no Brasil. Também a Dapsona ${ }^{\circledR}$ e a Minococlina ${ }^{\circledR}$ são relatadas como fármacos com interação com anticoncepcionais orais. (BRASIL, 2010; SOUZA et al, 2005).

A Rifampicina ${ }^{\circledR}$ é um potente indutor do sistema microssomal P-450, responsável pelo metabolismo de algumas drogas, incluindo os contraceptivos orais; atua induzindo enzimas hepáticas, estimulando seu metabolismo e reduzindo sua eficácia. (MILLER; HELMS; BRODELL, 1994; HERSH, 1999; SCHOLTEN et al., 1998).

Nota-se que os esquemas alternativos também podem trazer riscos à saúde da mulher, pois, em gestantes, nos casos de intolerância à Dapsona ${ }^{\circledR}$, o esquema terapêutico recomendado é a associação da Rifampicina ${ }^{\circledR}$ com a Clofazimina ${ }^{\circledR}$, pelo risco para o feto do uso da Ofloxacino ${ }^{\circledR}$ e da Minociclina ${ }^{\circledR}$. (BRASIL, 2010).

O tratamento das reações hansênicas também é ambulatorial e existem esquemas preconizados com potentes agentes anti-inflamatórios representados pela classe dos corticosteróides. Estes fármacos são utilizados no tratamento de diversas patologias nas quais 
ocorre inflamação. Por exemplo, no caso de reação do tipo I, recomenda-se o uso de prednisona ${ }^{\circledR}$ de 1 a $1,5 \mathrm{mg} / \mathrm{Kg} /$ dia até a melhora clínica, ou seja, até a redução do edema e das algias espontâneas dos nervos (à palpação). Esse tratamento leva em média de seis a nove meses (BRASIL, 2010).

Para tratar a reação do tipo II o medicamento preconizado é a talidomida ${ }^{\circledR}$, porém como previsto na Lei $\mathrm{n}^{\circ} 10.651$, de $16 / 4 / 2003$, para utilizar-se a talidomida no tratamento de hanseníase em mulheres em idade fértil faz-se necessário orientar sobre os efeitos teratogênicos do fármaco e assegurar a contracepção. A dose recomendada é de 100 a 400 mg/dia, conforme avaliação clínica, e deve-se manter a mesma dose até a melhora clínica (BRASIL, 2007a).

O exato mecanismo de ação da talidomida no Eritema Nodoso Hansênico (ENH) não é bem estabelecido, entretanto, acredita-se que a talidomida ${ }^{\circledR}$ iniba de maneira seletiva a produção do fator de necrose tumoral alfa (TNF- $\alpha$ ) em monócitos humanos. Logo ao iniciar a terapia com esse fármaco o corre uma diminuição dos sinais e sintomas do $\mathrm{ENH}$ acompanhada de uma diminuição das concentrações séricas de algumas citocinas próinflamatórias como a (TNF- $\alpha$ ) e das interleucinas IL-6, IL-8, IL-10 e de concentrações da proteína C Reativa (VALENTE; VIEIRA, 2010).

Na reação hansênica tipo II ocorre vasculite por deposição de imunocomplexos que se depositam na parede dos vasos. Frações do sistema complemento são ativadas (C3a, C5a) e atraem neutrófilos polimorfonucleares, que por meio de suas enzimas proteolíticas lisam os focos infiltrativos da parede dos vasos envolvidos. A Talidomida ${ }^{\circledR}$, por mecanismos imunorregulatórios, controla essa reação, por reduzir a quimiotaxia dos neutrófilos, aumento do número de células $\mathrm{TCD}_{4}+$ infiltrativa e a atividade dos monócitos. Além disso, a talidomida diminui a produção de TNF- $\alpha$ e IFN- $\gamma$, e suprime a adesão endotelial dos linfócitos, polimorfonucleares e monócitos por redução das moléculas de adesão (ICAM-1) e dos antígenos de histocompatibilidade (MHC-II). O uso de prednisona ${ }^{\circledR}$ para tratar a reação do tipo II é indicado na mesma concentração da recomendada para o tratamento do tipo I nos seguintes casos: mulheres em idade fértil, gestantes, quando há comprometimento de nervos; irite ou iridociclite; orquiepididimite; mãos e pés reacionais; nefrite; eritema nodoso necrotizante; vasculite (fenômeno de Lúcio). O tratamento com Prednisona ${ }^{\circledR}$ leva em média de três a cinco meses (SOCIEDADE BRASILEIRA DE HANSENOLOGIA, 2003).

Em casos de eritema nodoso severo crônico, a OMS recomenda o uso de $300 \mathrm{mg} / \mathrm{dia}$ de Clofazimina ${ }^{\circledR}$ por no máximo 90 dias associada ao corticoide. Como alternativa em mulheres 
em idade fértil com reação do tipo II, recomenda-se o uso de Pentoxifilina ${ }^{\circledR}$ e Ciclosporina ${ }^{\circledR}$ (BRASIL, 2010).

Tanto para o tratamento das reações do tipo I quanto para o tratamento das reações do tipo II com Prednisona ${ }^{\circledR}$ é necessário obedecer a um esquema de retirada, visto que o medicamento deve ser reduzido gradativamente a fim de evitar a insuficiência adrenal aguda, a exacerbação da reação e a síndrome de retirada (BRASIL, 2010).

A insuficiência adrenal aguda ocorre pela queda acentuada dos níveis séricos sanguíneos de cortisol causados por suspensão abrupta da medicação. É raro e em geral está associado a situações de grande estresse como traumas e cirurgias. A exacerbação da reação se dá pela reativação do processo inflamatório na pele, o que leva a um aumento do limiar da dor no nervo, do edema ou eritema nas lesões cutâneas, piora da função neural e exacerbação de sintomas oculares. A síndrome de retirada caracteriza-se pelos seguintes sintomas que estão associados à redução da dose: mialgia, artralgias, febrícula e mal estar (BRASIL, 2010). A Talidomida ${ }^{\circledR}$ ainda pode causar vários efeitos indesejáveis como lesões vesiculares, erupção cutânea, constipação intestinal, diarreia, linfopenia, teratogenicidade, tontura, cefaléia, amenorreia, sonolência e diminuição da libido (Penna; Pinheiro; Hajjar, 1998).

As equipes de saúde devem estar atentas quanto ao surgimento dessas reações adversas e precisam estar preparadas para prevenir e tratar tais efeitos, de modo a contribuir para o sucesso terapêutico e consequentemente a uma melhor qualidade de vida desses pacientes. Os efeitos adversos potenciais provocados por esses fármacos muitas vezes, levam os pacientes a interromper o tratamento, tornando esse motivo a principal causa do abandono do tratamento.

É importante ressaltar a contra indicação do uso da Talidomida® para mulheres em idade fértil em consonância com a Lei $\mathrm{n}^{\mathrm{o}} 10.651$, de 16 de abril de 2003, que dispõe sobre o uso deste fármaco (BRASIL, 2003). O Ministério da Saúde, por meio da Portaria $\mathrm{N}^{\circ} 3.125$, de 7 de outubro de 2010, preconiza que mulheres grávidas ou sob risco de engravidar (mulheres em idade fértil) devem ser aconselhadas à anticoncepção (BRASIL, 2010).

$\mathrm{Na}$ hanseníase, os sinais clínicos refletem além do estágio evolutivo da doença, com implicações significativas na resposta imunológica, observa-se ainda, que no sexo feminino as alterações hormonais da puberdade, gestação, puerpério e menopausa bem como o estado fisiológico de imunodepressão (TALHARI; NEVES, 2006). Os níveis elevados de esteróides, hormônio tireoidiano e de estrógenos que ocorrem na gestação causam depleção da imunidade celular, fundamental na defesa contra o M. leprae. Quando coexistem dois fatores como puberdade e gestação precoce, esses efeitos são aditivos (CESTARI; MAROJA, 2006). 
Estudo pioneiro realizado por Tajiri (1936) citado por Sousa-Araújo (1946), com 112 portadoras de hanseníase identificou que 50\% das mulheres referiram piora ou início dos sintomas da doença na gestação e puerpério. Outro estudo realizado no Pará em 1937 apresentou os mesmos achados (TALHARI; NEVES, 2006).

Em estudo realizado, com mulheres grávidas portadoras de hanseníase durante a gravidez, puerpério e lactação observaram-se episódios reacionais com neurite em 54\% dos casos. As reações de tipo eritema nodoso hansênico constituem-se um problema comum da gestação e lactação e podem ser confundidas com sintomas da exacerbação da doença. $\mathrm{O}$ mesmo estudo identificou que mulheres grávidas portadoras de hanseníase e reações hansênicas tiveram recém-nascidos prematuros em $25 \%$ dos casos e com baixo peso em $16 \%$, principalmente entre parturientes multibacilares (TALHARI; NEVES, 2006).

Estudos realizados com mulheres grávidas portadoras de hanseníase corroboram os resultados descritos anteriormente. Nesses estudos, observou-se também, que as pacientes negaram qualquer sinal ou sintoma compatível com a hanseníase antes do período gravídico. Entretanto houve exacerbação dos sinais e sintomas, principalmente no terceiro trimestre gestacional (DUNCAN, 1993; BÖDDINGHAUS et al., 2007).

No que concerne à associação temporal entre aparecimento de várias lesões e a forma multibacilar durante a gravidez, postula-se que a supressão da imunidade mediada por células na gestação provoque a manifestação da hanseníase (BÖDDINGHAUS et al., 2007). Da mesma forma, este impacto no sistema imune pode levar a reativação da hanseníase antes ou depois do parto (DUNCAN, 1993; SAUNDERSON; GEBRE; BYAS, 2000).

Estudos anteriores sugerem que crianças nascidas de mães com hanseníase ou que vivem em famílias acometidas pela hanseníase apresentam um risco aumentado para desenvolver a doença na puberdade. Entretanto, já se demonstrou que o aleitamento materno pode ser considerado como uma profilaxia eficaz para o recém-nascido caso a mãe receba tratamento adequado (DUNCAN, 1993; JAIN et al., 2002).

Recomenda-se evitar a gestação em portadores de hanseníase, até que a doença tenha sido controlada e tratada. Para tanto, é imprescindível que mulheres portadoras de hanseníase associem o uso de métodos contraceptivos ao tratamento, incluindo outras ações do planejamento familiar, principalmente as mulheres com as formas multibacilares da doença. Nessas formas, a probabilidade de ocorrer episódios reacionais é alta e o manejo de pacientes grávidas com reação hansênica é mais difícil em razão dos efeitos adversos da corticoterapia prolongada (OPROMOLLA, 2004). 
Já é conhecida a associação da gravidez ao aparecimento, agravamento e recidivas da hanseníase como também a um aumento da frequência dos estados reacionais entre os quais, o fenômeno de Lúcio (BUFFON et al 2001; CAMAROTTI et al. 1990; HELMER et al., 2004; LOPES; SARNO, 1994).

A exacerbação da hanseníase no final da gestação e no puerpério foi pela primeira vez descrita por Ryrie em 1938. Desde então, a gestação tem sido associada ao aparecimento dos primeiros sinais ou ao agravamento da hanseníase. Outros estudos apontam resultados considerando que a hanseníase não apresenta qualquer efeito sobre o curso da gravidez, entretanto, a gravidez exerce importante efeito no curso da hanseníase materna (LOCKWOOD; SINHA, 1999).

Durante a gravidez e a lactação, níveis aumentados de corticosteróides endógenos, alfamacroglobulina e outras substâncias supressoras interferem na resposta da célula $T$, determinando a diminuição da imunidade contra o Mycobacterium leprae. Pacientes com formas bacilíferas apresentam percentuais maiores de gestações ectópicas, óbitos fetais, crescimento intra-uterino retardado, baixo peso fetal e placentário, abortamentos e prematuridade, o que está provavelmente mais relacionado ao estado geral e à condição socioeconômica da paciente do que a doença em si. Há relatos quanto à possibilidade de transmissão congênita do Mycobacterium leprae, que se daria por infecção placentária ou na passagem do feto pelo canal do parto onde há numerosos bacilos (CAMAROTTI et al., 1990).

Os recém-nascidos cujas mães eram portadoras de hanseníase na gravidez geralmente apresentam peso menor do que a média para a população geral (LOPES; SARNO, 1994) e maior incidência de problemas respiratórios (MORRISON, 2000) devido à insuficiência placentária e retardo de crescimento intra-uterino, porém, não há estudo prospectivo controlado que evidencie complicações da gestação de mulheres tratadas com PQT/OMS (LOCKWOOD; SINHA, 1999). Podem ocorrer, ao recém-nato, a dermatite esfoliativa nas primeiras semanas de vida, pelo uso da sulfona, e a impregnação da Clofazimina ${ }^{\circledR}$ na pele, que apresenta coloração pardacenta (LOPES; SARNO, 1994). Assim, mulheres devem ser encorajadas a tratar a hanseníase com poliquimioterapia antes de considerar uma futura gravidez (MORISON, 2000).

Em que pese a recomendação à restrição da ingestão de drogas no primeiro trimestre da gravidez, ressalta-se que, os esquemas de PQT/OMS para tratamento da hanseníase têm sua utilização positivamente afirmada. Contudo, mulheres com diagnóstico de hanseníase e não grávidas devem receber aconselhamento para planejar a gestação, após a finalização do tratamento (BRASIL, 2009b). 


\subsection{Políticas públicas de saúde da mulher: a integralidade em questão}

As Políticas Públicas na área da saúde da mulher vem sendo ampliada desde o século XX, com a mobilização dos setores civis e governamentais. Em 2004, foi criada a Política Nacional de Atenção Integral à Saúde da Mulher - PNAISM, com vistas a definir diretrizes e ações programáticas que possam servir de base para mudanças e melhorias na saúde da mulher (GOMES, 2011).

Apesar da evolução na área da saúde da mulher, observa-se que muitos desafios devem ser enfrentados para facilitar seu acesso, aumentar a cobertura e melhorar a qualidade dos serviços de saúde que ainda são precários em boa parte do país. Estes desafios devem orientar gestores e profissionais de saúde na tomada de decisões para implantação de novas condutas, elaboração e implantação de novas estratégias para que se alcancem as metas da atenção integral à saúde da mulher (GOMES, 2011).

É relevante ressaltar que a integralidade é um dos princípios doutrinários do SUS, tendo repercussão em vários níveis das políticas públicas em saúde; neste sentido, a saúde da mulher enquadra-se nos diversos sistemas assistenciais, envolvendo e acolhendo a mulher em toda sua integralidade (MEDEIROS; GUARESCHI, 2009).

Tal tema é discutido por alguns autores que frisam que a integralidade na saúde da mulher está inserida nos atributos das práticas de saúde, utiliza-se desta para questionar se essa continua sendo uma noção útil para identificar certos valores e características que julgamos importante no nosso sistema de saúde (MATTOS, 2004).

Mattos (2001) apoiou o princípio da integralidade e questionou as teorias biomédicas reducionistas, o que implicará em práticas possivelmente, desfavoráveis à implementação de estratégias que visem a melhoria da qualidade na atenção integral à saúde da mulher de modo a contar com a adesão dos profissionais de saúde a desenvolver ações que tenham uma abordagem holística.

O Programa de Assistência Integral à Saúde da Mulher (PAISM) e a Política Nacional de Atenção Integral à Saúde da Mulher, enfatizam que a mulher deve receber suporte nas diversas fases de sua vida, em toda sua integralidade, devendo os profissionais de saúde compreender e articularem-se às diversas políticas públicas para assegurar uma atuação intersetorial (MEDEIROS; GUARESCHI, 2009).

A integralidade busca a possibilidade de apreender as necessidades mais abrangentes do ser humano, valorizando a articulação entre os saberes e práticas assistenciais (COELHO 
et al., 2009). O modelo biomédico constitui um obstáculo epistemológico, pois, não valoriza as crenças e o conhecimento dos usuários, importante para a proposta de integralidade, sobretudo porque, os problemas de saúde surgem articulados a contextos socioculturais, políticos, econômicos, que influenciam no processo saúde-doença numa complexidade que impõe limites e uma multiplicidade de desafios (CAMARGO JÚNIOR, 2003). Assim, políticas destinadas a dar respostas a um determinado problema de saúde, ou evidenciar respostas a certo grupo populacional, podem trazer as marcas da integralidade (COELHO et al., 2009).

No que concerne à atenção a saúde das mulheres, compreende-se a integralidade como a concretização de práticas de atenção que garantam o acesso das mulheres a ações resolutivas, construídas segundo as especificidades do ciclo vital feminino e do contexto em que as necessidades são transpostas. Dessa forma, o cuidado deve ser permeado pelo acolhimento com escuta sensível e qualificada de suas demandas, com valorização das diversas influências tais como: as relações de gênero, raça/cor, classe e geração no processo de saúde e de adoecimento das mulheres (COELHO et al., 2009). Ademais, a assistência à saúde da mulher deve ser compreendida por outras tantas questões de saúde da população em geral. A mulher está sujeita a agravos decorrentes não apenas de sua função reprodutiva, mas também de sua condição feminina (BRASIL, 2007a).

O Programa de Assistência Integral à Saúde da Mulher (PAISM) foi publicado em 1983, que tinha como foco à saúde da mulher, principalmente no que tange aspectos de saúde reprodutiva, no entanto, com pensamento na atenção integral à mulher. Este Programa foi criado fruto de ideais feministas, assim, representou uma ruptura com a perspectiva biológica materno-infantil. Propõe-se a atender as necessidades mais amplas em saúde, valorizando a mulher como sujeito historicamente determinado, e ao longo de 20 anos, o PAISM passou por avanços e retrocessos. Na atualidade, a Política Nacional de Atenção Integral à Saúde da Mulher (PNAISM) resgata os seus princípios, com ênfase na abordagem de gênero e na integralidade como norteadores das práticas de cuidado à saúde das mulheres (BRASIL, 2004 a).

O Ministério da Saúde lançou em 1983 as bases programáticas do PAISM, que foi elaborado com a colaboração de representantes de grupos feministas, gestores estaduais e pesquisadores das universidades. O PAISM propunha uma abordagem global da saúde da mulher em todas as fases do seu ciclo vital, e não apenas o ciclo gravídico-puerperal. É possível se ver que esse Programa significou um avanço em termos de direitos reprodutivos 
para as mulheres brasileiras, entretanto, enfrentou entraves políticos, financeiros e operacionais para sua implementação (BRASIL, 2004a).

O PAISM consolidou-se como uma das mais importantes políticas públicas nacionais na área de saúde, estabelecendo-se em suas linhas de ação e estratégias um modelo assistencial cujo contexto se inclui os princípios da integralidade e a equidade, compreendendo que a mulher deve ser atendida de forma digna e integral, em todas as etapas do seu ciclo de vida (OSIS, 1998).

O PAISM emerge como uma nova abordagem à saúde da mulher, no entanto, este programa propôs a regulação da fecundidade por meio do planejamento familiar, o que fez suscitar na ocasião, suspeitas acerca de possíveis intenções ocultas de controle da natalidade. O caráter pioneiro desse Programa, principalmente devido a seu significado social, inclusive no cenário mundial, se deu ao se propor o atendimento à saúde reprodutiva das mulheres, no âmbito da atenção integral à saúde, e não mais a utilização de ações isoladas em planejamento familiar (OSIS, 1998). Não obstante, os movimentos de mulheres, de imediato, passaram a lutar por sua implementação. Nas entrelinhas do Programa encontra-se a definição de saúde reprodutiva adotada pela OMS em 1988, ampliada e consolidada no Cairo em 1994 e em Beijing em 1995, consequentemente, representou um passo significativo em direção ao reconhecimento dos direitos reprodutivos das mulheres (OSIS, 1998).

Em 2004, o Ministério da Saúde elaborou a PNAISM, em parceria com diversos setores da sociedade, em especial com o movimento de mulheres e com os gestores do SUS. Essa política reflete o compromisso com a implementação de ações de saúde que contribuam para a garantia dos direitos humanos das mulheres e reduzam a morbimortalidade por causas preveníeis e evitáveis. Enfatiza a melhoria da atenção obstétrica, o planejamento familiar, a atenção ao abortamento inseguro e às mulheres e às adolescentes em situação de violência doméstica e sexual. Além disso, amplia as ações para grupos a margem das políticas públicas nas suas especificidades e necessidades (BRASIL, 2004a).

Em 22 de março de 2005, o Ministério da Saúde lançou a Política Nacional dos Direitos Sexuais e dos Direitos Reprodutivos. Entre as diretrizes e ações propostas por essa política estão: a ampliação da oferta de métodos anticoncepcionais reversíveis no SUS, incentivo à implementação de atividades educativas em saúde sexual e saúde reprodutiva para usuários (as) da rede SUS; capacitação dos profissionais da atenção básica em saúde sexual e saúde reprodutiva; ampliação do acesso à esterilização cirúrgica voluntária (laqueadura tubária e vasectomia) no SUS; implantação e implementação de redes integradas para atenção às mulheres e as adolescentes em situação de violência doméstica e sexual; ampliação dos 
serviços de referência para a realização do aborto previsto em lei e garantia de atenção humanizada e qualificada às mulheres em situação de abortamento; entre outras ações (BRASIL, 2005).

Os direitos das mulheres, a saúde sexual e a saúde reprodutiva estão, portanto, inseridos na agenda ministerial. Além disso, a implementação das diretrizes preconizadas pela Política Nacional dos Direitos Sexuais e dos Direitos Reprodutivos tem apresentado demanda crescente pela sociedade e vem sendo monitorada pela sociedade civil organizada. Diante das conquistas legais e políticas enfocadas nestas diretrizes, os gestores e os profissionais de saúde têm papel fundamental para conhecê-las e torná-las uma realidade no planejamento e na prática de atenção à saúde (BRASIL, 2004b).

Em 2007, o governo federal lançou o Programa de Aceleração do Crescimento (PAC), que busca aliar o crescimento econômico com o desenvolvimento e a equidade social. A saúde conforma-se em um dos campos de atuação fundamental do PAC. Nesse sentido, o Ministério da Saúde elaborou o Programa Mais Saúde: Direito de Todos, que objetiva, numa perspectiva abrangente, aprofundar e atualizar os grandes intuitos da criação do SUS, num contexto contemporâneo, agregando novos desafios e dimensões para que os princípios de universalidade, equidade e integralidade possam se concretizar. O programa contém 73 medidas e 165 metas. Entre as medidas do eixo promoção da saúde, está a expansão das ações de planejamento familiar (BRASIL, 2007b).

Em âmbito mundial, na cúpula do milênio em 2000, a Organização das Nações Unidas (ONU) promoveu e discutiu com líderes das grandes potências mundiais e chefes de Estado de 189 países, dentre eles o Brasil, a gravidade do estado social de muitos países do mundo e definiram os oito Objetivos de Desenvolvimento do Milênio (ODM), (figura1). Reconheciam que, da saúde ao meio ambiente, da educação à igualdade entre sexos, uma crescente demanda de temas em desenvolvimento não mais poderia ser administrada exclusivamente dentro das fronteiras de uma única nação. Não só reafirmaram e ampliaram os compromissos anteriormente traçados, mas também estabeleceram metas específicas, que apontavam para ações em áreas prioritárias. As 18 metas estabelecidas foram detalhadas em 48 indicadores e, na sua maior parte, deveriam ser alcançadas até 2015 (SANTOS et al., 2012). 


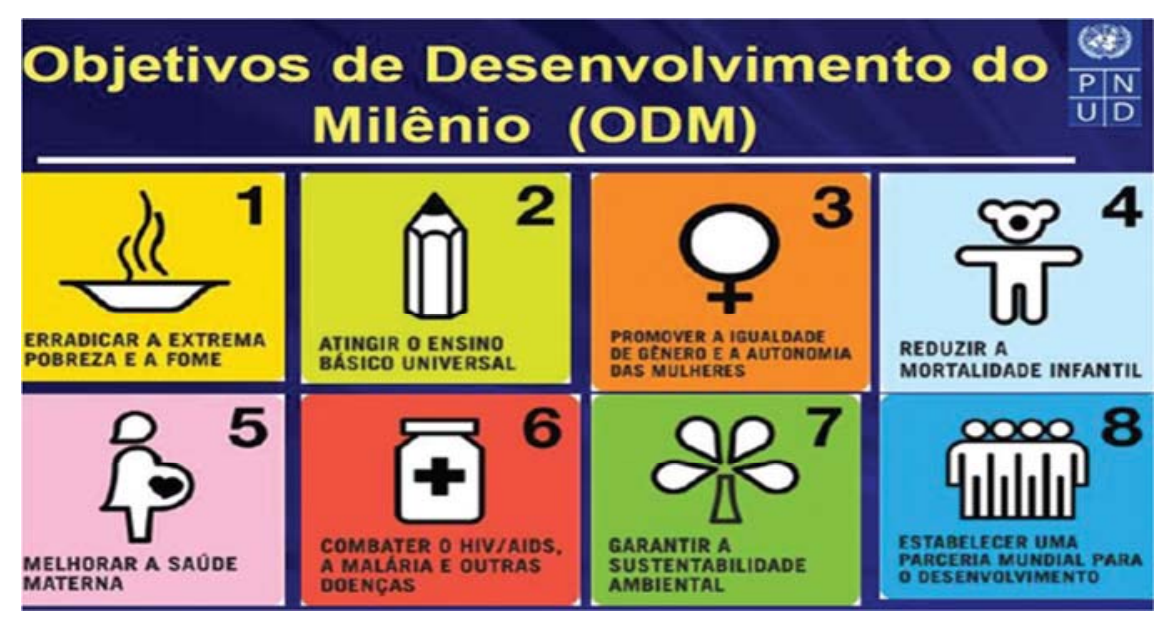

Figura 1 - Objetivos de Desenvolvimento do Milênio. Fonte: Programa das Nações Unidas para o Desenvolvimento (PNUD) - Brasil (ONU, 2000).

O Projeto do Milênio, da ONU, congregou um plano de ação global para combater o panorama sintomático grave em países em desenvolvimento. Nesse panorama destaca-se o objetivo número 5 cuja meta é melhorar a saúde materna, haja visto que, algo em torno de 530.000 mulheres em idade reprodutiva morrem no mundo de problemas facilmente tratáveis, de acordo com a ONU (ONU, 2000). Assim, firmou-se um Plano de Ação Global com a força-tarefa na Saúde Materna e Infantil, mediante recomendações políticas para fortalecer o sistema de saúde, garantir a disponibilidade medicamentosa e o acesso universal ao atendimento.

Ainda no que concerne aos ODM, alguns deles têm relação direta com a saúde sexual e a saúde reprodutiva refletindo na saúde das mulheres, quais sejam, a promoção da igualdade entre os sexos e a autonomia das mulheres; a melhoria à saúde materna; o combate ao HIV/AIDS, malária e outras doenças endêmicas e a redução da mortalidade infantil. No Brasil a taxa de mortalidade infantil caiu de 61,7\% entre 1990 e 2010 (em 20 anos) para 47\% entre 2000 e 2010 (10 anos) e em 2012 o Brasil atingiu a $4^{\mathrm{a}}$ meta ODM (redução da mortalidade infantil), três anos antes da data limite fixada pela Organização das Nações Unidas. No entanto, o progresso na razão de mortalidade maternal é difícil de ser avaliado, uma vez que a tendência temporal do indicador vem sendo afetada por melhorias nas estatísticas vitais, mas há evidências de diminuição nas razões de óbitos maternos nos últimos trinta anos. Entretanto, a Meta do Milênio número 5 (redução de três quartos da mortalidade materna entre 1990 e 2015) possivelmente não será alcançada (VICTORA et al., 2011).

No que diz respeito aos direitos sexuais e direitos reprodutivos, estes são conceitos desenvolvidos recentemente que já são reconhecidos perante leis nacionais e documentos 
internacionais por sua pertinência enquanto direito humano e que representam uma conquista histórica, fruto da luta pela cidadania e pelos direitos humanos. A partir da Declaração Universal dos Direitos Humanos, adotada no ano de 1948, a comunidade internacional, por meio da ONU, vem firmando uma série de convenções internacionais nas quais são estabelecidos estatutos comuns de cooperação mútua e mecanismos de controle que garantam um elenco de direitos considerados básicos a uma vida digna. Ressalta-se que nas duas últimas décadas, registraram-se grandes avanços na legislação internacional e nacional sobre as dimensões da reprodução e da sexualidade como direitos humanos e de cidadania (VILLELA; ARILHA, 2003).

Dois marcos referenciais internacionais definiram os direitos sexuais e os direitos reprodutivos: a Conferência Internacional sobre População e Desenvolvimento (CIPD), promovida pela ONU, realizada no Cairo, em 1994, conferiu um papel primordial à saúde, aos direitos sexuais e aos direitos reprodutivos, abandonando a ênfase na necessidade de limitar o crescimento populacional como forma de combater a pobreza e as desigualdades, com foco no desenvolvimento do ser humano. A CIPD levou em consideração, no debate sobre população e desenvolvimento, as questões sobre a mulher - desigualdades de gênero - meio ambiente e os direitos humanos. Estabeleceu acordos internacionais que foram assumidos por 179 países. Também a IV Conferência Mundial sobre a Mulher, realizada em Beijing, China, em 1995, além de reafirmar os acordos estabelecidos no Cairo, avançou-se na definição dos direitos sexuais e direitos reprodutivos como direitos humanos (CORRÊA; ALVES; JANUZZI, 2006).

Nas décadas de 1950 e 1960, no auge do temor à "explosão populacional", os formuladores de políticas passaram a defender a disseminação de métodos anticoncepcionais, mesmo que contrariando os interesses individuais. Em contrapartida, os movimentos feministas legitimavam sobre o direito de escolha e a liberdade de decisão das mulheres nos assuntos sexuais e reprodutivos (CORRÊA; ALVES; JANUZZI, 2006).

$\mathrm{Na}$ década de 90, a confluência de um ambiente macroeconômico e político favorável, juntamente com a presença ativa de representantes dos movimentos feministas, ambientalistas e de direitos humanos possibilitaram que os avanços teórico-conceituais fossem transformados em princípios assumidos pela Conferência sobre População e Desenvolvimento do Cairo (CORRÊA; ALVES; JANUZZI, 2006).

O reconhecimento da universalidade dos direitos sexuais e dos direitos reprodutivos é, portanto, fundamental para a qualificação da proposição de políticas públicas que contemplem as especificidades dos diversos segmentos da população. A prática sexual e a 
maternidade/paternidade são direitos de todos, que devem ser garantidos pelo Estado, mediante ações e estratégias que promovam o compromisso e responsabilidade dos cidadãos de modo responsável e mediante condições saudáveis e isenta de riscos.

Em âmbito nacional, dentre os marcos referenciais em relação aos direitos sexuais e aos direitos reprodutivos, destacam-se: o Programa de Assistência Integral à Saúde da Mulher - PAISM/MS/1984; a Constituição Federal de 1988; a Lei no 9.263/1996, que regulamenta o planejamento familiar; a Política Nacional de Atenção Integral à Saúde da Mulher/MS/2004; e a Política Nacional dos Direitos Sexuais e dos Direitos Reprodutivos/MS/2005. (BRASIL, 1984; BRASIL, 1988; BRASIL, 1966; BRASIL, 2004; BRASIL, 2005).

Nas primeiras décadas do século XX, a saúde da mulher foi incorporada às políticas nacionais de saúde, porém, os programas implementados ainda voltavam-se exclusivamente para aspectos referentes à gestação e ao parto. De fato, em termos de políticas públicas, a atenção à saúde da mulher no Brasil, até o surgimento do PAISM, traduziu-se na preocupação com o grupo materno-infantil que, inclusive, sempre permaneceu como o mais enfatizado por essas políticas. O enfoque central dos vários programas de saúde materno-infantil estava em intervir sobre os corpos das mulheres-mães, de maneira a assegurar que os corpos dos filhos fossem adequados às necessidades da reprodução social. Com o advento do PAISM que trouxe a tona o conceito de "atenção integral à saúde das mulheres" houve o rompimento com a visão tradicional acerca desse tema, sobretudo no âmbito da medicina, que centralizava o atendimento às mulheres nas questões relativas à reprodução (CANESQUI, 1987; OSIS, 1994).

Avanços ocorreram, mas ainda hoje, urge-se que as instâncias gestoras do SUS transponham as lacunas dessa assistência, em todos os seus níveis de atenção, de forma responsável e comprometida para garantir e advogar pela a atenção integral à saúde da mulher que inclua a assistência à concepção e à contracepção, de modo a otimizar os desfechos de saúde dessa população. Além disso, é premente enfatizar o redirecionamento das práticas em saúde da mulher com a finalidade de fornecer respostas ágeis e mais resolutivas segundo os princípios norteadores da PNAISM. A escuta, a responsabilização e a criação de vínculos com a inserção da abordagem de gênero oferecem à mulher possibilidades de serem sujeitos e devem fazer parte de um projeto de reorganização das práticas direcionadas pela integralidade do cuidado (COELHO et al., 2009). 


\subsection{Planejamento Familiar}

Desde o lançamento do PAISM, em 1983, o governo brasileiro tem atuado nas questões relativas ao planejamento familiar, adotando políticas e medidas para permitir o acesso da população aos meios de contracepção (BRASIL, 2004; OSIS, 1998). Do ponto de vista legal, até 1988, havia uma lacuna em relação ao planejamento familiar no país, incluindo a esterilização cirúrgica. Com a aprovação da Constituição de 1988 o planejamento familiar é tido comum direito legal do cidadão. Os primeiros esforços para implementar o PAISM incluíram a provisão de insumos contraceptivos para os serviços públicos de saúde e a capacitação dos profissionais para proverem atenção em planejamento familiar com qualidade. Todavia, esses esforços foram marcados pela descontinuidade e baixa efetividade, e os avanços foram muito lentos na segunda metade dos anos de 1980 e quase que durante toda a década seguinte (OSIS et al., 2006).

Embora a população e muitos planejadores de saúde não reconheçam o planejamento familiar como uma atribuição do Estado e de programas de saúde, haja vista as dificuldades de implementação do PAISM (OSIS, 1998), sua inclusão deve ser considerada um componente crucial na assistência à saúde da mulher, devido a sua relação com prevenção do aborto provocado, gravidez não desejada, mortalidade materna e outros agravos à saúde relacionados à morbimortalidade reprodutiva, e, sobretudo por constituir um direito de cidadania (VIEIRA et al., 2002).

O planejamento familiar, enquanto ação em saúde tem sido reconhecida como uma necessidade do ser humano, mas apresenta controvérsias entre o que é praticado pela sociedade e o que é normatizado pelo Estado e, ainda, disponibilizado pelos serviços de saúde. Não obstante, as controvérsias sobre o planejamento familiar perpassam pela enfermagem, haja vista que esta prática social, basicamente se concretiza nas instituições de saúde, tendo como cerne de sua ação o cuidar e o assistir (COELHO, 2005).

Informações sobre saúde reprodutiva foram amplamente disseminadas, particularmente a partir do PAISM, e tal conquista se mantém na atual PNAISM como ação para reduzir a mortalidade materna e perinatal por causas preveníveis e evitáveis, além de fomentar a implementação de ações que contribuam para a garantia dos direitos humanos das mulheres. Portanto, pode-se afirmar que, em termos de políticas públicas, o Ministério da Saúde do Brasil apresenta uma proposta avançada de planejamento familiar (SILVA et al., 2011). 
A PNAISM/MS, ao reiterarem seus princípios doutrinários a assistência ao planejamento familiar prevê que o acesso à atenção de boa qualidade é essencial para que seja bem sucedido, mediante escolha livre de métodos, informações e acompanhamento dos usuários. Espera-se que todas as mulheres em idade fértil sejam atendidas no serviço de saúde, independente de suas patologias, e sejam educadas e orientadas (BRASIL, 2006b).

O planejamento familiar chegou a América Latina por volta de 1960 e tem contribuído sobremaneira para a diminuição da taxa global de fecundidade. A taxa global de fecundidade caiu pela metade em 30 anos, ou seja, de seis filhos por mulher em 1960, para 3,1 em 1990. A previsão é de que essa média continuará diminuindo nos próximos 30 anos, chegando a 2,2 filhos por mulher no ano de 2020 (LOPES, 2008).

A Constituição Federal Brasileira de 1988 inclui no Título VIII da Ordem Social, em seu Capítulo VII, art. 226, $\S 7^{\circ}$, a responsabilidade do Estado no que se refere ao planejamento familiar, nos seguintes termos:

Fundado nos princípios da dignidade da pessoa humana e da paternidade
responsável, o planejamento familiar é livre decisão do casal, competindo ao Estado
propiciar recursos educacionais e científicos para o exercício desse direito, vedada
qualquer forma coercitiva por parte de instituições oficiais ou privadas (BRASIL,
1988, P.6).

A Lei $n^{\circ}$ 9.263, de 12 de janeiro de 1996, que regulamenta o $\S 7^{\circ}$ do art. 226 da Constituição Federal, referente ao planejamento familiar, estabelece em seu art. $2^{\circ}$ :

\begin{abstract}
[...] entende-se planejamento familiar como o conjunto de ações de regulação da fecundidade que garanta direitos iguais de constituição, limitação ou aumento da prole pela mulher, pelo homem ou pelo casal. Parágrafo único - É proibido à utilização das ações a que se refere o caput para qualquer tipo de controle demográfico (BRASIL, 1996, P.01).
\end{abstract}

Esta mesma Lei, ao estatuir sobre o planejamento familiar, e mais adiante em seu art. $9^{\circ}$, determina para o exercício do direito ao planejamento no que tange a escolha da família de ter ou não ter filhos, o número desejado, quando tê-los, o direito à assistência para a concepção e contracepção, por meio de métodos e técnicas cientificamente aceitas, as quais não colocam em risco a vida e a saúde das pessoas, como o uso de pílulas, preservativos masculinos e femininos, cirurgia de ligadura de trompas e vasectomia. A lei proíbe a indução à esterilização em massa ou que se façam campanhas direcionadas à esterilização de determinadas raças ou etnias (BRASIL, 1996).

No que concerne ao atendimento em saúde dirigido às mulheres e direcionado ao planejamento familiar, inclui-se o acesso que deve ser universal e a abordagem que deve estar 
pautada no princípio da integralidade, considerando as questões que permeiam todo o atendimento a população feminina em situação de maior vulnerabilidade social (SANTOS; FREITAS, 2011).

A eficiência do processo educativo aumenta as possibilidades de efetividade do planejamento familiar, ou seja, capacita os usuários na tomada de decisões sobre a dinâmica da família. A qualidade da informação segundo Bruce (1990) aponta que é necessário que o usuário compreenda e retenha a informação, para que seja efetivo o uso dos métodos anticoncepcionais (CAMIÁ; MARIN; BARBIERI, 2001).

Apesar de considerar a importância do processo educativo e de pesquisas já desenvolvidas nas áreas do planejamento familiar, muitos problemas ainda são muito expressivos. O planejamento familiar foi definido como instrumento da assistência maternoinfantil e advém de um processo de informação e de educação aos casais e à população em geral, sobre a reprodução, a importância da família na comunidade, o papel da mulher, o papel do pai e do filho dentro desse contexto e, finalmente, sobre as repercussões de tudo isso na comunidade (SANTOS; FREITAS, 2011).

Camiá, Marin e Barbieri (2001) definem o planejamento familiar como um mecanismo importante na prevenção primária de saúde, auxiliando as usuárias com informações necessárias para a escolha e para o uso efetivo de métodos anticoncepcionais mais adequados. Embora esta definição contemple elementos de prevenção à saúde, ainda é uma visão focada apenas na saúde da mulher e no controle do número de filhos. Em um estudo, a análise da participação masculina nas atividades de planejamento familiar revelou envolvimento bastante reduzido dos homens e a inexistência de programas para saúde sexual e reprodutiva masculina em todas as capitais (OSIS et al., 2006).

Os serviços de planejamento familiar tradicionais atuam em função da vida reprodutiva com responsabilidade exclusivamente feminina e prioridade social. E ainda assim, o planejamento familiar, muitas vezes, só é iniciado depois do primeiro filho. Outra fragilidade é a falta de adequação do programa às características individuais e familiares dos envolvidos. Os valores, as características de personalidade, a história de vida das famílias de origem são elementos que interferem diretamente na estrutura familiar que está sendo formada. Desconsiderar isso é adotar um modelo verticalizado de planejamento familiar, de modo que os envolvidos sejam passivos no processo (SANTOS; FREITAS, 2011).

Em se tratando de planejamento familiar, as atividades de informação e educativas são extremamente relevantes ao alcance dos objetivos de serviços e usuários, exigindo dos profissionais de saúde atitude de empenharem-se em bem informar de forma consciente e 
responsável para que a clientela conheça as alternativas de concepção e anticoncepção disponíveis e, assim, possa participar ativamente da definição e do alcance de suas metas reprodutivas (MOURA; SILVA, 2004).

Para Bruce (1990), a qual afirma que a informação dada ao cliente se constitui em elemento da qualidade do planejamento familiar, descreve três componentes principais envolvidos nesse processo de informação: 1) proporcionar aos clientes a apreciação dos métodos de anticoncepção e de suas principais características; 2) seu emprego eficaz de modo a reconhecer que o método pode provocar alterações físicas saudáveis ou riscos e interferir em atividades cotidianas, inclusive na sexualidade do casal; e 3) desenvolver no cliente uma expectativa apropriada a respeito do que o serviço de saúde oferece e garante.

É primordial, que a formação profissional subsidie o desenvolvimento de habilidades para a oferta de informação adequada em planejamento familiar, de modo a atender as necessidades dos clientes, sob a perspectiva dos direitos sexuais e reprodutivos, primando pela atualização contínua (MOURA; SILVA, 2005). A informação adequada em planejamento familiar possibilita ao cliente exercer seus direitos, reconhecer métodos contraceptivos e fazer escolhas com autonomia. Além disso, os serviços de saúde devem dispor de métodos e técnicas para o controle da fecundidade.

Em planejamento familiar, a falta de competência técnica pode ser atribuída à ausência do ensino desse conteúdo nos currículos de graduação, ao enfoque em métodos anticoncepcionais, à negligência de aspectos como sexualidade humana e técnicas de comunicação, à falta de atualização dos profissionais e oferta de capacitação pelos gestores, a concentração das ações do planejamento familiar sobre a figura do médico (DÍAZ, M.; DÍAZ, J., 1999; MOURA; SILVA, 2005). O Ministério da Saúde, em relatório de avaliação das Equipes de Saúde da Família, revelou que mais da metade dos profissionais médicos e enfermeiros, atuantes em saúde da mulher, não foram capacitados para as ações em planejamento familiar (BRASIL, 2004b). Outro estudo sobre a temática evidenciou que a capacitação em planejamento familiar ocorre de forma desigual e insuficiente. Além disso, os profissionais de saúde não o percebem como parte da atenção básica (OSIS et al., 2006).

A capacitação dos profissionais de saúde que atuam na atenção primária a saúde em planejamento familiar, foi proposta pelo PAISM, porém, ao longo dos anos, sofreu descontinuidade e apresentou baixa efetividade (OSIS et al., 2006). Dentre as ações educativas do planejamento familiar, a orientação sobre métodos anticoncepcionais é o principal tópico abordado. Em contrapartida, aspectos relacionados à saúde sexual e reprodutiva são negligenciados e/ou pouco abordados (PIERRE; CLAPIS, 2010). 
No Brasil, apesar de o planejamento familiar ser responsabilidade de todos os níveis de atenção em saúde, é desenvolvido, principalmente, na atenção básica, por meio da Estratégia Saúde da Família, que tem, dentre suas diretrizes, a participação comunitária, considerada fator que possibilita identificar e atender as necessidades de saúde das pessoas (SILVA et al., 2011).

Nesse sentido, no final da década de 80 , foi proposto um referencial teórico no qual é caracterizada a assistência de qualidade em planejamento familiar, na perspectiva dos direitos reprodutivos e sexuais. Esse referencial teórico é composto por seis elementos de qualidade: a oferta e a livre escolha por métodos anticoncepcionais; a informação disponibilizada aos clientes; a competência técnica dos profissionais; as relações interpessoais entre clientes e profissionais; acompanhamento dos clientes que fazem uso de métodos; e a integração do planejamento familiar ao atendimento em saúde reprodutiva (BRUCE, 1990).

Como proposta de reorganização do atendimento às mulheres na atenção primária à saúde com vistas à ampliação da cobertura das ações de planejamento familiar, deve-se considerar as práticas educativas em grupo com a finalidade de integrar as ações de saúde em geral as quais são cruciais para o atendimento em saúde sexual e reprodutiva. Essas práticas traduzem oportunidade para a abordagem adequada com as (os) usuárias (os), de temas como planejamento familiar e contracepção, prevenção de doenças sexualmente transmissíveis, violência sexual e doméstica e questões de gênero. O modelo participativo, com troca de informações e experiências entre profissionais de saúde e grupos de usuárias (os) em vários encontros é reconhecidamente um instrumento de empoderamento das mulheres e dos profissionais de saúde envolvidos no processo educativo (SANTOS; FREITAS, 2011).

Segundo o educador Paulo Freire (1996), ensinar não é transferir conhecimento, mas criar as possibilidades para a sua produção ou a sua construção. A partir dessa concepção, recomenda-se que as práticas educativas façam uso de metodologia participativa, com abordagem pedagógica centrada no sujeito. Para se obter bons resultados, no que se refere à saúde sexual e à saúde reprodutiva, é importante considerar o conhecimento e experiência dos participantes, permitindo a troca de experiências e ideias sobre sexualidade, reprodução, relacionamento humano e sobre os fatores socioeconômicos e culturais que influenciam nessas questões. Essa metodologia estimula a pessoa a construir um processo decisório autônomo e centrado em seus interesses.

A variedade de métodos anticoncepcionais (MAC) é limitada e sua provisão é irregular, percebendo-se, pois, uma distância entre o que está proposto como política e o que é realizado na prática (MOURA; SILVA; GALVÃO, 2007). Os serviços de planejamento 
familiar ainda precisam ampliar o diálogo e a participação de seus usuários como pessoas capazes de interagir e agir na realização de suas próprias escolhas. Nessa concepção, a mulher é capaz de articular ideias, agrupar e reagrupar informações e exercer diferentes papéis na busca de atos benéficos para si e para a família. A capacidade de refletir, simbolizar, criar e comunicar situa a mulher numa posição de tomar decisões, julgar possibilidades e selecionar eventos significativos ao seu bem-estar e ao do outro. Assim, o planejamento familiar deve ser um elemento essencial na prevenção primária de saúde, auxiliando as pessoas que procuram os serviços, oferecendo-lhes informações necessárias para a escolha e o uso efetivo dos MAC que melhor se adaptem às condições atuais de saúde (SILVA et al., 2011).

No contexto internacional, a Conferência de Beijing (China), promovida pela ONU em 1995, alerta para a importância da divisão da responsabilidade pela anticoncepção entre ambos os sexos, visando à promoção da saúde reprodutiva, enfatizando a sua relevância para a consolidação de uma sociedade democrática e para o desenvolvimento da cidadania (PIOVESAN; PIROTTA, 1998; SILVA et al., 2011).

Dificuldades para a efetiva implementação do planejamento familiar, no que se refere à informação e fornecimento de métodos anticoncepcionais, são verificadas em alguns municípios brasileiros (OSIS et al., 2004). Delinear o panorama dessa assistência pode contribuir para o planejamento e programação das atividades, de modo a revisar prioridades, subsidiando a tomada de decisões e contribuindo para o alcance de melhores resultados em termos de impacto sobre a saúde sexual e reprodutiva da população (PIERRE; CLAPIS, 2010).

$\mathrm{O}$ conhecimento dos MAC deve estar relacionado à prevenção da gravidez indesejada, do aborto provocado, da mortalidade materna e de outros agravos à saúde relacionados à morbimortalidade reprodutiva. Promover o acesso a tais informações e aos meios para a regulação da fecundidade é um dos aspectos importantes do planejamento familiar, e uma das ações do PAISM (VIEIRA et al., 2002).

No entanto, a atenção ao planejamento familiar no Brasil continua a ser marcada pela indisponibilidade de métodos anticoncepcionais nos serviços públicos de saúde e pela capacitação desigual e insuficiente dos profissionais para atuarem nessa área. O PAISM prevê as ações de planejamento familiar como parte da atenção integral à saúde da mulher, principalmente a atenção básica, de acordo com o modelo de atenção à saúde adotada no Brasil desde a criação do SUS que adota a Estratégia de Saúde da Família (OSIS, 1998; OSIS et al., 2006). 
As ações de planejamento familiar, com frequência, são executadas de forma isolada, desintegrada e não priorizadas com os demais componentes da atenção primária a saúde; evidencia-se ainda uma dificuldade significativa de funcionamento de um sistema de referência e contra referência, fundamental para racionalizar a utilização dos recursos disponíveis. Desse modo, as ações de educação em saúde são oportunas, por seu potencial sensibilizante e capacitador para a mulher, a fim de torná-la capaz de identificar suas necessidades e lutar por seus direitos, entre os quais, os insumos necessários para a anticoncepção (OSIS et al., 2006; SILVA et al., 2011). 


\section{JUSTIFICATIVA}

\subsection{Justificativa e relevância do estudo}

As estatísticas no período de 2006 a 2011 referentes ao número de mulheres em idade fértil, na faixa etária de 10 a 49 anos, que foram notificadas com hanseníase no estado de Alagoas, registram um número de 779 mulheres (ALAGOAS, 2007). O município de Maceió se configurou como detentor de 49,5\% destes casos no estado, com 386 mulheres em idade fértil, portadoras e ex-portadoras de hanseníase, dentre as quais, 217 foram tratadas em Unidades Básicas de Saúde (UBS) e as outras 169 mulheres foram diagnosticadas e tratadas em Unidades de Referência de Maceió.

O foco deste trabalho se restringe às mulheres tratadas na atenção primária à saúde. A relevância do estudo é refletida pelo risco real que estas mulheres apresentam ao engravidarem e ainda, frente às alterações orgânicas decorrentes de uma futura gestação, que pode influenciar na evolução da hanseníase e, particularmente, no que tange às reações hansênicas, aos riscos obstétricos e aos riscos para o concepto.

Infere-se que há necessidade do conhecimento da situação desta população em relação ao planejamento familiar e sobre a disponibilidade dos métodos contraceptivos, pois os dados em âmbito nacional e internacional sobre esta temática específica são escassos. Assim, os produtos resultantes deste trabalho poderão fornecer subsídios para o planejamento de ações e intervenções que possibilitem às mulheres, portadoras de hanseníase, proteção efetiva no sentido da prevenção das complicações decorrentes das manifestações reacionais.

Diante do exposto, urge conhecer a situação da saúde reprodutiva da mulher portadora e ex-portadora de hanseníase nos serviços de planejamento familiar, pois as ações conjuntas a esse grupo são componentes importantes para a assistência à saúde reprodutiva, com potencial para minimizar as chances de uma gravidez de alto risco, de modo a prevenir reações hansênicas (tipo I e II). 


\section{OBJETIVOS}

\subsection{Objetivo Geral}

Conhecer a situação da saúde reprodutiva das mulheres portadoras e ex-portadoras de hanseníase, na rede de Atenção Básica do município de Maceió.

\subsection{Objetivos Específicos}

- Descrever o perfil sociodemográfico e epidemiológico das mulheres em idade fértil, portadoras e ex-portadoras de hanseníase;

- Identificar os métodos contraceptivos e o uso dos mesmos entre mulheres em idade fértil, portadoras e ex-portadoras de hanseníase;

- Verificar a relação acerca do uso e conhecimento dos métodos contraceptivos e as variáveis sociodemográficas. 


\section{MÉTODO}

\subsection{Delineamento metodológico}

Trata-se de estudo descritivo de corte transversal e com abordagem quantitativa dos dados. O estudo de corte transversal obtém informações sobre variáveis em diferentes contextos, mas simultaneamente. É um instantâneo de uma situação em andamento. Assim, os fenômenos sobre o estudo são obtidos durante um período de coleta de dados e são especialmente apropriados para descrever a situação, o status do fenômeno, e tecer relações. A principal vantagem é que a pesquisa transversal é de baixo custo e fácil de controlar os vieses (POLIT; BECK, 2011).

A pesquisa quantitativa é definida como método de pesquisa no qual as variáveis predeterminadas são mensuradas e expressas numericamente, se apropriando da análise estatística para o tratamento dos dados (GRAZIOS; LIEBANO; NEHAS, 2011). Essa abordagem metodológica atua em nível de realidade e tem como objetivo buscar a magnitude e as causas dos fenômenos, trazendo à luz dos dados, indicadores e tendências observáveis, sem interesse pela dimensão subjetiva (SERAPIONI, 2000; TURATO, 2005).

\subsection{Local do estudo}

Maceió é a maior cidade do estado de Alagoas, com uma área territorial de 503,072 km² com uma população de 996.733 habitantes (Instituto Brasileiro de Geografia e Estatística/IBGE, 2013). O município pertence a $1^{\mathrm{a}}$ Macrorregião (SEDE), a $1^{\mathrm{a}}$ Região de Saúde (Município de Saúde), a $1^{\text {a }}$ Microrregião de Saúde (Município Sede) e representa 29,96\% da população do estado, o que o faz enquadrar-se como município prioritário, nas ações de controle da hanseníase. A capital alagoana é referência estadual para assistência de média e alta complexidade em hanseníase, concentrando mais de 37\% dos casos novos do estado (IBGE, 2013; SISTEMA DE INFORMAÇÃO DE AGRAVO DE NOTIFICAÇÃO, 2009).

No município de Maceió, no período do estudo, a atenção básica era composta por 65 UBS e destas, 36 faziam parte da Estratégia de Saúde da Família (ESF). Ressalta-se que apenas 
$28 \%$ da população era coberta pela ESF e 48 UBS dispunham de profissionais capacitados para realizar ações de diagnóstico e tratamento de casos de hanseníase; no entanto, em apenas 28 UBS eram realizadas tais ações. Além disso, 10 unidades de referência dispunham de médico dermatologista sanitário e enfermeiro em seu quadro de profissionais de saúde.

\subsection{Amostra}

A população deste estudo foi constituída por 217 mulheres em idade fértil com diagnóstico de hanseníase cadastradas nas 28 UBS que realizavam ações de diagnóstico, tratamento e controle da doença e gerenciadas pela Secretaria Municipal de Saúde de Maceió (SMS/Maceió) nos sete Distritos Sanitários. No entanto, este estudo foi realizado em 14 UBS, selecionadas a partir de critérios, como: ter endereço encontrado pelos entrevistadores, residir em Maceió, não ter ido a óbito, não ter mudado de município ou estado. Nestas 14 UBS, estavam registradas 60 mulheres que atendiam a estes critérios.

A partir dessa casuística, as UBS foram visitadas após o acesso às listas com registros de mulheres diagnosticadas e notificadas com hanseníase. Tais listas foram pesquisadas na SMS/Maceió e comparadas com as informações contidas nos livros de registros de Hanseníase das UBS. Em seguida, as mulheres diagnosticadas entre o período de 2006 a 2011 foram visitadas em seus domicílios e identificamos que 60 delas iriam compor a amostra. Foi realizado convite a estas participantes para reuniões nas UBS, onde informações acerca da pesquisa lhes foram dadas, solicitadas autorização para o levantamento de dados de prontuário e as entrevistas. As mulheres faltosas às reuniões foram novamente visitadas e, nessa ocasião, após consentimento, realizamos as entrevistas.

\subsubsection{Critérios de inclusão}

- Mulheres portadoras ou ex-portadoras de hanseníase diagnosticadas no período de 2006-2011;

- Idade compreendida entre 14 a 49 anos no diagnóstico;

- Residentes de Maceió; 


\subsubsection{Critérios de exclusão}

- Mulheres que realizaram histerectomia;

\subsection{Aspectos Éticos da Pesquisa}

Buscando zelar pela integridade ética dos sujeitos envolvidos no estudo, e com base nas diretrizes regulamentadoras das pesquisas com seres humanos contidas na resolução CNS 196/96 (BRASIL, 1996), o presente estudo foi apreciado e aprovado pelo Comitê de Ética em Pesquisa da Faculdade de Ciências Biológicas e da Saúde do Centro Universitário de Maceió (CESMAC) sob protocolo de pesquisa $n^{\circ}$ 1291/12 (ANEXO 2). Anteriormente, também foi solicitada a permissão das instituições de saúde da atenção básica nas instâncias envolvidas sendo autorizada pela Secretaria Municipal de Saúde de Maceió (ANEXO 3).

Todos os participantes foram informados sobre a finalidade, objetivos e os métodos do estudo por meio do Termo de Consentimento Livre e Esclarecido (TCLE). Foram elaborados dois TCLE, um para as mulheres acima de 18 anos, e outro para os responsáveis pelas mulheres menores de 18 anos (Apêndices II e III). Esses termos foram redigidos em linguagem clara e objetiva, por meio da qual os sujeitos foram informados sobre os objetivos do estudo, os procedimentos de coleta de dados, possíveis constrangimentos ou benefícios, sendo garantido o sigilo e respeitado o desejo ou não de participar. Constava nos TCLE, o pedido de autorização dos voluntários para a apresentação dos resultados encontrados em eventos científicos, a informação de que os sujeitos envolvidos na pesquisa eram livres para decidir em participar ou não da investigação, de desistirem em qualquer momento sem justificativas, sem que isso lhes acarretasse prejuízos. Foi-lhes esclarecido que a inserção de dados no questionário se daria de forma anônima, protegendo-os e assegurando suas identidades. Desse modo, o anonimato e a privacidade dos participantes foram resguardados, bem como o direito de deixar a pesquisa em qualquer momento.

No que tange aos riscos desta pesquisa, os mesmos estão relacionados a não interpretação idônea deste estudo tanto pelas mulheres em idade fértil, portadoras e exportadoras de hanseníase, uma vez que, estas poderiam sentir-se constrangidas diante dos questionamentos. Para diminuir estes riscos, agimos de maneira transparente e clara com as 
entrevistadas, dando informações relativas à pesquisa e durante toda a condução da entrevista, mantendo sempre o sigilo. Assim, a identificação dos participantes da pesquisa foi realizada por meio do número do instrumento e do prontuário.

Os benefícios da pesquisa dizem respeito às informações (orientações) obtidas pelas entrevistadas no que concerne à importância do planejamento familiar para a anticoncepção, com enfoque na prevenção, evitando riscos gestacionais e para o concepto. Tais informações foram repassadas por meio de técnicas de dinâmicas de grupos com metodologias ativas para facilitar a compreensão e entendimento da temática pelas mulheres, de modo a primar pela compreensão das ações de planejamento familiar como prevenção de uma gravidez de risco.

Em relação aos critérios para interromper a pesquisa, ressalta-se que a mesma seria suspensa caso houvesse a retirada da autorização por parte do Gestor Municipal (Secretário Municipal de Saúde de Maceió), como também a perda dos dados coletados e/ou rasuras dos questionários que inviabilizassem as interpretações dos dados coletados e/ou a desistência dos sujeitos em participar do presente estudo, respeitando, portanto, a autonomia dos sujeitos quanto à livre voluntariedade para a participação.

\subsection{Coleta de dados}

\subsubsection{Procedimentos de coleta de dados}

O recrutamento das participantes dessa pesquisa e a aquisição do Termo de Consentimento Livre e Esclarecido (TCLE) se deram após um levantamento de dados das mulheres com idade fértil, na faixa etária selecionada, a partir de variáveis descritivas (pessoa, tempo e lugar), junto ao Sistema de Informação de Agravos de Notificação (SINAN) no Setor de Vigilância Epidemiológica da SMS/Maceió. O levantamento dessas informações foi realizado e disponibilizado após a autorização da SMS/Maceió e aprovação do Comitê de Ética em Pesquisa ao qual foi submetido o estudo.

Em seguida, as 28 UBS foram visitadas com o intuito de dar ciência da pesquisa aos gestores e profissionais de saúde, bem como para entrega dos documentos de autorização do Comitê de Ética em Pesquisa e da SMS/ Maceió; além disso, foi solicitado que os agentes 
comunitários de saúde e os agentes de endemias participassem na visitação às residências de difícil acesso e áreas de risco (violentas), com a finalidade de convidar as mulheres participantes do estudo para uma reunião na UBS. Nesta reunião, foram dadas informações acerca da pesquisa, realizado acolhimento, procedeu-se à leitura do TCLE, solicitadas autorização para a busca dos aspectos clínicos da doença no prontuário e iniciadas as entrevistas.

Para as mulheres que não puderam comparecer nas UBS para a primeira reunião, prosseguiu-se com contato telefônico, em que foi possível agendar visita posterior para a realização das entrevistas no próprio domicílio. Vale ressaltar que muitas mulheres não foram encontradas por razões diversas, tais como: endereços não encontrados, telefones desatualizados, alterações de endereço, mudanças de municípios e de estado; e também, informações de terceiros e familiares acerca do óbito dessas mulheres.

As entrevistas foram realizadas pela pesquisadora e entrevistadores, estudantes do curso de Enfermagem de instituições de ensino superior - Universidade Federal de Alagoas, Faculdade Maurício de Nassau, Faculdade Integrada Tiradentes e Faculdade Estácio de Alagoas - participantes do Grupo de Pesquisa e Extensão "Hanseníase na Comunidade". Estes entrevistadores foram capacitados por meio de: 1) Curso de Hansenologia, com carga horária de 40 horas; 2) Oficina de Pesquisa, em que lhes foram apresentados o projeto de pesquisa e os instrumentos de coleta de dados por meio de metodologia ativa, dramatização, com foco na entrevista e preenchimento do referido instrumento.

A pesquisadora iniciou a fase de entrevistas acompanhando os entrevistadores às UBS e realizando de 1 a 2 entrevistas na presença destes, que logo após, deram continuidade. $\mathrm{O}$ instrumento de coleta de dados utilizado nesta fase consta no APÊNDICE I e foi elaborado com base em uma revisão abrangente da literatura científica, seguido de validação de face e conteúdo por painel de especialistas. A pesquisadora realizou ainda supervisões quinzenais em cada UBS e reuniões mensais com os entrevistadores.

Após as entrevistas, realizou-se busca de dados nos prontuários para o levantamento dos aspectos clínicos da doença, que foram registrados no tópico "Dados Referentes à Doença/Coleta de Dados” (APÊNDICE I). 


\subsubsection{Instrumento de coleta de dados}

Para o presente trabalho, foi eleito, por conveniência, um painel de especialistas composto por seis profissionais com domínio nas áreas de Hansenologia e Saúde da Mulher (uma médica dermatologista hansenóloga, com nível de mestrado acadêmico, e cinco enfermeiras com titulação de Doutorado). São profissionais atuantes nos estados de Alagoas, Ceará e São Paulo, detentoras de experiência singular quanto ao contexto dessa pesquisa, o que as qualificava para contribuir na avaliação e validação de face e conteúdo do questionário proposto pela pesquisadora.

O instrumento de coleta de dados (Apêndice I) denominado "Questionário sobre mulheres em idade fértil, portadoras e ex-portadoras de hanseníase no município de Maceió/Alagoas" constou de 45 questões fechadas divididas em IV partes, contendo dados sociodemográficos, dados clínicos da doença, dados da história reprodutiva das mulheres e informações sobre o planejamento familiar.

\subsubsection{Variáveis envolvidas no estudo}

A primeira parte do instrumento de coleta de dados compreendeu variáveis sociademográficas, como:

- idade no diagnóstico da hanseníase;

- se tem companheiro;

- grau de escolaridade;

- profissão;

- ocupação;

- religião;

- itens de conforto.

A segunda parte do questionário foi composta por variáveis clínicas da doença:

- data da notificação;

- data do diagnóstico; 
- forma clínica da doença;

- classificação operacional da doença;

- resultado de baciloscopia;

- data de início do tratamento;

- grau de incapacidade física no momento do diagnóstico e na alta por cura;

- número de lesões cutâneas;

- modo de detecção;

- conhecimento acerca dos riscos de desenvolvimento das reações hansênicas ao engravidar, durante e após o tratamento;

- tipos de reações hansênicas;

A terceira parte do questionário constituiu-se por variáveis referentes à história reprodutiva da mulher, tais como:

- número de filhos;

- número de gestações;

- gravidez no momento do diagnóstico da hanseníase;

- gravidez no percurso da doença (tratamento, alta por cura e pós alta)

- número de gestações;

- número de partos;

- número de abortos;

- idade no primeiro parto;

- idade no último parto;

- amamentação;

A quarta e última parte do instrumento de coleta de dados trouxe à tona variáveis referentes ao planejamento familiar:

- métodos anticoncepcionais que essas mulheres já ouviram falar;

- acesso aos métodos anticoncepcionais;

- orientações quanto à utilização dos métodos anticoncepcionais;

- apresentação de sinais e sintomas da doença ou reação hansênica antes, durante a gravidez, no puerpério ou na lactação; 


\subsection{Análise dos dados}

Inicialmente o banco de dados foi construído, sendo os dados coletados armazenados em uma planilha do software EXCEL (Microsoft Office) para a codificação das variáveis, com digitação dupla, por pesquisadores distintos, e seguiu-se com a validação dessas planilhas. Após essa etapa, o banco de dados foi importado e processado pelo programa Statistical Package for the Social Sciences (SPSS) versão 17.0 para Windows. As análises descritivas foram realizadas visando caracterizar a população do estudo, e inclui o cálculo de frequência, média, desvio-padrão, sendo também apresentados os valores mínimo e máximo de cada variável contínua. A distribuição de normalidade dos dados foi verificada pelo teste de Kolmorogov-Smirnov, bem como a igualdade de variâncias foi observada pelo teste de Levene.

Os resultados foram organizados em tabelas, e a análise e discussão foram baseadas na literatura científica atual consultada. Associações estatísticas de análises bivariadas foram realizadas por meio do teste de $\chi^{2}$. Analisou-se as correlações das variáveis por meio dos coeficientes $r$ de Pearson e/ou $\mathrm{r}_{\mathrm{s}}$ de Spearman.

As médias dos grupos foram analisadas pelo teste t de Student para as variáveis comdistribuição Gaussiana (normal),ou por meio do teste de Mann-Whitney para àquelas variáveis sem distribuição normal e pelo teste F de Snedecor (ou Friedman). As comparações múltiplas foram feitas pelo teste de Tukey ou de Games-Howell, se paramétricas e pelo teste de Dunn, se não paramétricas. Diferenças entre as variáveis foram consideradas estatisticamente significativas quando $\mathrm{p}<0,05$ (para $\alpha=5 \%$; $\beta=0,2$ e IC $=95 \%$ ).

Os resultados provenientes desta pesquisa, que serão apresentados a seguir, referem-se à descrição e análise da saúde reprodutiva de mulheres portadoras e ex-portadoras de Hanseníase de Maceió, capital do estado de Alagoas, no período de 2006 a 2011. A primeira parte dos resultados apresenta as variáveis sociodemográficas (idade, grau de escolaridade, profissão, se tem companheiro, ocupação e religião); a segunda parte se refere aos dados das variáveis clínicas da doença (forma clínica, classificação operacional, resultados da baciolospia, grau de incapacidade física no momento do diagnóstico e no momento da alta, número de lesões cutâneas, modo de detecção, tipos de reações hansênicas e conhecimento acerca dos riscos de desenvolvimento destas reações ao engravidar, durante e após o tratamento). 
A terceira parte apresenta variáveis referentes à história reprodutiva destas mulheres, tais como: número de gestações, número de partos, número de filhos, número de abortos, idade no primeiro parto, idade no último parto e amamentação. Na última parte (quarta), se encontram dados referentes ao planejamento familiar e reações hansênicas, segundo gravidez, puerpério e lactação, como também as associações referentes ao conhecimento espontâneo e uso de métodos contraceptivos. 


\section{RESULTADOS}

\section{1 Caracterização Sociodemográfica}

Analisando a Tabela 1, os dados nos revelam que as mulheres pesquisadas tinham idade entre 15 a 49 anos, sendo que a maioria delas se encontrava na faixa de 30 a 49 anos (75\%), destacando-se também que o menor percentual encontrado foi na faixa de 15 a 19 anos $(5 \%)$.

Em relação a ter ou não companheiro, observa-se que $70 \%$ delas afirmaram ter. Considerando a escolaridade, observou-se a predominância de analfabetas ou com o ensino fundamental incompleto (53,3\%); apenas $8,6 \%$ das entrevistadas estavam matriculadas nas escolas e $91,4 \%$ estavam fora do ambiente escolar. Em relação à ocupação, $45 \%$ eram do lar e 55\% desempenhavam outras ocupações remuneradas, incluindo marisqueiras, empregadas domésticas, rendeiras, diaristas, e entre outras.

Quanto ao número de pessoas que residiam com estas mulheres, a maior frequência encontrada foi de uma a três $(36,7 \%)$ e merece destaque as coabitações com seis a quatorze pessoas $(28,3 \%)$. Quanto à religião, houve predominância da religião católica, com $(61,7 \%)$, seguida da evangélica $(26,7 \%)$. 
Tabela 1 - Distribuição das mulheres portadoras e ex-portadoras de Hanseníase, em idade fértil, segundo características sociodemográficas, Maceió-Alagoas, 2006 a 2011. (n=60).

\begin{tabular}{lcc}
\hline & \multicolumn{2}{c}{ Distribuição } \\
\cline { 2 - 3 } Idade & $\mathbf{N}$ & $\mathbf{\%}$ \\
\hline $15-19$ & 3 & 5,0 \\
$20-29$ & 12 & 20,0 \\
$30-49$ & 45 & 75,0 \\
\hline Companheiro & & \\
\hline Sim & 42 & 70,0 \\
Não & 17 & 28,3 \\
Não respondeu & 1 & 1,70 \\
\hline Escolaridade & & \\
\hline Anal./Fund. Inc. & 32 & 53,3 \\
Fund. Comp./Méd. Inc. & 13 & 21,7 \\
Médio Completo & 12 & 20,0 \\
Superior Completo & 3 & 5,0 \\
\hline Religião & & \\
\hline Ignorado & 3 & 5,00 \\
Católica & 37 & 61,7 \\
Evangélica & 16 & 26,7 \\
Espírita & 1 & 1,70 \\
Não tem religião & 3 & 5,00 \\
\hline Ocupação & & \\
\hline Do lar & 27 & 45,0 \\
Outras & 33 & 55,0 \\
\hline No Pessoas na Família & & 36,7 \\
\hline 1 a 3 & 22 & 28,3 \\
4 a 5 & 17 & \\
6 a 14 & Anal./Fund. Inc.; Fundamental Completo / Médio Incompleto \\
\hline ota: Analfabeto / Fundamental Incompleto & \\
Fund. Comp./Méd. Inc. & & \\
& & \\
\hline
\end{tabular}

\subsection{Aspectos Clínicos}

De acordo com os dados da Tabela 2, observa-se que os modos de detecção mais frequentes foram o encaminhamento e a demanda espontânea com $30 \%$ de casos em cada modalidade. Destaca-se o menor índice para o exame de contatos, com apenas 1,7\%.

Em relação ao modo de entrada das mulheres nas UBS, observa-se que 73,3\% dos casos foram notificados como caso novo. Outro modo de entrada que se destaca foi o de recidiva $(3,3 \%)$, reingresso $(3,3 \%)$ e modo de entrada ignorado $(3,3 \%)$. 
Tabela 2 - Distribuição das mulheres portadoras e ex-portadoras de Hanseníase, em idade fértil, segundo modo de detecção e modo de entrada no sistema de saúde, Maceió-Alagoas, 2006 a 2011 . $(n=60)$.

\begin{tabular}{lcc}
\hline & \multicolumn{2}{c}{ Distribuição } \\
\cline { 2 - 3 } Modo de detecção $^{\mathbf{1}}$ & $\mathbf{N}$ & $\mathbf{\%}$ \\
\hline Encaminhamento & 18 & 30,0 \\
Demanda espontânea & 18 & 30,0 \\
Exame de coletividade & 2 & 3,30 \\
Exame de contatos & 1 & 1,70 \\
Ignorado & 21 & 35,0 \\
\hline Modo de entrada $^{2}$ & & \\
\hline Caso novo & 44 & 73,3 \\
Transferência & 10 & 16,7 \\
Recidiva & 2 & 3,30 \\
Reingresso & 2 & 3,30 \\
Ignorado & 2 & 3,30 \\
\hline
\end{tabular}

Nota 1 - Modo de detecção: é a informação que é dada na ficha de notificação compulsória que informa como caso foi identificado para o diagnóstico da Hanseníase.

Nota 2 - Modo de entrada: é a informação que é dada na ficha de notificação compulsória que identifica como o caso deu entrada para o diagnóstico de hanseníase.

Quanto às variáveis clínicas da doença, segundo a classificação de Madri (Tabela 3), a forma Dimorfa foi a mais frequente com $30,0 \%$ dos casos, seguida da forma Tuberculoide (20\%). Destacam-se o diagnóstico precoce, na forma Indeterminada, que ocorreu em apenas $15 \%$ das mulheres. Já a forma Virchowiana ocorreu em $6 \%$ das mulheres e houve um alto percentual $(25,0 \%)$ de formas clínicas não classificadas. O maior percentual da classificação operacional foi de multibacilares com $56,7 \%$.

Em relação aos dados das baciloscopias, observa-se que $81,7 \%$ não têm registro deste exame no prontuário. Das baciloscopias realizadas encontramos positividade em apenas $6,7 \%$ dos registros.

Considerando o número de lesões dermatológicas no diagnóstico, observa-se que $41,6 \%$ destas mulheres apresentaram seis ou mais lesões, critério que define a classificação operacional como multibaciliar. Destaca-se ainda que 48,4\% apresentavam de uma a cinco lesões, o que as classificam como Paucibacilares. 
Tabela 3 - Distribuição das mulheres portadoras e ex-portadoras de Hanseníase, em idade fértil, segundo forma clínica, classificação operacional, baciloscopia e número de lesões, Maceió-Alagoas, 2006 a 2011. $(\mathrm{n}=60)$.

\begin{tabular}{lcc}
\hline & \multicolumn{2}{c}{ Distribuição } \\
\cline { 2 - 3 } Forma Clinica & $\mathbf{N}$ & $\mathbf{\%}$ \\
\hline Indeterminada & 9 & 15,0 \\
Tuberculóide & 12 & 20,0 \\
Dimorfa & 18 & 30,0 \\
Virchowiana & 6 & 10,0 \\
Não classificada & 15 & 25,0 \\
\hline Classificação Operacional & & \\
\hline Paucibacilar & 25 & 41,7 \\
Multibacilar & 34 & 56,7 \\
Não classificado & 1 & 1,70 \\
\hline Baciloscopia & & \\
\hline Positiva & 4 & 6,70 \\
Negativa & 7 & 11,7 \\
Não realizada & 49 & 81,7 \\
\hline Número de lesões & & \\
\hline 0 & 6 & 40,0 \\
1 a 5 & 29 & 41,6 \\
6 e mais & 25 & \\
\hline
\end{tabular}

Os resultados da Tabela 4 nos permitem afirmar que a maioria (53,3\%) apresentava Grau $\mathrm{O}$ de incapacidade física no momento do diagnóstico. Entretanto, destaca-se que 30\% destas mulheres foram diagnosticadas com comprometimento neural (Grau 1 de incapacidade) e 3,3\% apresentavam Grau 2 de incapacidade.

No momento da alta por cura, $46 \%$ das mulheres não realizaram o Exame Neurofuncional Simplificado de Avaliação do Grau de Incapacidade Física. Entre as 28 mulheres avaliadas na alta, $9(32,1 \%)$ apresentavam Grau 1 de incapacidade. 
Tabela 4 - Distribuição das mulheres portadoras e ex-portadoras de Hanseníase, em idade fértil, segundo o grau de incapacidade física no diagnóstico e na alta, Maceió-Alagoas, 2006 a 2011. $(n=60)$.

\begin{tabular}{lcc}
\hline & \multicolumn{2}{c}{ Distribuição } \\
\cline { 2 - 3 } Grau de incapacidade física no diagnóstico & $\mathbf{N}$ & $\mathbf{\%}$ \\
\hline 0 (Zero) & 32 & 53,3 \\
1 (Um) & 18 & 30,0 \\
2 (Dois) & 2 & 3,30 \\
Não avaliado & 5 & 8,30 \\
Ignorado & 3 & 5,00 \\
\hline Grau de Incapacidade física na alta & & \\
\hline (Zero) & 18 & 30,0 \\
1 (Um) & 9 & 15,0 \\
2 (Dois) & 1 & 1,70 \\
Não avaliado & 28 & 46,7 \\
Ignorado & 4 & 6,60 \\
\hline
\end{tabular}

Em relação aos dados da tabela 5 podemos observar que, do total de contatos registrados, 55\% das mulheres tinham de um a cinco pessoas da família registradas como contatos domiciliares, enquanto $10 \%$ tinham de seis a dez.

Destaca-se que $50 \%$ das mulheres não tiveram seus contatos examinados e dentre aquelas cujos contatos foram avaliados, $41,6 \%$ tiveram de um a cinco contatos examinados.

Tabela 5 - Distribuição das mulheres portadoras e ex-portadoras de Hanseníase, em idade fértil, segundo número de contatos registrados e contatos examinados no momento do diagnóstico, Maceió-Alagoas 2006 a 2011. $(\mathrm{n}=60)$.

\begin{tabular}{lcc}
\hline \multirow{2}{*}{$\mathbf{N}^{\mathbf{0}}$ contatos registrados } & \multicolumn{2}{c}{ Distribuição } \\
\cline { 2 - 3 } 0 & $\mathbf{N}$ & $\mathbf{\%}$ \\
1 a 5 & 18 & 30,0 \\
6 a 10 & 33 & 55,0 \\
$>10$ & 6 & 10,0 \\
\hline $\mathbf{N}^{\mathbf{0}}$ contatos examinados & 3 & 5,00 \\
\hline 0 & & \\
1 a 5 & 30 & 50,0 \\
6 a 10 & 25 & 41,6 \\
$>10$ & 3 & 5,00 \\
\hline
\end{tabular}

De acordo com os dados da Tabela 6 , dentre as mulheres, $16,7 \%$ informaram ter apresentado reações hansênicas antes do diagnóstico. 
Quanto às reações hansênicas durante o tratamento, 28,3\% informaram ter tido estas reações, enquanto $21,7 \%$ tiveram surtos reacionais pós-tratamento. Entre as mulheres que apresentaram reações hansênicas, $8,3 \%$ eram do tipo I, enquanto $66,7 \%$ eram do tipo II.

Tabela 6 - Distribuição das mulheres portadoras e ex-portadoras de Hanseníase, em idade fértil, segundo reações hansênicas e história reprodutiva no momento do diagnóstico, MaceióAlagoas 2006 a 2011. $(\mathrm{n}=60)$.

\begin{tabular}{lcccccc}
\hline & \multicolumn{3}{c}{ Portadoras e ex-portadoras de Hanseníase } \\
\cline { 2 - 7 } Reações Hansênicas & \multicolumn{2}{c}{ Sim } & \multicolumn{3}{c}{ Não } & \multicolumn{2}{c}{ Ignorados } \\
\cline { 2 - 7 } & $\mathbf{N}$ & $\mathbf{\%}$ & $\mathbf{N}$ & $\mathbf{\%}$ & $\mathbf{N}$ & $\mathbf{\%}$ \\
\hline Antes do diagnóstico & 10 & 16,7 & 40 & 66,7 & 10 & 16,7 \\
Durante o tratamento & 17 & 28,3 & 33 & 55,0 & 10 & 16,7 \\
Pós tratamento & 13 & 21,7 & 37 & 61,7 & 10 & 16,7 \\
\hline História reprodutiva & & & & & & \\
\hline Gravidez no diagnóstico & 3 & 5,0 & 56 & 93,3 & 1 & 1,7 \\
Puerpério no diagnóstico & 1 & 1,7 & 58 & 96,7 & 1 & 1,7 \\
Lactação no diagnóstico & 1 & 1,7 & 58 & 96,7 & 1 & 1,7 \\
\hline
\end{tabular}

\subsection{História Reprodutiva}

Os dados da Tabela 7 evidenciam que entre as mulheres pesquisadas, três delas (5\%) estavam grávidas no momento do diagnóstico, uma $(1,7 \%)$ se encontrava no período puerperal e outra $(1,7 \%)$ estava amamentando.

Em relação à história reprodutiva das mulheres portadoras ou ex-portadoras de Hanseníase, observa-se que 63,3\% informaram ter engravidado de uma a três vezes, enquanto que $26,6 \%$ engravidaram de quatro a dez vezes. Em relação ao número de partos, $75 \%$ tiveram de um a três partos. O número de filhos dessas mulheres variou de um a dez, em que $71,6 \%$ delas tiveram de um a três filhos e 18,2\%, de quatro a dez. Entre as entrevistadas, $21,5 \%$ tiveram de um a três abortamentos. 
Tabela 7 - Distribuição das mulheres portadoras e ex-portadoras de Hanseníase, em idade fértil, segundo número de gestações, partos, número de filhos e abortos, Maceió-Alagoas 2006 a 2011. $(n=60)$.

\begin{tabular}{lcc}
\hline & \multicolumn{3}{c}{ Distribuição } \\
\cline { 2 - 3 } $\mathbf{N}^{\mathbf{0}}$ Gestações & $\mathbf{N}$ & $\mathbf{\%}$ \\
\hline 0 & 6 & 10,0 \\
1 a 3 & 38 & 63,3 \\
4 a 6 & 12 & 20,0 \\
7 a 10 & 4 & 6,60 \\
\hline Paridade & & \\
\hline 0 & 6 & 10,0 \\
1 a 3 & 45 & 75,0 \\
4 a 6 & 5 & 8,30 \\
7 a 10 & 4 & 6,60 \\
\hline $\mathbf{N}^{\mathbf{0}}$ filhos & & \\
\hline 0 & 6 & 10,0 \\
1 a 3 & 43 & 71,6 \\
4 a 6 & 7 & 11,6 \\
7 a 10 & 4 & 6,60 \\
\hline $\mathbf{N}^{\mathbf{0}}$ abortos & & \\
\hline 0 & 47 & 78,3 \\
1 & 10 & 16,6 \\
2 & 2 & 3,30 \\
3 & 1 & 1,60 \\
\hline
\end{tabular}

Em relação à Tabela 8 , observa-se que $40 \%$ das mulheres do estudo tiveram sua primeira gravidez na adolescência, em que 3,3\% com idade menor que 14 anos e 36,6\% entre 15 a 19 anos.

Em relação à idade do último parto, este dado revela que $8,3 \%$ das mulheres pesquisadas estavam ainda na adolescência e $66,6 \%$ se encontravam na faixa de idade entre 20 a 34 anos. 
Tabela 8 - Distribuição das mulheres portadoras e ex-portadoras de Hanseníase, em idade fértil, segundo idade do primeiro parto e último parto, Maceió-Alagoas, 2006 a 2011. (n=60).

\begin{tabular}{lcc}
\hline & \multicolumn{2}{c}{ Distribuição } \\
\cline { 2 - 3 } Idade no primeiro parto & $\mathbf{N}$ & \% \\
\hline$<14$ & 2 & 3,3 \\
15 a 19 & 22 & 36,6 \\
20 a 24 & 20 & 33,3 \\
25 a 29 & 7 & 11,6 \\
$>30$ & 1 & 1,6 \\
Ignorado & 8 & 13,3 \\
\hline Idade do último parto & & \\
\hline 17 a 19 & 5 & 8,3 \\
20 a 24 & 15 & 25 \\
25 a 29 & 12 & 20 \\
30 a 34 & 13 & 21,6 \\
$>35$ & 4 & 6,6 \\
Ignorado & 11 & 18,3 \\
\hline
\end{tabular}

Considerando os dados encontrados na Tabela 9, podemos observar que três mulheres estavam grávidas no momento do diagnóstico e que uma $(1,7 \%)$ delas se encontrava na faixa etária de 20 a 29 anos; as outras duas (3,3\%), na faixa etária de 30 a 34 anos.

Dentre as mulheres que estavam grávidas no momento do diagnóstico, duas $(3,3 \%)$ informaram ter companheiro e uma $(1,7 \%)$ delas, não; apenas uma $(1,7 \%)$ com ocupação remunerada.

Tabela 9 - Distribuição do número de mulheres grávidas no momento do diagnóstico segundo características sociodemográficas, Maceió-Alagoas, 2006 a 2011. (n=60).

\begin{tabular}{|c|c|c|c|c|}
\hline \multirow{3}{*}{$\begin{array}{l}\text { Características } \\
\text { sociodemográficas }\end{array}$} & \multicolumn{4}{|c|}{ Gravidez no momento do diagnóstico } \\
\hline & \multicolumn{2}{|c|}{ Sim } & \multicolumn{2}{|c|}{ Não } \\
\hline & $\mathbf{N}$ & $\%$ & $\mathbf{N}$ & $\%$ \\
\hline $20-29$ & 1 & 1,7 & 11 & 19,6 \\
\hline $30-34$ & 2 & 3,3 & 42 & 75,0 \\
\hline Companheiro & 2 & 3,3 & 39 & 69,6 \\
\hline Ocupação remunerada & 1 & 1,7 & 25 & 44,6 \\
\hline
\end{tabular}




\section{4 Planejamento Familiar com associações entre conhecimento e uso de métodos anticoncepcionais}

A Tabela 10, que trata da distribuição numérica e percentual das mulheres segundo o conhecimento espontâneo de métodos contraceptivos, apresentou os seguintes resultados acerca dos seguintes métodos: condom masculino (98,3\%), pílula/ método hormonal oral $(88,3 \%)$, laqueadura tubária $(86,7 \%)$, condom feminino $(76,7 \%)$, injetável/ método hormonal injetável (71,7\%), DIU (60\%), Ogino-Knaus (58,3\%), vasectomia $(51,7 \%)$.

A mesma tabela apresenta os seguintes dados quanto ao uso destes métodos, com maiores percentuais encontrados para: pílula/ método hormonal oral $(73,3 \%)$, condom masculino $(70,0 \%)$, laqueadura tubária $(53,3 \%)$ e vasectomia $(51,7 \%)$.

Tabela 10 - Distribuição do número de mulheres, em idade fértil, portadoras e ex-portadoras de Hanseníase, segundo o conhecimento espontâneo e o uso de método contraceptivo, Maceió-Alagoas 2006 a 2011. $(n=60)$.

\begin{tabular}{l|cc|cc|ccc|cc}
\hline \multirow{2}{*}{ Métodos } & \multicolumn{4}{|c|}{ Conhecimento } & \multicolumn{4}{c}{ Uso } \\
\cline { 2 - 10 } & \multicolumn{3}{|c}{ Sim } & \multicolumn{2}{c|}{ Não } & \multicolumn{3}{c}{ Sim } & \multicolumn{2}{c}{ Não } \\
\hline Ogino-Knaus & 35 & 58,3 & 25 & 41,7 & 13 & 21,6 & 47 & \% \\
Muco & 4 & 4,70 & 56 & 93,3 & 11 & 17,4 & 49 & 81,7 \\
Temperatura & 9 & 15,0 & 51 & 85,0 & 10 & 16,7 & 50 & 83,3 \\
Coito & 18 & 30,0 & 42 & 70,0 & 19 & 31,7 & 41 & 68,3 \\
Aleitamento materno & 19 & 31,7 & 41 & 68,3 & 14 & 23,4 & 46 & 76,7 \\
Pílula & 53 & 88,3 & 6 & 10,0 & 44 & 73,3 & 16 & 26,7 \\
Injeção & 43 & 71,7 & 16 & 26,7 & 22 & 36,6 & 38 & 63,3 \\
DIU & 36 & 60,0 & 24 & 40,0 & 13 & 21,6 & 47 & 78,3 \\
Diafragma & 9 & 15,0 & 51 & 85,0 & 11 & 18,3 & 49 & 81,7 \\
Espermicida & 8 & 13,3 & 52 & 86,7 & 11 & 18,3 & 49 & 81,7 \\
Condom feminino & 46 & 76,7 & 14 & 23,3 & 14 & 23,3 & 46 & 76,7 \\
Condom masculino & 59 & 98,3 & 1 & 1,70 & 42 & 70,0 & 18 & 30,0 \\
Pílula de emergência & 25 & 41,7 & 35 & 58,3 & 16 & 26,6 & 44 & 73,3 \\
Laqueadura tubária & 52 & 86,7 & 8 & 13,3 & 32 & 53,3 & 28 & 46,7 \\
Vasectomia & 31 & 51,7 & 29 & 48,3 & 31 & 51,7 & 29 & 48,3 \\
Implante & 8 & 13,3 & 52 & 86,7 & 8 & 13,3 & 52 & 86,7 \\
Outros & 3 & 5,00 & 57 & 95,0 & 3 & 5,00 & 57 & 95,0 \\
\hline
\end{tabular}

Ao analisar descritivamente a Tabela 11, verificou-se que as mulheres que engravidaram no percurso da doença, responderam possuir conhecimento espontâneo acerca dos métodos: tabela de Ogino-Knaus $(21,4 \%)$, pílula/ método hormonal oral $(18,9 \%)$, injeção/ 
método hormonal injetável (21,3\%), dispositivo intrauterino (DIU), $(20 \%)$, condom feminino $(19,6 \%)$, condom masculino $(18,6 \%)$, pílula de emergência $(24,1 \%)$ e laqueadura $(18,9 \%)$, respectivamente.

Ao realizar uma análise inferencial com os dados sobre mulheres que engravidaram no percurso da doença e do conhecimento espontâneo sobre métodos anticoncepcionais, observou-se que os resultados indicaram que nenhum dos métodos anticoncepcionais apresentou relação significativa entre conhecimento espontâneo e gravidez no percurso da doença $(\mathrm{p}>0,05)$.

Tabela 11 - Distribuição do número de mulheres em idade fértil, portadoras e ex-portadoras com Hanseníase, segundo gravidez no percurso da doença e conhecimento espontâneo sobre método anticoncepcional, Maceió-AL, 2006 a 2011. ( $\mathrm{n}=60)$.

\begin{tabular}{|c|c|c|c|c|c|}
\hline \multirow{3}{*}{$\begin{array}{l}\text { Métodos } \\
\text { Tabela de Ogino-Knaus }\end{array}$} & \multicolumn{4}{|c|}{$\begin{array}{c}\text { Portadoras e ex-portadoras de } \\
\text { Hanseníase }\end{array}$} & \multirow{3}{*}{ p-valor } \\
\hline & \multicolumn{2}{|c|}{ Sim } & \multicolumn{2}{|c|}{ Não } & \\
\hline & $N$ & $\%$ & $N$ & $\%$ & \\
\hline $\operatorname{Sim}$ & 9 & 21,4 & 33 & 78,6 & 0,344 \\
\hline Não & 2 & 11,1 & 16 & 88,9 & \\
\hline \multicolumn{6}{|l|}{ Pílula } \\
\hline Sim & 10 & 18,9 & 43 & 81,1 & 0,896 \\
\hline Não & 1 & 16,7 & 5 & 83,3 & \\
\hline \multicolumn{6}{|l|}{ Injeção } \\
\hline Sim & 10 & 21,3 & 37 & 78,7 & 0,304 \\
\hline Não & 1 & 8,30 & 11 & 91,7 & \\
\hline \multicolumn{6}{|c|}{ Dispositivo Intrauterino - DIU } \\
\hline $\operatorname{Sim}$ & 8 & 20,0 & 32 & 80,0 & 0,637 \\
\hline Não & 3 & 15,0 & 17 & 85,0 & \\
\hline \multicolumn{6}{|l|}{ Condom Feminino } \\
\hline Sim & 10 & 19,6 & 41 & 80,4 & 0,544 \\
\hline Não & 1 & 11,1 & 8 & 88,9 & \\
\hline \multicolumn{6}{|l|}{ Condom Masculino } \\
\hline Sim & 11 & 18,6 & 48 & 81,4 & $0,633^{(1)}$ \\
\hline Não & - & - & 1 & 100 & \\
\hline \multicolumn{6}{|l|}{ Pílula de Emergência } \\
\hline Sim & 7 & 24,1 & 22 & 75,9 & 0,261 \\
\hline Não & 4 & 12,9 & 27 & 87,1 & \\
\hline \multicolumn{6}{|l|}{ Laqueadura Tubária } \\
\hline Sim & 10 & 18,9 & 43 & 81,1 & 0,768 \\
\hline Não & 1 & 14,3 & 6 & 85,7 & \\
\hline
\end{tabular}

(1)Qui-Quadrado com continuidade de correção. 
Os dados da Tabela 12 tratam do conhecimento espontâneo sobre métodos anticoncepcionais, segundo características sociodemográficas dessas mulheres, as quais informaram se: tinham companheiro, completaram ou não o ensino fundamental, qual sua ocupação e religião, se estudavam, o número de pessoas na família, e classificação operacional da doença (paucibacilar ou multibacilar).

Destacamos que os maiores percentuais encontrados quanto ao conhecimento espontâneo sobre métodos anticoncepcionais e características sociodemográficas foram: pílula $(87,8 \%)$, injeção $(75,6 \%)$, tabela $(71,4 \%)$, DIU $(64,3 \%)$, condom masculino $(100 \%)$, laqueadura tubária $(85,7 \%)$. No entanto, $70,6 \%$ conheciam a vasectomia, mas não tinham companheiro. Realizando-se uma análise inferencial quanto aos métodos contraceptivos, os dados denotam uma relação significativa com associação entre a temperatura e ocupação, aleitamento materno e número de pessoas na família, pílula e número de pessoas, injeção e escolaridade da mulher, injeção e ocupação, diafragma e número de pessoas, espermicida e número de pessoas, vasectomia e se estudava, com $\mathrm{p}>0,05$. 
Tabela 12 - Distribuição do percentual de mulheres portadoras e ex-portadoras de hanseníase, com conhecimento espontâneo sobre métodos anticoncepcionais e características sociodemográficas, Maceió-Alagoas 2006 a 2011. (n=60).

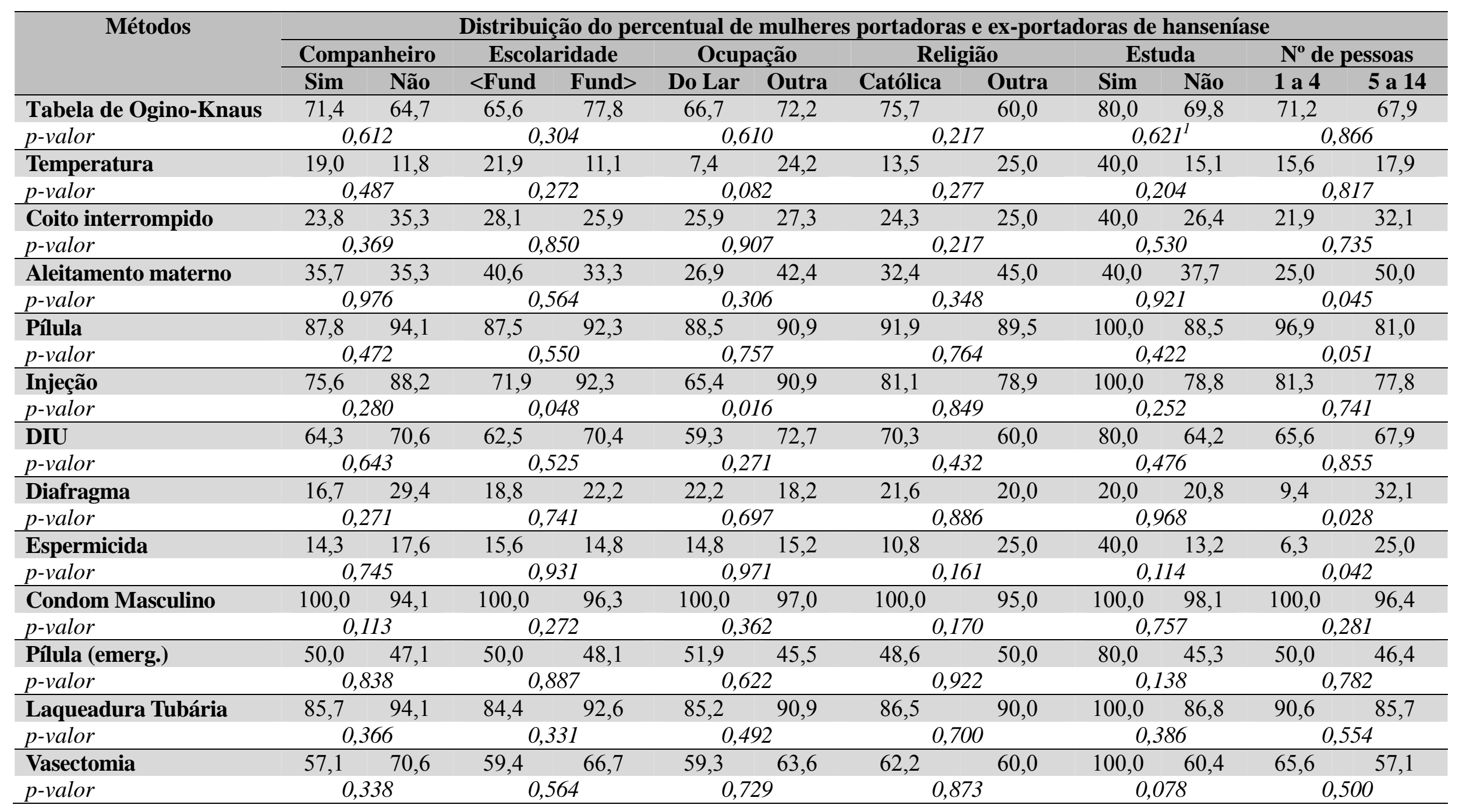


Em relação à Tabela 13, que trata de informações sobre métodos anticoncepcionais segundo de quem ouviu falar, foram o médico e o enfermeiro os que mais contribuíram em fornecer informações, principalmente para o grupo de adolescentes na faixa etária de 15 a 19 anos, com 66, 7\%. Em relação à faixa etária de 15 a 49 anos, o índice foi de 56,8\% paro o médico e de 52,8\% para o enfermeiro. Os meios midiáticos exercem uma grande influência, principalmente a televisão, o rádio e a revista.

Tabela 13 - Distribuição do percentual de mulheres portadoras e ex-portadoras de hanseníase, segundo de quem ouviu falar sobre métodos anticoncepcionais e características sociodemográficas e clínicas, Maceió-Alagoas 2006 a 2011. (n=60).

\begin{tabular}{|c|c|c|c|c|c|c|c|c|c|c|c|c|c|c|c|c|c|}
\hline \multirow{3}{*}{ Método } & \multicolumn{17}{|c|}{ Distribuição percentual } \\
\hline & \multicolumn{3}{|c|}{ Faixa Etária } & \multicolumn{2}{|c|}{ Companheiro } & \multicolumn{2}{|c|}{ Escolaridade } & \multicolumn{2}{|c|}{ Ocupação } & \multicolumn{2}{|c|}{ Religião } & \multicolumn{2}{|c|}{ Estuda } & \multicolumn{2}{|c|}{$\mathbf{N}^{0}$ Pessoas } & \multicolumn{2}{|c|}{ Forma clinica } \\
\hline & $15-19$ & $20-29$ & $30-49$ & Sim & Não & $<$ Fund & Fund $>$ & Do Lar & Outra & Cat. & Outra & Sim & Não & 1 a 4 & 5 a 14 & Pauci & Multi \\
\hline Médico & 66,7 & 58,3 & 45,5 & 58,8 & 46,3 & 51,6 & 48,1 & 50,0 & 48,5 & 52,8 & 45,0 & 60,0 & 48,1 & 45,2 & 53,6 & 56,0 & 45,5 \\
\hline Enfermeiro & 66,7 & 41,7 & 50,0 & 46,3 & 58,8 & 54,8 & 40,7 & 42,3 & 54,5 & 41,7 & 60,0 & 60,0 & 46,2 & 48,4 & 50,0 & 64,0 & 36,4 \\
\hline Farmacêutico & 0 & 25,0 & 0 & 4,9 & 5,9 & 6,5 & 3,7 & 0 & 9,1 & 5,6 & 5,0 & 0 & 5,8 & 6,5 & 3,6 & 8,0 & 3,0 \\
\hline Amigo & 33,3 & 66,7 & 34,1 & 34,1 & 52,9 & 41,9 & 40,7 & 34,6 & 45,5 & 41,7 & 30,0 & 60,0 & 38,5 & 41,9 & 39,3 & 56,0 & 30,3 \\
\hline TV & 100,0 & 75,0 & 79,5 & 82,9 & 70,6 & 74,2 & 88,9 & 80,8 & 78,8 & 77,8 & 80,0 & 100,0 & 78,8 & 77,4 & 82,1 & 76,0 & 81,8 \\
\hline Radio & 66,7 & 58,3 & 29,5 & 39,0 & 35,3 & 35,5 & 40,7 & 26,9 & 45,5 & 41,7 & 30,0 & 40,0 & 38,5 & 38,7 & 35,7 & 44,0 & 33,3 \\
\hline Parceiro & 0 & 8,3 & 13,6 & 12,5 & 11,8 & 16,1 & 7,4 & 11,5 & 12,1 & 11,1 & 10,0 & 20,0 & 9,6 & 16,1 & 7,1 & 16,0 & 9,1 \\
\hline Parente & 33,3 & 16,7 & 22,7 & 22,0 & 23,5 & 16,1 & 29,6 & 26,9 & 18,2 & 27,8 & 15,0 & 40,0 & 21,2 & 25,8 & 17,9 & 20,0 & 24,2 \\
\hline Revista & 66,7 & 41,7 & 36,4 & 41,5 & 35,3 & 41,9 & 37,0 & 42,3 & 36,4 & 41,7 & 35,0 & 40,0 & 38,5 & 35,5 & 42,9 & 36,0 & 42,4 \\
\hline
\end{tabular}


Fazendo uma análise da tabela 14, sobre o recebimento dos métodos por níveis de atenção à saúde, observamos que foram as unidades básicas de saúde que mais contribuíram para a atividade de planejamento familiar, alcançando um percentual de contribuição de $63,3 \%$ para a faixa etária de 20 a 29 anos e de 65,1\% para a faixa de 30 a 49 anos. Em relação à variável UBS, receberam anticoncepcionais nestas unidades, em maior percentual, mulheres que tinham companheiro (71,8\%), enquanto que $68 \%$ eram do lar e $100 \%$ católicas, $80 \%$ estudavam e $74,2 \%$ tinham de 1 a 4 pessoas na família.

Tabela 14 - Distribuição do percentual de mulheres portadoras e ex-portadoras de hanseníase, de dados demográficos segundo o recebimento dos métodos por níveis de atenção à saúde, Maceió-Alagoas 2006 a 2011. (n=60).

\begin{tabular}{|c|c|c|c|c|c|c|c|c|c|c|c|c|c|c|}
\hline \multirow{3}{*}{ Método } & \multicolumn{14}{|c|}{ Distribuição percentual } \\
\hline & \multicolumn{2}{|c|}{ Faixa Etária } & \multicolumn{2}{|c|}{ Companheiro } & \multicolumn{2}{|c|}{ Escolaridade } & \multicolumn{2}{|c|}{ Ocupação } & \multicolumn{2}{|c|}{ Religião } & \multicolumn{2}{|c|}{ Estuda } & \multicolumn{2}{|c|}{$\mathbf{N}^{\circ}$ Pessoas } \\
\hline & $20-29$ & $30-49$ & Sim & Não & Fund $>$ & Fund $>$ & Do Lar & Outra & Cat. & Outra & Sim & Não & 1 a 4 & 5 a 14 \\
\hline UBS & 63,3 & 65,1 & 71,8 & 50 & 70,0 & 59,0 & 68,0 & 62,5 & 100,0 & 100,0 & 80,0 & 62,0 & 74,2 & 53,8 \\
\hline p-valor & \multicolumn{2}{|c|}{0,927} & \multicolumn{2}{|c|}{0,109} & \multicolumn{2}{|c|}{0,720} & \multicolumn{2}{|c|}{0,666} & \multicolumn{2}{|r|}{-} & \multicolumn{2}{|c|}{0,425} & \multicolumn{2}{|c|}{0,109} \\
\hline UESP & 27,3 & 14,0 & 15,4 & 16,7 & 13,3 & 18,5 & 4,0 & 2,5 & 76,5 & 45,0 & 20,0 & 14,0 & 16,1 & 15,4 \\
\hline p-valor & \multicolumn{2}{|c|}{0,290} & \multicolumn{2}{|c|}{0,902} & \multicolumn{2}{|c|}{0,592} & \multicolumn{2}{|c|}{0,31} & \multicolumn{2}{|c|}{0,19} & \multicolumn{2}{|c|}{0,717} & \multicolumn{2}{|c|}{0,939} \\
\hline Hospital & 18,2 & 20,9 & 20,5 & 16,7 & 16,7 & 22,2 & 20,0 & 18,8 & 11,8 & 30,0 & 20,0 & 20,0 & 19,4 & 19,2 \\
\hline p-valor & \multicolumn{2}{|c|}{0,732} & & & \multicolumn{2}{|c|}{0,596} & \multicolumn{2}{|c|}{0,906} & \multicolumn{2}{|c|}{0,96} & \multicolumn{2}{|c|}{1.000} & \multicolumn{2}{|c|}{0,991} \\
\hline
\end{tabular}


Analisando a tabela 15, que trata dos dados sobre orientação e/ou informação sobre os métodos anticoncepcionais e características sociodemográficas, o médico foi o profissional que mais ofertou para a faixa etária de 20 a 49 anos, com média de 38,7\%, seguindo-se do profissional enfermeiro, com média de $25 \%$. Já na faixa etária de 20 a 39 anos, observa-se que a televisão, jornais e revistas, alcançou percentuais de 27,3\% e 15,9\%. A variável amigo se destacou nas faixas etárias de 20 a 29 anos $(18,2 \%)$ e de 30 a 49 anos $(15,9 \%)$. 
Tabela 15 - Distribuição do percentual de mulheres portadoras e ex-portadoras de hanseníase, segundo meio de orientação / informação sobre métodos anticoncepcionais e características, Maceió-Alagoas, 2006 a 2011. ( $\mathrm{n}=60)$.

\begin{tabular}{|c|c|c|c|c|c|c|c|c|c|c|c|}
\hline \multirow{3}{*}{ Método } & \multicolumn{11}{|c|}{ Distribuição Percentual } \\
\hline & \multicolumn{2}{|c|}{ Faixa Etária } & \multicolumn{2}{|c|}{ Escolaridade } & \multicolumn{2}{|c|}{ Ocupação } & \multicolumn{2}{|c|}{ Religião } & \multirow{2}{*}{$\begin{array}{c}\text { Estuda } \\
\text { Sim }\end{array}$} & \multicolumn{2}{|c|}{$\mathbf{N}^{0}$ Pessoas } \\
\hline & $20-29$ & $30-49$ & $<$ Fund & Fund $>$ & Do Lar & Outra & Cat. & Outra & & 1 a 4 & 5 a 14 \\
\hline Medico & 36,4 & 40,9 & 41,9 & 37,0 & 36,0 & 42,4 & 36,1 & 46,7 & 40,0 & 30,0 & 50,0 \\
\hline Enfermeiro & 18,2 & 31,8 & 35,5 & 22,2 & 28,0 & 30,3 & 27,8 & 40,0 & 20,0 & 26,7 & 32,1 \\
\hline Farmacêutico & 9,1 & 4,5 & 6,5 & 7,4 & 8,0 & 6,1 & 5,6 & 6,7 & 0 & 3,3 & 10,7 \\
\hline Escola & 0 & 13,6 & 16,1 & 7,4 & 16,0 & 9,1 & 11,1 & 13,3 & 13,7 & 3,3 & 21,4 \\
\hline TV & 0 & 27,3 & 29,0 & 14,8 & 24,0 & 21,2 & 22,2 & 20,0 & 0 & 16,7 & 28,6 \\
\hline Jornal/revista & 0 & 15,9 & 19,4 & 7,4 & 12,0 & 15,2 & 11,1 & 13,3 & 0 & 6,7 & 21,4 \\
\hline Amigo & 18,2 & 15,9 & 25,8 & 11,1 & 20,0 & 18,2 & 13,9 & 26,7 & 20,0 & 16,7 & 21,4 \\
\hline Mãe & 0 & 6,8 & 9,7 & 0 & 12,0 & 0 & 2,8 & 13,8 & 0 & 0 & 10,7 \\
\hline Pai & 0 & 2,3 & 3,2 & 0 & 4,0 & 0 & 0 & 6,7 & 0 & 0 & 3,6 \\
\hline
\end{tabular}




\section{DISCUSSÃO}

A análise das ações de anticoncepção em mulheres portadoras e ex-portadoras de hanseníase, em Maceió-Alagoas, no período de 2006 a 2011, apresentam características importantes no que diz respeito aos cuidados que estas mulheres necessitam, com muitas dificuldades que envolvem a assistência prestada a essas usuárias. Em estudo de Silva (2006), destaca-se uma predominância de casos de hanseníase em mulheres, isto se justifica pela maior procura destas pelos serviços de saúde e também, por estas estarem mais preocupadas com a sua autoimagem.

Os dados levantados por Talhari, Neves (2006) e Le Grand (1997), corroboraram também com esses achados. Vale ressaltar que as mulheres procuram mais os serviços de saúde, obtendo maior cobertura no acesso a assistência, favorecendo o diagnóstico da doença.

Apesar de as equipes da atenção básica ter como um dos eixos as ações de controle da doença, com vistas ao diagnóstico, seu impacto é baixo na identificação precoce de seus sinais e sintomas em sua forma inicial. As ações de promoção, prevenção e controle desta patologia parecem estar longe de serem efetivados, pois, como doença milenar, o seu processo de cura está cientificamente estabelecido, mas ainda permanece como um importante desafio à saúde pública global (FIGUEREDO; SILVA, 2003).

De acordo com os dados apresentados, é alto índice de mulheres portadoras e exportadoras de hanseníase na faixa etária de 30 a 49 anos (75\%). Estudo conduzido por Miranzi et al (2010) encontrou que 31,4\% dos portadores de hanseníase estavam na faixa etária de 34 a 49 anos de idade.

Estudos apontam que a hanseníase atinge predominantemente pessoas com média de idade entre 42 a 44 anos (LYON, 2005; GROSSI, 2005; CASTORINA-SILVA, 2008); sendo esta uma faixa etária economicamente ativa, pode trazer repercussões no trabalho e na vida doméstica e social.

Apesar de a doença afetar pessoas de todas as idades e de ambos os sexos, as condições individuais e outros fatores relacionados, como alta endemicidade e condições socioeconômicas desfavoráveis, como também o número de pessoas da família numerosas, têm influência no risco de infecção e adoecimento.

Analisando a escolaridade destas mulheres, observou-se o alto percentual de analfabetas ou com o ensino fundamental incompleto. Estudos de caso-controle realizados por KerrPontes et al (2006), com pacientes de hanseníase, corroboram com os citados resultados, a 
variável baixa escolaridade mostrou-se como um fator de risco, devido à associação com precariedade na condição de vida e saúde.

Conforme foi apresentado nos resultados, o catolicismo foi observado como a religião mais evidente. Haja vista que, ter religião influencia em suas práticas, crenças e orientações, quanto ao seu modo de vida e na saúde sexual reprodutiva (BRASIL, 2008b).

Quanto às variáveis relacionadas às formas clínicas, segundo resultados da classificação de Madri, a forma indeterminada apresentou baixo índice no diagnóstico de Hanseníase, denotando que a identificação das formas precoces ainda está precária. Portanto, nesta fase, o diagnóstico adequado e tratamento precoce evitam a transmissão com quebra da cadeia de transmissão da doença. Contanto, destaca-se o percentual das formas não classificadas (25\%) ao qual podemos inferir que os profissionais de saúde possuem dificuldades para diagnosticar estas formas clínicas no momento da assistência.

Observou-se que a forma dimorfa respondeu por $30 \%$ das mulheres pesquisadas, seguida pela forma virchowiana, que representou $10 \%$. A predominância de formas multibacilares se apresetaram com a mesma tendência encontrada em estudos realizados em Mato Grosso do Sul (LONGO; CUNHA, 2006), onde casos multibacilares representavam 67,2\% dos indivíduos.

A Organização Mundial da Saúde, em 1988, estabeleceu critérios clínicos, em que considera paucibacilares casos de pessoas com até cinco lesões cutâneas e/ou um tronco nervoso acometido e multibacilares, casos com mais de cinco lesões cutâneas e/ou mais de um tronco nervoso acometido (RODRIGUES; LOCKWOOD, 2011).

O tratamento específico é encontrado nos serviços públicos de saúde e é chamado de PQT/OMS, porque utiliza a combinação de três medicamentos. Para pacientes paucibacilares é preconizada a Rifampicina ${ }^{\circledR}$ e Dapsona ${ }^{\circledR}$ - em 6 doses administradas em até 9 meses, para pacientes multibacilares, a Rifampicina ${ }^{\circledR}$, Dapsona ${ }^{\circledR}$ e Clofazimina ${ }^{\circledR}$ - em 12 doses administradas em até 18 meses. Além disso, o paciente vai ao serviço mensalmente para tomar a dose supervisionada pela equipe de saúde, e recebe a medicação para as doses que serão autoadministradas. $\mathrm{O}$ encerramento da poliquimioterapia deve ser estabelecido segundo critérios de regularidade ao tratamento (BRASIL, 2010).

Pacientes que, no momento do diagnóstico e na alta por cura, apresentam reações ou deficiências sensitivo-motoras e/ou incapacidades físicas, devem ser monitoradas. Os pacientes deverão ser orientados a retornar a unidade de saúde, em caso de novas lesões de pele e/ou de dores nos trajetos dos nervos periféricos e/ou piora da função sensitiva e/ou motora. É importante diferenciar um quadro de estado reacional de um caso de recidiva. No 
caso de recidiva, o paciente deverá ser encaminhado para um centro de referência para confirmação da recidiva e reinicio do tratamento PQT/OMS. Estes casos são raros em pacientes tratados regularmente com esquema poliquimioterápicos, geralmente ocorre em período superior a 5 anos após cura (BRASIL, 2010).

Em relação aos dados das baciloscopias das mulheres pesquisadas observou-se que $81,7 \%$ não realizaram este exame. O exame de baciloscopia no diagnóstico laboratorial da hanseníase é crucial para o diagnóstico diferencial, nos casos suspeitos de recidivas e na própria classificação da hanseníase. A baciloscopia, realizada a partir do raspado intradérmico, é um método de fácil execução, pouco invasivo e de baixo custo. $\mathrm{O}$ resultado positivo do exame baciloscópico, independentemente do número de lesões dermatológicas, é classifica o portador como caso multibacilar. (BRASIL, 2010).

Os dados sobre a avaliação do grau de incapacidade física no momento do diagnóstico das mulheres pesquisadas ressaltaram um alto percentual com Grau Zero, o que significa que as mesmas não apresentavam nenhum comprometimento neurológico nos olhos, nas mãos e nos pés. No entanto, um significativo índice de Grau I foi perceptível, revelando diagnósticos tardios; o pequeno percentual de mulheres com Grau Dois, com presença de sequelas neurológicas e denota a demora na detecção de casos.

O grau I e II indica o comprometimento de mecanismos de defesa devido ao processo do adoecimento, como a sensação dolorosa, deixando assim, o portador de hanseníase mais vulnerável a queimaduras, feridas, infecções, amputações, dentre outros (BRASIL, 2008a).

Segundo Croft et al (2000) reconhecem que o grau de incapacidade física está diretamente relacionado com o tempo de evolução da doença, o que reforça a necessidade de estruturação de seguimento qualificado, na perspectiva da integralidade de todos os casos diagnosticados durante e após a poliquimioterapia.

De acordo com Diffey et al (2000), as pessoas acometidas pela hanseníase podem sofrer prejuízos na sua capacidade de trabalho por ocasião das deformidades e, consequentemente, no auto sustento e sustento da família, gerando repercussões de ordem psicológica, social e física.

Observando os resultados da avaliação de incapacidades físicas no momento da alta, identificamos um alto percentual $(46 \%)$ de mulheres que não realizaram esta avaliação no momento da alta por cura. Sabemos que o impacto da deficiência para pacientes em sua função social e física pode estar relacionado com o acompanhamento pelo profissional de saúde como relatam Silva, Matias e Gomes (2007). 
Conforme foi analisado sobre o modo de detecção, observou-se que na maioria das UBS os sintomáticos dermatológicos, que incluem os possíveis casos suspeitos, procuraram estes serviços espontaneamente e, muitas vezes, tardiamente. O segundo maior índice encontrado foi o de encaminhamentos em estas mulheres foram direcionadas para as Unidades Básicas de Saúde onde havia ações de diagnóstico e tratamento implantadas. Este dado nos revela que profissionais priorizam o tratamento em detrimento do diagnóstico da doença e, portanto, recebem pacientes oriundos de Unidades Especializadas (de Referência) para o programa da Hanseníase em nível municipal e/ou estadual.

Em relação aos dados de contatos registrados das mulheres em idade fértil com Hanseníase, a vigilância epidemiológica dos mesmos, que seria pertinente ao momento de registro e exame demartoneurológico das pessoas que convivem ou conviveram com portadores de hanseníase nos últimos cinco anos, Magalhães e Rojas (2008) constataram que em todo o Brasil o número de contatos examinados é menor que $30 \%$, de todos os comunicantes registrados.

Os dados mostraram precariedade entre os contatos registrados e os avaliados. Entretanto, essa deficiência não é uma realidade apenas no município de Maceió, pois também é recorrente em outras localidades (CUNHA et. al, 2007).

Pinto Neto et. al (2002) afirmam que apesar da importância dos comunicantes na cadeia epidemiológica da hanseníase como sendo grupo de risco para adquirir a doença, as atividades relacionadas ao controle dos mesmos têm sido pouco valorizadas pelos serviços e profissionais de saúde.

No tocante aos episódios reacionais, foi observado que $66,7 \%$ das mulheres pesquisadas com hanseníase apresentaram reações hansênicas em algum momento de suas vidas (antes do diagnóstico, durante o tratamento e pós-tratamento). Pode ser visto que destas, 8,3\% apresentaram reação hansênica tipo I e 66,7\% tipo II.

De acordo com Silva e Griep (2007), as reações hansênicas são classificadas como: reação hansênica do tipo 1 e tipo 2 . Na reação tipo 1 ou reação reversa, os portadores de hanseníase apresentam novas lesões dermatológicas, infiltrações, alterações de cor e edema nas lesões antigas, bem como dor ou espessamento de nervos (neurites). Na reação tipo II ou eritema nodoso hansênico (ENH) pode ser observado sintomas como febre, astenia, anorexia, artralgias, orquite e, muitas vezes presença de nódulos subcutâneos, vermelhos e dolorosos disseminados. Alguns portadores podem também apresentar reações mistas, ou seja, reações tipo 1 e 2 ao mesmo tempo e reações tipo eritema polimorfo. 
Os episódios reacionais são sintomas agudos da doença que podem incidir segundo Jopling e Mcdougall (1991), em qualquer forma clínica exceto a indeterminada, sendo mais frequentes nos portadores da forma multibacilar. Os episódios reacionais podem acontecer em qualquer fase do tratamento poliquimioterápico, sendo associado à resposta terapêutica e à capacidade de resposta imunológica do doente (FOSS, 1999).

Quanto à história reprodutiva evidencia-se um baixo percentual $(5 \%)$ de mulheres grávidas no momento do diagnóstico de hanseníase, no período da coleta de dados. No entanto, sabe-se que a gestação leva à diversas alterações hormonais, aumentando o risco de reações hansênicas e evolução da doença.

Autores relatam a importância da anticoncepção e afirmam que a educação em saúde das mulheres portadoras de hanseníase é primordial para a prevenção ou adiamento da gravidez. (OLIVEIRA et al, 2011).

\footnotetext{
A gravidez é um evento em que o organismo é induzido a diversas adaptações fisiológicas para manter a viabilidade fetal, porém tais alterações podem interferir no padrão imunológico da mulher, levando a aquisição de infecções. Neste caso, estas podem propiciar uma situação de risco para a mãe e/ou feto (LIMA et al, 2011,p.02).
}

De acordo com Rozario et al, (2013), o número de adolescentes grávidas vem reduzindo. Apenas 2,3\% eram mães adolescentes e 2,9\% com mais de 35 anos. Corroborando com os presentes dados, 36,3\% estavam entre a faixa etária de 15 - 19 anos e, apenas 1,6\% tinham idade maior que 30 anos.

No estudo de Andrade e Silva (2009), mais da metade das mulheres tinha idade entre 25 a 34 anos, representando $58 \%$ da amostra, sendo semelhante com a presente pesquisa, atingindo $66,6 \%$ das entrevistadas. Quanto ao número de gestações $74 \%$ referiram duas ou mais gestações, assemelhando-se com os dados analisados, $63 \%$ tiveram de uma a três gestações.

Analisando a variável paridade, foi observado que 75\% das entrevistadas tiveram de um a três partos, divergindo do estudo realizado em Fortaleza, que apresenta um percentual de $27 \%$ de um a dois partos (NICOLAU et al, 2010).

Tratando da relação de frequência de partos em adolescentes se verifica nesta pesquisa um percentual de 36,6\% com faixa etária entre 15 a 19 anos, representando um número inferior encontrado no Rio de Janeiro que corresponde a $25 \%$, demostrando que a região Nordeste ainda continua com elevados índices de gravidez na adolescência (SANTOS et al, 2009). 
Em relação ao percentual de abortos, constatou-se que 78,3\% das entrevistadas não tiveram aborto, assemelhando-se ao percentual encontrado no estudo realizado no Ceará de $79,9 \%$ (MOURA et al, 2010). Quanto à variável número de filhos foi observado que 71,6\% relataram ter de um a três filhos, aproximando-se dos resultados de um estudo do Rio de Janeiro com 43,1\% (XAVIER et al, 2013).

Quanto à multiparidade (7 a 10 partos/mulheres) foi observado um baixo percentual 6,6\%, assemelhando-se com o estudo realizado em Fortaleza que representaram 7,6\%. Percebe-se uma mudança comportamental nas mulheres na fase reprodutiva, reduzindo significativamente o número de gestações e, consequentemente, de possíveis partos (NICOLAU et al., 2010).

Em relação ao período de lactação no momento do diagnóstico, percebeu-se que uma amostra, de apenas 1,7\% estavam amamentando, enquanto que 96,7\% informaram negativamente. Com isso, a gravidez e o aleitamento materno não contraindicam o tratamento de hanseníase com a PQT/OMS (BRASIL, 2010). O leite materno é o alimento essencial para o recém-nascido, pois atende todas as necessidades nutricionais, imunológicas e psicológicas, exercendo um efeito protetor contra várias infecções (CASTRO; OLIVEIRA, BOTELHO, 2009).

Analisando a faixa etária das mulheres portadoras e ex-portadoras de hanseníase, identificamos um percentual de 66,6\%, de mães com idade entre 20 a 34 anos. Constata-se uma redução significativa quanto comparada ao estudo de Fuzero e Oliveira (2010) que encontraram um percentual de $85,3 \%$ de mães adultas. No entanto, pode ser analisado que em ambos os estudos, apesar do significativo percentual de mães adultas, há declarações que estas não amamentaram $(68,3 \%)$, levando-se a crer, que foram deficientes as orientações quanto à amamentação, e que ainda está muito aquém do preconizado pelo Ministério da Saúde.

Observando o contexto da primiparidade, pode-se avaliar que 36,6\% das mulheres estudadas pariram pela $1^{\text {a }}$ vez com idade entre 15 a 19 anos, dado este inferior ao encontrado no estudo realizado em São Gonçalo do Pará/MG que apresentou um percentual de 76,7\% (TAVEIRA; SANTOS; ARAÚJO, 2012). Estima-se que de 20 a 25\% do total de gestantes no Brasil sejam adolescentes, ou seja, em média, há uma adolescente entre cada cinco mulheres grávidas (MANFRÉ; QUEIRÓZ; MATTHES, 2010).

Pode-se avaliar que $11(18,3 \%)$ mulheres se encontravam grávidas durante o percurso da doença, assemelhando-se com pesquisa realizada no Ceará de $10 \%$. A infecção pelo Micobacterium leprae nas mulheres, geralmente, mostram sinais evidentes da doença na 
gravidez, propiciando ao bacilo oportunidade para se manifestar e desenvolver a doença (OLIVEIRA et al, 2011).

Sabe-se que as características imunológicas são muito importantes na avaliação prognóstica da hanseníase, levando ao risco de aparecimento de reações hansênicas, especialmente no que se refere a danos neurológicos. Portanto, as alterações no equilíbrio do bacilo e hospedeiro aumentam a susceptibilidade expondo os portadores e ex-portadores dessa patologia a um maior risco de reações hansênicas. Uma das situações de risco são as alterações hormonais da puberdade e da gestação levando a um estado físiológico de imunossupressão (NOGUEIRA et al, 2012).

Nogueira et al (2012) apontam que as mudanças que ocorrem no corpo da gestante, refere-se aos níveis de esteroides, hormônios tireóideo e de estrógenos, o que acarreta em uma diminuição da imunidade celular, mais precisamente de citocinas do tipo Th 1 , na resposta dos linfócitos, levando a resposta do tipo Th 2. O quadro de imunossupressão reverte apenas em torno da $12^{\mathrm{a}}$ semana pós-parto. O que pode claramente explicar a susceptibilidade da gestante às infecções, como exemplo a hanseníase. As manifestações clínicas dessa doença são decorrentes das respostas do tipo Th1 e Th2.

Ryrie em 1938 declarou “A hanseníase não apresenta qualquer efeito sobre o curso da gravidez, que, entretanto exerce importante efeito no curso da hanseníase". A partir de então, o período gestacional tem sido relacionado à elevada incidência de aparecimento sinais ou piora do quadro da hanseníase (HERMER et al, 2004).

Quanto ao método contraceptivo mais citado pelas usuárias foi a pílula anticoncepcional, seguido da Camisinha Masculina. Comparando com outro estudo, esta relação foi inversa, o uso de preservativo $38,5 \%$ seguido de $20,5 \%$ de contraceptivo oral. Sendo estes dados positivos, pois, portadoras e ex-portadoras de Hanseníase necessitam de contraceptivos seguros, no entanto, alguns fármacos utilizados durante o tratamento podem interferir e reduzir a ação dos anticoncepcionais orais, nesta situação ainda é mais indicado o método de barreira, a camisinha (OLIVEIRA et al, 2011).

Ainda no tocante ao método contraceptivo, pode ser visto, no estudo por inquérito telefônico que cerca de $70 \%$ das mulheres utiliza algum método de planejamento familiar, sendo o mais utilizado os Anticoncepcionais Orais, 33,8\%. No entanto, avalia-se que há uma preocupação quanto ao modo que estes fármacos estão sendo utilizados, afirmando que o uso inadequado esteve presente em $13,1 \%$ da população brasileira. Tal informação é preocupante, visto que, $18,3 \%$ das mulheres entrevistadas estavam grávidas no período da doença, basta 
saber se engravidaram antes ou depois de serem informadas que estavam infectadas pela Hanseníase (CORRÊA, 2011).

Quanto à história reprodutiva se pode evidenciar um baixo percentual (5\%) de mulheres grávidas pesquisadas no momento do diagnóstico de hanseníase. No entanto, sabese que a gestação leva a diversas alterações hormonais, aumentando o risco de reações hansênicas e evolução da doença.

O período gestacional pode induzir recidivas, exacerbar lesões pré-existentes e aumentar a evolução, por exemplo, da forma indeterminada para a forma virchowiana em pessoas de incompetência imunológica e em pacientes que estão em tratamento irregular ou inadequado. Por vezes, o fator que desencadeia a hanseníase é o parto, e o período crítico pode ser correspondido entre o último trimestre e os três primeiros meses de lactação, período o qual a imunossupressão chega ao ápice (TALHARI, NEVES; 2006).

$\mathrm{Na}$ distribuição das mulheres em idade fértil, portadoras e ex-portadoras de hanseníase segundo idade do primeiro parto, visualizamos que 39,9\% das mesmas tinham entre 14 a 19 anos de idade e no ultimo parto 8,3\% respondiam pela faixa etária de 17 a 19 anos. Estes dados nos revelam a idade precoce da historia reprodutiva destas mulheres.

Segundo Manfré, Matthes e Queiróz (2010), a análise do conhecimento sobre anticoncepcionais hormonais entre adolescentes que ficaram grávidas demonstrou que aproximadamente $98 \%$ das adolescentes apresentaram baixo conhecimento referente sobre aquilo que realmente sabe a respeito e o conhecimento que julga ter.

Da amostra de mulheres com hanseníase, deste estudo observamos um alto índice da religião católica $(61,7 \%)$ e de outras $(33,3 \%)$ com ênfase na evangélica.

Estudo aponta que "o temor às crenças religiosas associadas ao desconhecimento sobre MAC pode ser prejudicial na escolha por um método" (KONJE et al, 1998).

Quanto ao conhecimento espontâneo do uso dos métodos contraceptivos, identificamos que as mulheres pesquisadas referiram ter informações com índices mais elevados acima de 58,3\% dos métodos: Ogino-Knaus, hormonal oral, hormonal injetável, DIU, condom feminino, condom masculino, laqueadura tubária e vasectomia.

Segundo Pierre e Clápis (2010) em seu estudo apontou que os métodos contraceptivos, mais eficazes são os mais orientados pelos profissionais aos clientes, e em contrapartida, os menos orientados são os mais oferecidos. Pressupomos que o desconhecimento espontâneo mais elevado das mulheres pesquisadas deve-se, dentre vários fatos possíveis, ao desconhecimento e à inadequada competência técnica profissional. 
$\mathrm{Na}$ análise da comparação da mediana por tempo de uso das mulheres portadoras e exportadoras de Hanseníase desta investigação, observamos que os métodos contraceptivos por mais tempo utilizados foram, em geral, a laqueadura tubária, pílula, a injeção, em seguida da camisinha masculina.

Centralizar o uso do MAC na esterilização cirúrgica e na pílula anticoncepcional proporciona discussões sobre as escolhas reais das opções das mulheres em relação aos métodos anticoncepcionais. A limitação desse conhecimento é uma das explicações que, possivelmente, restringe as escolhas. Escolher um método implica também na quantidade de métodos oferecidos (ESPEJO et al, 2003).

Em relação às informações de métodos anticoncepcionais segundo de quem ouviu falar, chamou-nos atenção que o médico e o enfermeiro foram as pessoas que mais contribuíram nas orientações sobre os métodos contraceptivos. Esses profissionais devem ter habilidades para oferecer orientação, informação para a tomada de decisões quanto ao método contraceptivo mais indicado para cada indivíduo (BRASIL, 1996). 


\section{CONCLUSÕES}

Em relação ao perfil sociodemográfico das entrevistadas, $75 \%$ das mulheres estavam na faixa etária de 30 a 49 anos; 70\% delas referiram ter companheiro e houve predominância de analfabetas ou com o ensino fundamental incompleto (53,3\%). A maioria (55\%) desempenhava ocupações remuneradas e 45\% eram do lar. Em sua maioria, eram católicas $(61,7 \%)$ ou evangélicas $(26,7 \%)$.

Residiam com essas mulheres, com maior frequência, de uma a três pessoas $(36,7 \%)$, porém, houve destaque para as coabitações com seis a quatorze pessoas $(28,3 \%)$, reforçando o caráter de doença transmissível por contato íntimo e prolongado da hanseníase.

Quanto aos aspectos clínicos da doença, as mulheres foram acometidas pelas formas Dimorfa (30,0\%), Tuberculóide (20\%), Indeterminada (15\%) e Virchowiana (6\%), merecendo destaque o percentual de formas clínicas não classificadas $(25,0 \%)$, o que é preocupante, pois infere-se que os profissionais de saúde possam não estar preparados ou seguros para realizar a classificação clínica, o que também implica em dificuldades para o acompanhamento e seguimento clínico dessas mulheres durante e após-tratamento da hanseníase.

Apesar de apenas três mulheres (5\%) afirmarem que estavam grávidas no momento do diagnóstico, uma (1,7\%) no período puerperal e outra $(1,7 \%)$ amamentando, observa-se que a gravidez não foi evento de ocorrência discreta durante o ciclo reprodutivo destas mulheres, pois, soma-se a isso, o número elevado de gravidezes vivenciadas: de uma a três vezes para $63,3 \%$ delas e de quatro a dez vezes para $26,6 \%$; em que $75 \%$ tiveram de um a três partos e $21,6 \%$ de um a três abortamentos. Além disso, o número de filhos dessas mulheres é elevado, pois variou de um a dez, em que $71,6 \%$ delas tiveram de um a três filhos e $18,2 \%$, de quatro a dez.

Reafirmando o fato de que estas mulheres vivenciam gravidez em quaisquer faixas etárias durante seu ciclo reprodutivo, pode-se observar que grande parte delas (40\%) teve sua primeira gravidez na adolescência, em que 3,3\% com idade menor que 14 anos e 36,6\% entre 15 a 19 anos. Já 8,3\% das mulheres estavam ainda na adolescência durante o último parto, entretanto, a maioria $(66,6 \%)$ se encontrava na faixa de idade entre 20 a 34 anos.

Neste sentido, as reações hansênicas se configuram em risco durante a vivência do ciclo reprodutivo dessas mulheres, pois $16,7 \%$ informaram ter apresentado essas reações antes do diagnóstico, 28,3\% durante o tratamento e 21,7\% no pós-tratamento, ratificando necessidade de ações de cuidado e controle quanto ao planejamento familiar, haja vista que a 
gravidez se torna iminentemente perigosa à saúde da mulher e do concepto para portadoras e ex-portadoras de hanseníase.

Sobre o conhecimento espontâneo das mulheres acerca dos métodos contraceptivos e seu uso, observa-se que há discrepância entre o conhecimento e uso destes métodos pelas gestantes durante o percurso da doença, comparativamente com o grupo de não gestantes no percurso da doença. Posto isto, pode-se atribuir a gravidez no percurso da doença à deficiência no conhecimento e uso de métodos contraceptivos.

Os maiores percentuais encontrados quanto ao conhecimento espontâneo sobre métodos anticoncepcionais e características sociodemográficas foram: pílula $(87,8 \%)$, injeção $(75,6 \%)$, tabela $(71,4 \%)$, DIU $(64,3 \%)$, condom masculino (100\%), laqueadura tubária (85,7\%). No entanto, 70,6\% conheciam a vasectomia, mas não tinham companheiro. Realizando-se uma análise inferencial quanto aos métodos contraceptivos, os dados denotam uma relação significativa com associação entre a temperatura e ocupação, aleitamento materno e número de pessoas na família, pílula e número de pessoas, injeção e escolaridade da mulher, injeção e ocupação, diafragma e número de pessoas, espermicida e número de pessoas, vasectomia e se estudava, com $\mathrm{p}>0,05$.

Notadamente, é nas unidades básicas de saúde que ocorre com maior frequência o recebimento de métodos contraceptivos, havendo grande contribuição deste nível de atenção à saúde para o planejamento familiar. Porém, isso não quer dizer que tais ações ocorram de modo pleno, haja vista que o planejamento familiar não se restringe à entrega de contraceptivos e que a ocorrência de gravidez não é rara durante o percurso da doença.

O médico e o enfermeiro foram os profissionais que mais ofertaram orientações e informações sobre os métodos anticoncepcionais, principalmente para o grupo de adolescentes na faixa etária de 15 a 19 anos, papel relevante devido à competência técnica destes profissionais nas ações de planejamento familiar. No entanto, amigos e meios midiáticos (televisão, rádio e revista), juntos, respondem por importante percentual na influência do conhecimento dessas mulheres acerca de métodos contraceptivos. 


\section{CONSIDERAÇÕES FINAIS}

Ao término deste trabalho, acerca da saúde reprodutiva de mulheres portadoras e exportadoras de hanseníase em uma capital do Nordeste - Brasil, 2006 - 2011, não podemos deixar de pensar na situação da referida endemia. A hanseníase, doença endêmica em todo o território nacional, tem colocado o Brasil na incômoda posição de segundo país do mundo e primeiro das Américas em número de casos registrados.

Atualmente existe tratamento adequado e eficaz para a hanseníase que, uma vez mantido suficiente cobertura dos serviços de saúde, possibilita a eliminação desta patologia, através da redução da prevalência.

No entanto, durante a gravidez, as alterações hormonais que são inerentes nesse período, explicam a susceptibilidade das gestantes a infecções, destacando-se entre estas a hanseníase. E ainda, há os riscos para o aparecimento de surtos reacionais, que podem prejudicar a saúde de mulheres e seus conceptos.

Além do comprometimento dermatoneurológico decorrente da hanseníase, que torna essa doença visível, há implicações de mudanças no contexto de vida dessas mulheres, com prejuízos e riscos para o processo familiar e âmbito profissional.

O aconselhamento para o adiamento da gravidez, por meio da inclusão das mulheres portadoras e ex-portadoras de hanseníase nos programas de planejamento familiar em UBS é uma medida necessária e de grande relevância para a saúde das mesmas em todos os aspectos inerentes ao ser humano, inclusive para a saúde física dessas mulheres e seus conceptos.

Portanto, a implantação e/ou implementação de ações de planejamento familiar para as mulheres em idade fértil diagnosticadas com hanseníase, foco deste estudo, deve ocorrer em consonância com as atividades de educação em saúde e de prevenção e controle da hanseníase. 


\section{REFERÊNCIAS}

1. ALAGOAS. Secretaria de Estado da Saúde. Departamento de Vigilância em Saúde. Situação epidemiológica da hanseníase em Alagoas no período de 2001-2006. Maceió, AL, 2007. Disponível em:

$<$ http://www.saude.al.gov.br/situaodahansenaseemalagoas20012006-24-10-2007> Acesso em: 20 Out. 2008.

2. ALAGOAS. Secretaria de Estado da Saúde. Departamento de Vigilância em Saúde. Nota Técnica $n^{\circ} 01 / 210$. Situação epidemiológica do comportamento da hanseníase em Alagoas. Maceió, AL, 2010.

3. ANDRADE, E. C.; SILVA, L. R. Planejamento familiar: uma questão de escolha. Rev. Eletr. Enf.[Internet], v.11, n.1, p.85-93, 2009. Disponível em:

$<$ http://scielo.iec.pa.gov.br/pdf/ess/v19n2/v19n2a08.pdf.> Acesso em: 20 Jan. 12.

4. ANTÔNIO, J. R. et al. Fenômeno de Lúcio. RBM. v. 62, n. 3, p. 103-6, Mar 2003. Disponível em:

$<$ http://www.moreirajr.com.br/revistas.asp?fase=r003\&id_materia=2912>. Acesso em: 20/01/2012. Acesso em: 03 Jan. 2012.

5. ARANTES, C. K. et al. Avaliação dos serviços de saúde em relação ao diagnóstico precoce da hanseníase. Epidemiol. Serv. Saúde, Brasília, v. 19, n. 2, p. 155-164, abr./jun. 2010. Disponível em:

$<$ http://scielo.iec.pa.gov.br/pdf/ess/v19n2/v19n2a08.pdf.> Acesso em: 20 Jan. 12.

6. ARAÚJO, M. G. Hanseníase no Brasil. Rev. Soc. Bras. Med., Uberaba, v. 36, n. 3, p. 373-382, mai./jun. 2003. Disponível em: <

http://www.scielo.br/pdf/rsbmt/v36n3/16339.pdf.> Acesso em: 20/01/12.

7. BÍBLIA SAGRADA. 82a ed. São Paulo: Editora Ave Maria, 1992.

8. BÖDDINGHAUS, B. K. et al. Format Leprosy in Pregnancy. Infection, v. 35, n. 1, p.37-9, 2007.

9. BRASIL. Constituição (1988). Constituição da República Federativa do Brasil. Brasília, DF: Senado, 1988.

10. __ Escola Nacional de Saúde Pública. Informe ENSP. Meta do Brasil é eliminar a hanseníase até 2015. Rio de Janeiro, junho de 2012. Notícias. Disponível em: $<$ http://www.ensp.fiocruz.br/portal-ensp/informe/site/materia/detalhe/30519>. Acesso em: $15 /$ 09/2012.

11. L__ Lei $\mathrm{n}^{\circ}$ 9.263, de 12 de janeiro de 1996. Regula o $\S 7^{\circ}$ do art. 226 da Constituição Federal, que trata do planejamento familiar, estabelece penalidades e dá outras providências. Diário Oficial da República Federativa do Brasil, Brasília, DF, 1996. Disponível em: <http://www.planalto.gov.br/ccivil_03/leis/19263.htm.> Acesso em: 23 Abr. 2012. 
12. . Ministério da Saúde. Assistência ao planejamento familiar. Brasília, DF, 1996.

13. . Ministério da Saúde. Assistência em planejamento familiar: Manual Técnico. Brasília, 2006b.

14. . Ministério da Saúde. Avaliação normativa do programa de saúde da família no Brasil: monitoramento da implantação e funcionamento das equipes de saúde da família: 2001-2002. Brasília: Ministério da Saúde, 2004b. 140p. Disponível em: $<$ http://bvsms.saude.gov.br/bvs/publicacoes/avaliacao_normativa_ programa_saude_familia.pdf> Acesso em: 15 Fev. 2012.

15. . Ministério da Saúde. Diretrizes operacionais dos pactos pela vida, em defesa do SUS e de gestão. Brasília: Ed. Ministério da Saúde, 2006a.

16. . Ministério da Saúde. Gestão de políticas estratégicas: guia para utilização de medicamentos e imunobiológicos na área de Hanseníase, 2002.

17. . Ministério da Saúde. Guia de procedimentos técnicos baciloscopia em hanseníase. Brasília: Ministério da Saúde, 2010.54 p.

18. . Ministério da Saúde. Guia de vigilância epidemiológica. 7. ed. Brasília: Ministério da Saúde, 2009b. 816 p.

19. _. Ministério da Saúde. Hanseníase no Brasil: dados e indicadores selecionados. Brasília-DF. 2009a.

20. . Ministério da Saúde. Manual de prevenção de incapacidades. Departamento de Vigilância Epidemiológica, $3^{a}$. ed., Rev. e Ampl., Brasília: Ministério da Saúde, 2008a. $140 \mathrm{p}$.

21. . Ministério da Saúde. Norma operacional básica do Sistema Único de Saúde/NOB-SUS. Gestão Plena com Responsabilidade pela saúde e de Gestão. Brasília-DF, Ministério da Saúde, 2001.

22. . Ministério da Saúde. Pesquisa nacional de demografia e saúde da criança e da mulher - relatório. Brasília: Ministério da Saúde, 2008b, 308p.

23. . Ministério da Saúde. Plano nacional de eliminação da hanseníase em nível municipal, 2006-2010. Brasília: Ministério da Saúde, 2005. Disponível em: < http://bvsms.saude.gov.br/bvs/publicacoes/hanseniase_plano.pdf $>$ Acesso em: $15 \mathrm{Fev}$. 2012.

24. . Ministério da Saúde. Política nacional de atenção integral à saúde da mulher. 2004a.

25. _. Ministério da Saúde. Saúde Brasil 2010: uma análise da situação de saúde e de evidências selecionadas de impacto de ações de vigilância em saúde. Brasília: Ministério da Saúde, 2011, p.185-203. 
26. . Ministério da Saúde. Vigilância em saúde: situação epidemiológica da hanseníase no Brasil. 2008. Disponível em:

$<$ http://bvsms.saude.gov.br/bvs/publicacoes/vigilancia_saude_situacao_hanseniase.pdf >. Acesso em: 20 Abr. 2012

27. . Ministério da Saúde. Vigilância em saúde: dengue, esquistossomose, hanseníase, malária, tracoma e tuberculose. Brasília: Ministério da Saúde, 2007. Disponível em: < http://bvsms.saude.gov.br/bvs/publicacoes/cadernos_atencao_basica_vigilancia_saude .pdf $>$ Acesso em: 15 Fev. 2012.

28. BRUCE, J. Fundamental elements of the quality of care: a simple framework. Studies in Family Planning, v. 21, n. 2, p. 61-91, 1990.

29. BUFFON, L. P.; et al. Fenômenos de Lucio (eritema necrosante) na gestação: relato de caso e revisão de literatura. Anais Brasileiros de Dermatologia, v. 76, n. 4, p. 441448, 2001.

30. CAMARGO JÚNIOR, K. R. Um ensaio sobre a (in)definição da integralidade. In: PINHEIRO, R.; MATTOS, R. A. (Org.) Construção da integralidade: cotidiano, saberes e práticas em saúde. $2^{\mathrm{a}}$ ed. Rio de Janeiro (RJ): IMS/UERJ/ABRASCO, 2003, p. 35-44.

31. CAMAROTTI, L. M. et al. Hanseníase e gestação, Femina, v. 18, n. 4, p. 274-280, 1990.

32. CAMIÁ, G. E. K.; MARIN, H. F.; BARBIERI, M. Diagnósticos de enfermagem em mulheres que frequentam serviço de planejamento familiar. Rev. Latino-Am. Enfermagem, v. 9, n. 2, p. 26-34, 2001.

33. CANESQUI, A. M. Assistência Médica e à Saúde e Reprodução Humana. Textos NEPO, 13. Campinas: NEPO, Universidade Estadual de Campinas. 1987.

34. CASTRO, R. A.; OLIVEIRA, E. M.; BOTELHO, A. C. F. Aleitamento Materno em área de abrangência do Programa de Saúde da Família. Revista brasileira em Promoção da Saúde, v. 22, n. 1, p.30-35, 2009. Disponível em:

$<$ http://www.redalyc.org/articulo.oa?id=40811729006>. Acesso em: 25/ 02/2011.

35. CASTORINA-SILVA, R. Estudo do comportamento dos testes sorológicos ML Flow e ELISA (PGL-I) em áreas endêmica e não endêmica de hanseníase. 2008. Tese (Doutorado em Ciências da Saúde) - Universidade Federal de Minas Gerais, Belo Horizonte, 2008.

36. CESTARI, T. F.; MAROJA, M. F. Hanseníase e gestação. In: TALHARI, S. et al. Dermatologia tropical: hanseníase. $4^{\mathrm{a}}$ edição, Editora Tropical, Manaus, 2006.

37. CHIRWA, T.; FLOYD, S.; FINE, P. Estimating the extent of household contact misclassification with index cases of disease in longitudinal studies using a stochastic simulation model. Global Health Action. Atlanta, v. 6, p. 196-204, jul. 2013. 
38. COELHO, E. A. C. et al. Integralidade do cuidado à saúde da mulher: limites da prática profissional. Escola Anna Nery, Rio de Janeiro, v. 13, n. 1, mar. 2009.

39. COELHO, E. B. S. Enfermagem e o planejamento familiar: as interfaces da contracepção. Revista Brasileira de Enfermagem, v. 58, n. 6, p. 665-672, nov./dez. 2005.

40. CORRÊA, D. A. S. Uso de contraceptivos orais entre mulheres de 18 a 49 anos: inquérito populacional telefônico Belo Horizonte - MG [dissertação]. Minas Gerais: Escola de Enfermagem da Universidade Federal de Minas Gerais; 2012.

41. CORREAA, S.; ALVES, J. C. D.; JANNUZZI, P.M. 2006. Direitos e saúde sexual e reprodutivo: marco teórico-conceitual e sistema de indicadores. In: Cavenaghi, S (coord). Indicadores municipais de saúde sexual e reprodutiva. Rio de Janeiro, ABEP, p.14-26.

42. CROFT, R. P. et al. A clinical prediction rule for nerve function impairment in leprosy patients. Lancet, v. 355, n. 9215, p.1603-6, Mai. 2000.

43. CUNHA, M. D. et al. Os indicadores da hanseníase e as estratégias de eliminação da doença, em município endêmico do estado do Rio de Janeiro, Brasil. Caderno de Saúde Pública, v. 23, p.1187-97, 2007.

44. CURI, M. L. Excluir, isolar e conviver: um estudo sobre a lepra e a hanseníase no Brasil. 2010. Tese (Doutorado em História) - Universidade Federal de Minas Gerais, Belo Horizonte, 2010.

45. DÍAZ, M.; DÍAZ, J. Qualidade de atenção em saúde sexual e reprodutiva: estratégias para mudança. In: GALVÃO, L.; DÍAZ, J. (Org). Saúde Sexual e Reprodutiva no Brasil: dilemas e desafios. São Paulo (SP): Hucitec-Population Council, p. 209-236, 1999.

46. DIFFEY, B. et al. The effect of leprosy-induced deformity on the nutritional status of index cases and their household members in rural South India: a socio-economic perspective. Eur J Clin Nutr., v.54, p. 643-9, 2000.

47. DUNCAN, M. E. An historical and clinical review of the interaction of leprosy and pregnancy: a cycle to be broken. Soc Sci Med, v. 37, n. 4, p.457-472, Aug. 1993.

48. EICHELMANN, K. et al. Lepra: puesta al día. Definición, patogénesis, clasificación, diagnóstico y tratamiento. Actas Dermo-Sifiliofráficas, v. 104, p. 554-563, 2013.

49. EIDT, L. M. Breve história da hanseníase: sua expansão do mundo para as Américas, o Brasil e o Rio Grande do Sul e sua trajetória na saúde pública brasileira. Saúde e Sociedade, São Paulo, v. 13, n. 2, Aug. 2004.

50. ESPEJO, X. et al. Adequação do conhecimento sobre métodos anticoncepcionais entre mulheres de Campinas, São Paulo. Rev. Saúde Pública, São Paulo, v.37, n.5, Oct. 2003. Disponível em: $<$ http://www.scielo.br/scielo.php?pid=S003489102003000500006\&script=sci_arttext. $>$ Acesso: 20/01/12. 
51. EVANGELISTA, C. M. N. et al. Concentração do atendimento a pacientes com hanseníase em municípios do estado do Ceará. Cadernos de Saúde Coletiva, v. 16, n. 2, p. 231-242, 2008.

52. FIGUEIREDO, I. A.; SILVA, A. A. M. Aumento na detecção de casos de hanseníase em São Luís, Maranhão, Brasil, de 1993 a 1998: uma endemia está em expansão? Caderno de Saúde Publica, v.19, p. 439-445, 2003.

53. FOSS, N. T. Hanseníase, aspectos clínicos, imunológicos e terapêuticos. Anais Brasileiros de Dermatologia, v. 74, n. 2, p. 113-119, 1999.

54. FREIRE, P. Pedagogia da autonomia: saberes necessários à prática educativa. $13^{\mathrm{a}}$ ed. Rio de Janeiro: Paz e Terra, 1996.

55. FUZETO, K. L. R.; OLIVEIRA, A. C. L. Comparação da prática do aleitamento materno e da alimentação complementar entre mães adolescentes e adultas de Curitiba/PR. Cadernos da Escola de Saúde, n.3, p.1-16, 2010. Disponível em: $<$ http://apps. unibrasil.com.br/revista/index.php/saude/article/viewFile/334/264>. Acesso em: 29/012012.

56. GILBERT, D. et al. (1982) an Exposure and risk assessment for tetrachloroethylene (EPA-440/4-85-015).

57. GOMES, R. Desafios da atenção à saúde integral da mulher. Ciências \& Saúde Coletiva, Rio de Janeiro, v. 16, n. 5, Mai. 2011. Disponível em: $<$ http://www.scielo. br/pdf/csc/v16n5/a01v16n5.pdf>. Acesso em: 6/09/2011.

58. GRAZIOS, M. E. S.; LIEBANO, R. E.; NEHAS, F. X. Elaboração da Pergunta norteadora de pesquisa. Módulo científico. 2011. Disponível em: $<$ http://www.unasus.unifesp.br/biblioteca_virtual/esf/1/modulo_cientifico/Unidade_12 _complementar.pdf>. Acesso em: 17 abr. 2011.

59. GROSSI, M.A.F. Estudo das possíveis mudanças na classificação da hanseníase com a utilização do teste ML Flow e suas implicações no tratamento e controle da endemia em Minas Gerais. 2005. 192 p. Tese (Doutorado em Infectologia e Medicina Tropical) - Universidade Federal de Minas Gerais, Belo Horizonte, 2005.

60. HELMER, K. A. et al. Fenômeno de Lucio (eritema necrosante) na gestação. Anais Brasileiros de Dermatologia, v. 79, n. 2, p. 205-210, 2004.

61. HERSH, E.V. Adverse drug interactions in dental practice: interactions involving antibiotics. JADA, Chicago, v.130, p.236-251, Feb. 1999. Disponível em: http://www.geriatricoralhealth.org/topics/topic03/art/adverse-drug-interactions-2.pdf. Acesso em: 04/02/2012.

62. HELMER, K. A. et al. Fenômeno de Lúcio (eritema necrosante) na gestação. An. Bras. Dermatol. [artigo online]. 2004 Abr 79(2): 205-210. Disponível em: $<\mathrm{http}: / / \mathrm{www}$.scielo.br/scielo.php?script $=$ sci_arttext\&pid=S03655962004000200009\&lng=en>. Acesso em: 20/02/2012 
63. IGNOTTI, E.; DE PAULA, C. R. Situação epidemiológica da hanseníase no Brasil: análise de indicadores selecionados no período de 2001 a 2010. In: SECRETARIA DE VIGILÂNCIA EM SAÚDE. Saúde Brasil 2010: uma análise da situação de saúde e de evidências selecionadas de impacto de ações de vigilância em saúde. Brasília: Editora do Ministério da Saúde, p.185-203, 2011.

64. INSTITUTO BRASILEIRO DE GEOGRAFIA E ESTATÍSTICA. Banco de dados. 2013. Disponível em: <http://www.ibge.gov.br/>. Acesso em: 25/03/13.

65. INSTITUTO BRASILEIRO DE GEOGRAFIA E ESTATÍSTICA. Contagem Populacional. 2009. Disponível em: <http://www.sidra.ibge.gov.br/bda/popul/d...> Acesso em: 29/01/12.

66. JOPLING, W. H.; McDOUGALL, A. C. Manual de hanseníase. $4^{\text {a }}$ ed. Rio de Janeiro: Livraria Atheneu Editora, 1991.

67. JAIN, S. et al. Childhood leprosy in an urban clinic, Hyderabad, India: clinical presentation and the role of household contacts. Leprosy Review Journal, v. 73, p. 248-253, 2002.

68. KERR-PONTES et al. Socioeconomic, environment, and behavioural risk factors for leprosy in North-east Brazil: results of a case-control study. Int J Epidemiol, 27: 1-7, 2006.

69. KONJE, J. C et al. Factors determining the choice of contraceptive methods at the family clinic, University College Hospital, Ibadan, Nigeria. Br J Fam Plann, Chichester, v. p.107-110, Oct. 1998.

70. LE GRAND, A. Womenand Leprosy: a review. Lepr Rev 1997; v.68, p: 203-11.

71. LIMA, S. K. M. et al. VII Congresso Brasileiro de Enfermagem Obstétrica e Neonatal - I Congresso Internacional de Enfermagem Obstétrica e Neonatal. 2011. Disponível em:

$<$ http://www.redesindical.com.br/abenfo/viicobeon_icieon/files/0567.pdf.>

72. LOCKWOOD, D. N.; SINHA, H. H. Pregnancy and leprosy: a comprehensive literature review. International Journal of Leprosy and Other Mycobacterial Diseases, v. 67, p. 6-12, 1999.

73. LONGO, J. D. M; CUNHA, R. V. Perfil clínico-epidemiológico dos casos de hanseníase atendidos nenhum Hospital Universitário em Campo Grande, Mato Grosso do Sul, de janeiro de 1994 a julho de 2005. Hansen Int 2006; v. 31, p:9-14.

74. LOPES, V. G. S.; SARNO, E. N. Hanseníase e gravidez. Revista da Associação Médica Brasileira, v. 40, n. 3, p. 195-200, 1994.

75. LOPES, M. G. R; PONTES, M. D. M; COSTA, S. M. L. Programa de hanseníase (PROHANSEN): estrutura perfil epidemiológico dos acta atendidos nenhum período de abril de 2007 um fevereiro de 2008. Paraíba: Universidadade Federal da Paraíba; 2008. 
76. LYON, S. Estudo comparativo da carga bacilar em casos novos de hanseníase e o resultado do teste Sorológico ML Flow. 2005. Tese (Doutorado em Ciências da Saúde: Infectologia e Medicina Tropical) - Faculdade de Medicina. UFMG, Minas Gerais, 2005.

77. MAGALHÃES, M. C. C.; ROJAS, L. I. Evolución de la endemia de la lepra em Brasil. Revista Brasileira de Enfermagem. Brasília, v.61, n. esp, p. 738-43, 2008.

78. MANFRÉ, C.C.; QUEIRÓZ, S.G.; MATTHES, A.C.S. Considerações atuais sobre gravidez na adolescência. R. bras. Med. Fam. e Comum., Florianópolis, v. 5, n. 17, p. 48-54, 2010. Disponível em: <http://rbmfc.org.br/rbmfc/article/view/205/155>.

79. MATTOS, R. A. A integralidade na prática (ou sobre a prática da integralidade). Cadernos de Saúde Pública, Rio de Janeiro: ENSP, v. 20, n. 5, p. 1411-1416, 2004.

80. MATTOS, R. A. Os sentidos da integralidade: algumas reflexões acerca dos valores que merecem ser defendidos. In: PINHEIRO, R.; MATTOS, R. A. (Org.) Os sentidos da integralidade na atenção e no cuidado à saúde. Rio de Janeiro (RJ): IMS/UERJ/ABRASCO, p. 39-64, 2001.

81. MEDEIROS, P. F.; GUARESCHI, N. M. F. Políticas Públicas de Saúde da Mulher: a integralidade em questão. Estudos Feministas, Florianópolis, v. 17, n. 1, p. 31-48, jan./abr. 2009.

82. MILLER, D.; HELMS, S.E.; BRODELL, R.T. A practical approach to antibiotic treatment in women taking oral contraceptive. J. Am. Acad. Dermatol., St. Louis, v.30, n.6, p.1008-1011, 1994. Disponível em:

$<$ http://www.ncbi.nlm.nih.gov/pubmed/8188862>. Acesso em: 01/02/12.

83. MINISTÉRIO DA SAÚDE. Gabinete do Ministro. Portaria $\mathrm{n}^{\circ} 3.125$, de 7 de outubro de 2010. Aprova as Diretrizes para Vigilância, Atenção e Controle da hanseníase.

Diário Oficial da União, Brasília, DF, 2010. Disponível em:

$<$ http://www.saude.mt.gov.br/upload/legislacao/3115-\%5B3960-191010-SESMT\%5D.pdf>. Acesso em: 12/03/2011.

84. MIRANZI, S. S. C.; PEREIRA, L. H. M.; NUNES, A. A. Perfil epidemiológico da hanseníase em um município brasileiro nenhum período de 2000 a 2006 . Rev Soc Bras Med Trop, v. 43, n. 1, p. 62-67, 2010.

85. MONTEIRO, L. D. et al. Incapacidades físicas em pessoas acometidas pela hanseníase no período pós-alta da poliquimioterapia em um município no Norte do Brasil.

Cadernos de Saúde Pública, Rio de Janeiro, v. 29, n. 5, Mai. 2013.

86. MORRISON, A. A women with leprosy is in double jeopardy. Lepras Review, v. 71, n. 2, p. 128-143, 2000.

87. MOSCHELLA, S. L. The lepra reaction with necrotizing skin lesians: A report of six cases. Arch. Dermatol., v. 95, n. 6, p. 565-575, 1967. 
88. MOURA, E. R. F.; SILVA, R. M. Competência profissional e assistência em anticoncepção. Cadernos de Saúde Pública, v. 39, n. 5, p. 795-801, 2005.

89. MOURA, E. R. F.; SILVA, R. M. Informação e planejamento familiar como medidas de promoção da saúde. Ciência \& Saúde Coletiva, v. 9, n. 4, p.1023-1032, 2004.

90. MOURA, E. R. F.; SILVA, R. M.; GALVÃO, M. T. G. Dinâmica do atendimento em planejamento familiar no Programa Saúde da Família no Brasil. Cadernos de Saúde Pública, v. 23, n. 4, p. 961-970, 2007.

91. MOURA, E. R. F. et al. Perfil Demográfico, Socioeconômico e de Saúde Reprodutiva de mulheres atendidas em Planejamento Familiar no interior do Ceará. Revista

Baiana de Saúde Pública, v.34, n.1, p.119-133, 2010. Disponível em:

$<$ http://inseer.ibict.br/rbsp/index.php/rbsp/article/viewFile/22/22>. Acesso em: 05/02/2012.

92. NICOLAU, A. I. O. et al. História reprodutiva de mulheres laqueadas. Acta Paul Enferm. v. 23, n.5, p. 677-83, 2010. Disponível em:

$<$ http://www.scielo.br/pdf/ape/v23n5/15.pdf>. Acesso em: 03/12/2011.

93. NOGUEIRA, P. S. F. et al. Consequências da interação da hanseníase e gestação. Jornal de Enfermagem UFPE, v.6, n.9. 2014.

94. OLIVEIRA, S. G. et al. Gestação e hanseníase: uma associação de risco nos serviços de saúde. Hansen Int., v.36, n.1, p. 31-38, 2011. Disponível em:

$<$ http://www.ilsl.br/revista/detalhe_artigo.php?id=11560>. Acesso em: 22/03/12.

95. OPROMOLLA, D. V. A. Ação terapêutica das drogas antihansênicas e evidências de persistência microbiana nos casos paucibacilares. Hansenologia Internationalis, Bauru, v. 29, n. 01, p. 01-5, 2004.

96. ORGANIZAÇÃO DAS NAÇÕES UNIDAS. Declaração do Milênio. Assembléia Geral de 8 de setembro de 2000. Disponível em: <http://www.pnud.org.br/odm>. Acesso em: 04 de outubro de 2013.

97. ORGANIZAÇÃO MUNDIAL DA SAÚDE (OMS). Global leprosy situation, beginning of 2008. Weekly Epidemiol Record, v. 83, nº 33, p. 293-300, 2008.

98. _ Global Strategy for further reducing the leprosy burden and sustaining leprosy control activities: plan period: 2006-2010. Geneva: OMS; 2005.

99. Guia para eliminação da Hanseníase como problema de saúde pública. $1^{\text {a }}$ ed. Genebra, 2000.

100. Global leprosy situation, 2010. Weekly Epidemiological Record. Genebra, no 35, 2010, p. 337-348, Aug. 2010.

101. . Global leprosy situation, 2010. Weekly Epidemiological Record. Genebra, $\mathrm{n}^{\mathrm{o}} 35$, 2010, p.337-348, Aug. 2010. 
102. Global leprosysituation, 2012. Weekly Epidemiological Record. Genebra, volume 87, p.317-328, agosto 2012.

103. OSIS, M. J. D. Atenção Integral à Saúde da Mulher, o Conceito e o Programa: História de uma Intervenção. 1994. Dissertação (Mestrado). Universidade Estadual de Campinas, Campinas, 1994.

104. OSIS, M. J. D. et al. Atenção ao planejamento familiar no Brasil hoje: reflexões sobre os resultados de uma pesquisa. Cadernos de Saúde Pública, Rio de Janeiro, v. 22, n. 11, p. 2481-2490, Nov. 2006.

105. OSIS, M. J. D. et al. Escolha de métodos contraceptivos entre usuárias de um serviço público de saúde. Cadernos de Saúde Pública, v. 20, n. 6, p. 1586-1594, 2004.

106. OSIS, M. J. D. PAISM: um marco na abordagem da saúde reprodutiva no Brasil. Cadernos de Saúde Pública, v. 14, p. 25-32, 1998. Suplemento 1.

107. PALÁCIOS, V. R. C. M. et al. Analysis of the detection coefficient for the association between leprosy and pregnancy in the integration region of Carajás, State of Pará, Brazil. Revista da Sociedade Brasileira de Medicina Tropical, v. 46, n. 4, p. 460-465, Jul./Ago. 2013.

108. PALÁCIOS, V. R. C. M. et al. Leprosy and pregnancy in the State of Pará: an epidemiological perspective. Revista da Sociedade Brasileira de Medicina Tropical, v. 46, n. 4, p. 453-460, Jul./Ago. 2013a.

109. PENAFORTE, M. C. L. F. et al. Conhecimento, uso e escolha dos Métodos Contraceptivos por um Grupo de Mulheres de uma Unidade Básica de Saúde em Teresópolis, RJ. Cogitare Enferm, v. 15, n. 1, p. 124-30, jan./mar. 2010.

110. PENNA, M. L. F.; OLIVEIRA, M. L.; PENNA, G. O. The epidemiological behaviour of leprosy in Brazil. Leprosy Review Journal, v. 80, n. 3, p. 332-44, Set. 2009.

111. PENNA GO, PINHEIRO AMC, HAJJAR LA. Talidomida: mecanismo de ação, efeitos colaterais e uso terapêutico. An Bras Dermatol., v. 73, n. 6, p.501-4, 1998

112. PEREIRA JÚNIOR, A. C. Hanseníase de Lúcio. Anais Brasileiros de Dermatologia, v. 68, n. 1, p. 33-40, Jan./Fev. 1993.

113. PIERRE, L. A. S.; CLAPIS, M. J. Planejamento familiar em Unidade de Saúde da Família. Revista Latino-Am. Enfermagem, Ribeirão Preto, v. 18, n. 6, Nov./Dec. 2010.

114. PINTO NETO et al. Considerações epidemiológicas referentes ao controle dos comunicantes de hanseníase. Hansen int, v.27, n.1, p. 23-28, 2002. Disponível em: $<$ http://www.ilsl.br/revista/detalhe_artigo.php?id=10618\#>. Acesso em: 20/09/2013. 
115. PIOVESAN, F.; PIROTTA, W. R. B. A proteção dos direitos reprodutivos no direito internacional e no direito interno. In: PIOVESAN, F. Temas de direitos humanos. São Paulo: Max Limonad; p. 166-202, 1998.

116. POLIT, D. F.; BECK, C. T. Estruturas teóricas e conceituais. In Fundamentos de Pesquisa em Enfermagem. Porto Alegre, 2011, cap. 8, p. 221-245.

117. RODRIGUES, L. C.; LOCKWOOD, D. N. J. Leprosy now: epidemiology, progress, challenges, and research gaps. The Lancet Infectious Diseases, v. 11, p. 464-70, 2011.

118. ROZARIO, S. et al. Série temporal de características maternas e de nascidos vivos em Niterói, RJ. Rev. Bras. Saude Mater. Infant. [online]. 2013, v.13, n.2, pp. 137146. Disponível em:

http://www.scielo.br/scielo.php?script=sci_arttext\&pid=S151938292013000200007.

119. SILVA, S. F.; GRIEP, R. H. Reações Hansênicas em pacientes portadores de hanseníase em centros de saúde da área de planejamento 3.2 do município do Rio de Janeiro. Hansen. Int. Baurei, v.32, n.2, p.155-162, set, 2007.

120. SANTOS, G. H. N. et al. Impacto da idade materna sobre os resultados perinatais e via de parto. Rev. Bras. Ginecol. Obstet. [online], v.31, n.7, pp. 326-334, 2009.

Disponível em:

$<$ http://www.scielo.br/scielo.php?pid=S010072032009000700002\&script=sci_arttext $>$

121. SANTOS, J. C.; FREITAS, P. M. Planejamento familiar na perspectiva do desenvolvimento. Ciência \& Saúde Coletiva, v. 16, n. 3, p. 1813-1820, 2011.

122. SANTOS, S. R. et al. Objetivos de Desenvolvimento do Milênio e a Saúde da Criança: avanços e desafios. Residência Pediátrica, v. 2, n. 1, Jan./Abr. 2012.

123. SAUNDERSON, P.; GEBRE, S.; BYASS, P. Reversal reactions in the skin lesions of patients: incidence and risk factors. Leprosy Review Journal, v. 71, n. 3, p. 309$317,2000$.

124. SCHOLTEN, P.C. et al. No interaction between ciprofloxacin and an oral contraceptive. Antimicrob. Agents Chemother., Bethesda, v.42, n.12, p.3266-3268, 1998. Disponível em: <

http://www.ncbi.nlm.nih.gov/pmc/articles/PMC106032/pdf/ac003266.pdf.> Acesso em: 01/01/2012.

125. SISTEMA DE INFORMAÇÃO DE AGRAVO DE NOTIFICAÇÃO. SECRETARIA ESTADUAL DE SAÚDE (SESAU). Diretoria de Vigilância Epidemiológica/ DIVEP. Boletim Epidemiológico, Maceió (AL), 2009.

126. SERAPIONI, M. Métodos qualitativos e quantitativos na pesquisa social em saúde: algumas estratégias para a integração. Ciência \& Saúde Coletiva, v. 5, n. 1, p. 187192, 2000. 
127. SILVA, A. R. et al. Hanseníase no município de Buriticupu, estado do Maranhão: busca ativa de casos na população adulta. Rev Soc Bras Med Trop, v.43, p:691-694, 2010.

128. SILVA, R. M. et al. Planejamento familiar: significado para mulheres em idade reprodutiva. Ciência \& Saúde Coletiva, v. 16, n. 5, p. 2415-2424, 2011.

129. SILVA, S. F. Reações hansênicas em usuários de unidade básica de saúde de uma área de planejamento do Município do Rio de Janeiro. 2006.

130. SILVA, S. R. A.; MATHIAS, T. A. F.; GOMES, L.P.B. Avaliação grau de incapacidade em hanseníase: uma estratégia para sensibilização e capacitação da equipe de enfermagem. Rev Latino-Am Enfermagem, v.15, p:1125-1130, 2007.

131. SOCIEDADE BRASILEIRA DE HANSENOLOGIA \& SOCIEDADE BRASILEIRA DE DERMATOLOGIA. Hanseníase: Episódios Reacionais. p.1-15. 2003. Disponível em: <http://www.projetodiretrizes.org.br/projeto_diretrizes/056.pdf>

132. SOUSA-ARAÚJO, H. C. Da descoberta até o fim do domínio espanhol (15001640). In: História da lepra no Brasil. Rio de Janeiro: Imprensa Nacional, 1946. v. 1 p. $1-16$.

133. SOUZA, J. M. M. et al. Utilização de métodos contraceptivos entre as usuárias da rede pública de saúde do município de Maringá-PR. Rev Bras Ginecol Obstet., 28(5): 271-7, 2006.

134. TALHARI, S.; NEVES, R. G. Dermatologia Tropical, Hanseníase. $3^{\mathrm{a}}$ ed. Rio de Janeiro: Tropical, 2006.

135. TAVARES, C. M. Evolução da endemia hansênica no estado do Ceará: características epidemiológicas e operacionais no período de 1970 a 1996. Dissertação (mestrado) - Universidade Federal do Ceará, Fortaleza: 1997. 120p.

136. TAVEIRA, A. M; SANTOS, L. A; ARAÚJO,A. Perfil das adolescentes grávidas do município de São Gonçalo do Pará/MG. R. Enferm. Cent. O. Min. v.2, n.3, p.326-336, 2012. Disponível em: <

http://www.seer.ufsj.edu.br/index.php/recom/article/view/198/347>.

137. TURATO, E. R. Métodos qualitativos e quantitativos na área da saúde: definições, diferenças e seus objetos de pesquisa. Revista de Saúde Pública, v. 39, n. 3, p. 507$514,2005$.

138. UNICEF. Situação Mundial da Infância 2012. Crianças em um Mundo Urbano. 2012. Disponível em: <http://www.unicef.org/brazil/pt/PT-BR_SOWC_2012.pdf $>$. Acesso em: 12/03/2013.

139. VALENTE, M. S. S.; VIEIRA, J. L. F. Talidomida usada por pacientes com eritema nodoso hansênico. Revista da Sociedade Brasileira de Medicina Tropical, v.43, n.2, p. 201-204, 2010. 
140. VICTORA, C. et al. Maternal and child health in Brazil: progress and challenges. The Lancet, v. 377, n. 9780, p. 1863-1876, 2011.

141. VIEIRA, E. M. et al. Características do uso de métodos anticoncepcionais no estado de São Paulo. Revista de Saúde Pública, v. 36, p. 263-270, 2002.

142. VILLELA, W. V.; ARILHA, M. Sexualidade, gênero e direitos sexuais e reprodutivos. In: Berquó E, organizadora. Sexo \& Vida: panorama da saúde reprodutiva no Brasil. Campinas: Editora da UNICAMP; 2003. P. 95-150.

143. XAVIER, R. B.; JANNOTTI, C. B.; SILVA, K. S. et al. Risco reprodutivo e renda familiar: análise do perfil de gestantes. Ciênc. saúde coletiva [online], v.18, n.4, pp. 1161-1171, 2013. Disponível em:

$<$ http://www.scielo.br/scielo.php?pid=S141381232013000400029\&script=sci_arttext>

144. ZAMBACO PACHÁ, D. A. La leprae: atravers les siels et les Contrees. Paris: Massouol, 1914. 


\section{APÊNDICES}

APÊNDICE 1-QUESTIONÁRIO “Questionário sobre mulheres em idade fértil portadoras e ex-portadoras de hanseníase no município de Maceió/Alagoas”.

Título da pesquisa: A saúde reprodutiva de mulheres portadoras e ex-portadoras de hanseníase em uma capital do nordeste - Brasil, de 2006 a 2011.

Distrito Sanitário:

$\mathrm{N}^{\mathrm{o}}$ do instrumento:
Unidade Básica de Saúde:

No do Prontuário:

\section{DADOS PESSOAIS}

01. Idade:

02. Tem companheiro

1 ( ) Mora junto 2 ( ) Não mora junto 3 ( ) Não tem companheiro 4 ( ) Recusa-me a responder

03. Até que ano da escola você estudou?

\begin{tabular}{|l|l|l|}
\hline Escolaridade & 3.1. Entrevistada & 3.2. Chefe de Família \\
\hline 1 - Analfabeto/Fundamental Incompleto & & \\
\hline 2 - Fundamental Completo/ Básico Incompleto & & \\
\hline 3 - Básico Completo & & \\
\hline 4 - Superior Incompleto & & \\
\hline 5 - Superior Completo & & \\
\hline
\end{tabular}

0.4 - O que você tem, em sua casa? (ler alternativas) Quantos?

\begin{tabular}{|l|l|l|l|l|l|l|l|}
\hline & \multicolumn{6}{|l|}{ Quantidade que possui } \\
\hline Itens de conforto & Não tem & 01 & 02 & 03 & 04 & 05 & 06 \\
\hline 4.1 - Televisores (cores) & & & & & & & \\
\hline $4.2-$ Rádios & & & & & & & \\
\hline
\end{tabular}




\begin{tabular}{|l|l|l|l|l|l|l|l|}
\hline $4.3-$ Automóveis & & & & & & & \\
\hline 4.4 - Empregada fixa mensalista & & & & & & & \\
\hline 4.5 - Aspirador de pó & & & & & & & \\
\hline 4.6 - Máquina de lavar roupas & & & & & & & \\
\hline 4.7 - Geladeira & & & & & & & \\
\hline 4.8 - Videocassete / DVD & & & & & & & \\
\hline $4.9-$ Banheiros & & & & & & & \\
\hline
\end{tabular}

89 pontos ou mais (A) - 1, 59 a 88 (B) 2, - 35 a 58 (C) - 3, 20 a 34 (D), 0 a 19 (E)

05. Estuda atualmente?

1 ( ) Sim 2( ) Não

06. Profissão:

07. Ocupação:

08. Número de pessoas da família:

09. Qual a sua religião?

1 ( ) Católica 2( ) Evangélica 3( ) Espírita 4( ) Recusou-me a responder

5 ( ) Outras (citar):

Bairro:

Distrito:

\section{DADOS REFERENTES À DOENÇA \\ (Coleta de Prontuário)}

10. Data de notificação

11. Data do diagnóstico

12. Modo de entrada: 


\section{1 ( ) Caso novo 2( ) Transferência 3( ) Recidiva 4( ) Outro reingresso}

13. Forma Clínica segundo Classificação de Madri:
1 ( ) Indeterminada
2 ( ) Tuberculóide
3 ( ) Dimorfa
4 ( ) Virchowiana
5 ( ) Não classificado

14. Classificação Operacional:

1 ( ) Paucibacilar $2($ ) Multibacilar

15. Baciloscopia:

1 ( ) Positiva $2(\quad)$ Negativa $3(\quad)$ Não realizado

16. Data do início do tratamento:

1

\section{Grau de incapacidades físicas:}

17.1 No momento do diagnóstico:

17.2 No momento da alta

1 ( ) Zero

1 ( ) Zero

$2($ ) I

$2($ ) I

3 ( ) II

$3($ ) II

4 ( ) Não avaliado

4 ( ) Não avaliado

18. Número de lesões cutâneas

19. Modo de detecção:

1 ( ) Encaminhamento 2( ) Demanda espontânea 3( ) Exame de coletividade $4($ ) Exame de contatos 5( ) Outros métodos 6( ) Ignorado

20. Você estava grávida no momento do diagnóstico?

1 ( ) Sim 2( ) Não

21. Você estava no puerpério no momento do diagnóstico?

$1($ ) $\operatorname{sim}($ ) Não

22. Você estava no período de lactação no momento do diagnóstico? 
1 ( ) $\operatorname{Sim} 2$ ( ) Não

23. Número de contatos registrados:

24. Número e contatos examinados:

25. Você já apresentou Reações Hansenicas?

1 ( ) Antes do diagnóstico 2( ) Durante o tratamento 3 ( ) Pós tratamento

26.Caso responda SIM qual?

1. Tipo I 1( ) Sim 2( ) Não

2. Tipo II 1 ( ) $\operatorname{Sim}$ ( ) Não

\section{Dados referentes à Reprodução}

27. Está grávida:

$1($ ) Sim 2( ) Não $2($ ) Recusou-me a responder

28. $\mathrm{N}^{\mathrm{o}}$ de filhos:

29. $\mathrm{N}^{\mathrm{o}}$ de gestações:

30. $\mathrm{N}^{\mathrm{o}}$ de partos:

31. $\mathrm{N}^{\mathrm{o}}$ de abortos:

32. Idade no $1^{\circ}$ Parto:

33. Idade no último parto:

34. Amamentação:

$1($ ) Sim 2 ( ) Não $2($ ) Recusou-me a responder

\section{Dados referentes ao Planejamento familiar}

35. Quais os métodos anticoncepcionais que você conhece ou já ouviu falar?

\begin{tabular}{|l|l|l|l|l|}
\hline & \multicolumn{3}{|c|}{ 01. Sim 02. Não } \\
\hline & Espontâneo & Estimulado (Ler) & Já Usou & Tempo de Uso \\
\hline 01. Tabela & & & & \\
\hline 02. Muco & & & & \\
\hline
\end{tabular}




\begin{tabular}{|l|l|l|l|l|}
\hline 03. Temperatura & & & & \\
\hline 04. Coito Interrompido & & & & \\
\hline 05. Aleitamento Materno & & & & \\
\hline 06. Pílula & & & & \\
\hline 07. Injeção & & & & \\
\hline 08. DIU & & & & \\
\hline 09. Diafragma & & & & \\
\hline 10. Espermicida & & & & \\
\hline 11. Camisinha Feminina & & & & \\
\hline 12. Camisinha Masculina & & & & \\
\hline 13. Pílula de Emergência & & & & \\
\hline 14. Ligação de Trompas & & & & \\
\hline 15. Vasectomia & & & & \\
\hline 16. Implantes & & & & \\
\hline 17. Outros & & & & \\
\hline
\end{tabular}

36.0. Como ouviu falar sobre os métodos?

36.1 ( ) Médico

36.2 ( ) Enfermeiro

36.3 ( ) Farmacêutico

36.4 ( ) Parceiro

36.5 ( ) Parente
36.6 ( ) Amigo(a)

36.7 ( ) Televisão

36.8 ( ) Rádio

36.9 ( ) Leu em revista / jornal

36.10 ( ) Outros (Citar):

37. Onde conseguiu receber este(s) método(s)?

1 ( ) Unidade Básica de Saúde

2( ) Unidade Especializada

3 ( ) Hospital

4 ( ) Outros (citar):

38. Conseguiu com facilidade?

1( ) Sim 2( ) Não 3( ) Recuso-me a Responder 39. Se NÃO por quê? 
40. Recebeu alguma orientação para usá-los?

1 ( ) Sim 2( ) Não 3( ) Recuso-me a Responder

41. De quem recebeu estas orientações?

41.1 ( ) Médico

41.2 ( ) Enfermeiro

41.3 ( ) Farmacêutico

41.4 ( ) Escola

41.5 ( ) Televisão
41.6 ( ) Jornal / Revista

41.7 ( ) Amigo(a)

41.8 ( ) Mãe

41.9 ( ) Pai

41.10 Outros (Citar):

42. Você engravidou no percurso da doença?

1 ( ) Sim 2( ) Não 3( ) Não se aplica 4 ( ) Recusa-me a responder

43. Caso afirmativo, indique a fase.

1 ( ) Tratamento $2($ ) Cura $3($ ) Pós-alta

Caso afirmativo, e responda a questão 44. Caso negativo responda a questão 45.

44. Você durante a gravidez, puerpério e lactação apresentou alguma reação Hansênica?

1 ( ) Sim 2 ( ) Não 3 ( ) Não se aplica $\quad 4$ ( ) Recuso-me a responder.

Se SIM, quais os sinais e os sintomas apresentados?

1 ( ) novas lesões dermatológicas (manchas ou placas) $2(\quad)$ infiltração $3(\quad)$ alterações na cor $4(\quad)$ edema nas lesões antigas $5(\quad)$ dor ou espessamento dos nervos 6() nódulos vermelhos ou dolorosos $7($ ) febre $8($ ) dores articulares 9 ( ) dor e espessamento dos nervos 10 ( ) mal-estar generalizado $11($ ) nenhuma alteração nas lesões antiga

45. Se NÃO estava grávida, apresentou alguma reação Hansênica?

1 ( ) Sim 2 ( ) Não 3 ( ) Não se aplica 4 ( ) Recuso-me a responder.

Se SIM, quais os sinais e os sintomas apresentados?

1 ( ) novas lesões dermatológicas (manchas ou placas) $2(\quad)$ infiltração $3(\quad)$ alterações na cor $4(\quad)$ edema nas lesões antigas $5(\quad)$ dor ou espessamento dos nervos 6() nódulos vermelhos ou dolorosos 7() febre $8($ ) dores articulares 
9 ( ) dor e espessamento dos nervos 10 ( ) mal-estar generalizado $11($ ) nenhuma alteração nas lesões antiga

Instrumento adaptado baseado em informações na ficha de notificação e investigação de Hanseníase e formulários na área de saúde reprodutiva. 


\section{APÊNDICE II - TERMO DE CONSENTIMENTO LIVRE E ESCLARECIDO}

Título da pesquisa: A saúde reprodutiva de mulheres portadoras e ex-portadoras de hanseníase em uma capital do nordeste - Brasil, de 2006 a 2011

Pesquisadora responsável: Clodis Maria Tavares (Telefone para contato: 82/9925-2879 e-mail: clodistavares@yahoo.com.br

Orientadora: Profa. Dra. Ana Maria de Almeida (Telefone para contato: 16/3602-3432 e-mail: amalmeid@eerp.usp.br . Avenida Bandeirantes, 3900, Ribeirão Preto-SP.

A senhora esta sendo convidada a participar dessa pesquisa que tem a intenção de conhecer a realidade das mulheres em idade fértil portadoras e ex portadoras de hanseníase e sua inclusão e adesão no planejamento familiar.

Em recente publicação, o Ministério da Saúde preconiza que mulheres grávidas ou sob risco de engravidar (mulheres em idade fértil) devem ser aconselhadas para a anticoncepção. Na hanseníase, os sinais clínicos refletem além do estágio evolutivo da doença a resposta do sistema imunológico. Assim observa-se que no sexo feminino as alterações hormonais da puberdade, gestação, puerpério e menopausa bem como o estado fisiológico de imunodepressão, provocam reflexos definidos sobre a doença, gestação, puerpério e concepto.

Esta pesquisa tem como objetivo geral analisar as ações de saúde dirigidas a anticoncepção de mulheres em idade fértil portadoras de Hanseníase e objetivos específicos, investigar as ações de saúde dirigidas a anticoncepção de mulheres com hanseníase, pelos profissionais de saúde médicos e enfermeiros das unidades de referência e atenção básica e identificar entre mulheres em idade fértil portadoras de hanseníase que ações de anticoncepção estão sendo recomendadas para elas. Entendemos que a realização da pesquisa ira contribuir para melhoria da qualidade de vida dessas mulheres.

Caso aceite participar desta pesquisa você será entrevistada com perguntas sobre dados pessoais, dados referentes a doença, a reprodução e ao planejamento familiar. Nossa conversa terá duração aproximada de uma hora para o preenchimento do questionário.

Os resultados do estudo, sendo estes favoráveis ou não serão utilizados para elaboração de trabalhos e publicações no meio científico.

Assumimos o compromisso de manter sigilo sobre sua identidade assim como garantimos que o desenvolvimento da pesquisa não trará nenhum prejuízo a suas atividades laborais no serviço. Você não ira receber nenhuma remuneração pela sua participação assim, como não terá nenhum gasto. Será respeitada sua decisão de desistir da participação, no 
momento que desejar, mesmo que já tenha iniciado. Sua recusa ou desistência na participação da pesquisa não ira interferir nas suas atividades neste Serviço de saúde.

$\mathrm{Eu}$

$\mathrm{RG}$ abaixo assinado, tendo recebido as informações acima, e uma cópia deste termo assinada pela pesquisadora, ciente dos meus direitos concordo em participar da pesquisa.

Maceió de de 


\section{APÊNDICE III - TERMO DE CONSENTIMENTO LIVRE E ESCLARECIDO (<18 ANOS)}

Título da pesquisa: A saúde reprodutiva de mulheres portadoras e ex-portadoras de hanseníase em uma capital do nordeste - Brasil, de 2006 a 2011

Mulheres em idade fértil com hanseníase: importância da anticoncepção como prevenção dos estados reacionais

Pesquisadora responsável: Clodis Maria Tavares (Telefone para contato: 82/9925-2879 e-mail: clodistavares@yahoo.com.br

Orientadora: Profa. Dra. Ana Maria de Almeida (Telefone para contato: 16/3602-3432 e-mail: amalmeid@eerp.usp.br .Avenida Bandeirantes, 3900, Ribeirão Preto-SP.

Sua filha esta sendo convidada a participar dessa pesquisa que tem a intenção de conhecer a realidade das mulheres em idade fértil portadoras e ex-portadoras de hanseníase e sua inclusão e adesão no planejamento familiar.

Em recente publicação, o Ministério da Saúde preconiza que mulheres grávidas ou sob risco de engravidar (mulheres em idade fértil) devem ser aconselhadas para a anticoncepção. Na hanseníase, os sinais clínicos refletem além do estágio evolutivo da doença a resposta do sistema imunológico. Assim observa-se que no sexo feminino as alterações hormonais da puberdade, gestação, puerpério e menopausa bem como o estado fisiológico de imunodepressão, provocam reflexos definidos sobre a doença, gestação, puerpério e concepto.

Esta pesquisa tem como objetivo geral analisar as ações de saúde dirigidas a anticoncepção de mulheres em idade fértil portadoras de Hanseníase e objetivos específicos, investigar as ações de saúde dirigidas a anticoncepção de mulheres com hanseníase, pelos profissionais de saúde médicos e enfermeiros das unidades de referência e atenção básica e identificar entre mulheres em idade fértil portadoras de hanseníase que ações de anticoncepção estão sendo recomendadas para elas. Entendemos que a realização da pesquisa irá contribuir para melhoria da qualidade de vida dessas mulheres.

Caso aceite participar desta pesquisa sua filha será entrevistada com perguntas sobre dados pessoais, dados referentes à doença, a reprodução e ao planejamento familiar. Nossa conversa terá duração aproximada de uma hora para o preenchimento do questionário.

Os resultados do estudo, sendo estes favoráveis ou não serão utilizados para elaboração do trabalho e publicações no meio científico. 
Assumimos o compromisso de manter sigilo sobre sua identidade assim como garantimos que o desenvolvimento da pesquisa não trará nenhum prejuízo a suas atividades laborais no serviço. Ela não ira receber nenhuma remuneração pela sua participação assim, como não terá nenhum gasto. Será respeitada sua decisão de desistir da participação, no momento que desejar, mesmo que já tenha iniciado. Sua recusa ou desistência na participação da pesquisa não ira interferir nas suas atividades neste Serviço de saúde.

$\mathrm{Eu}$

$\mathrm{RG}$ , abaixo assinado, tendo recebido as informações acima, e uma cópia deste termo assinada pela pesquisadora, ciente dos meus direitos concordo em participar da pesquisa.

Maceió de de 


\section{ANEXO 1}

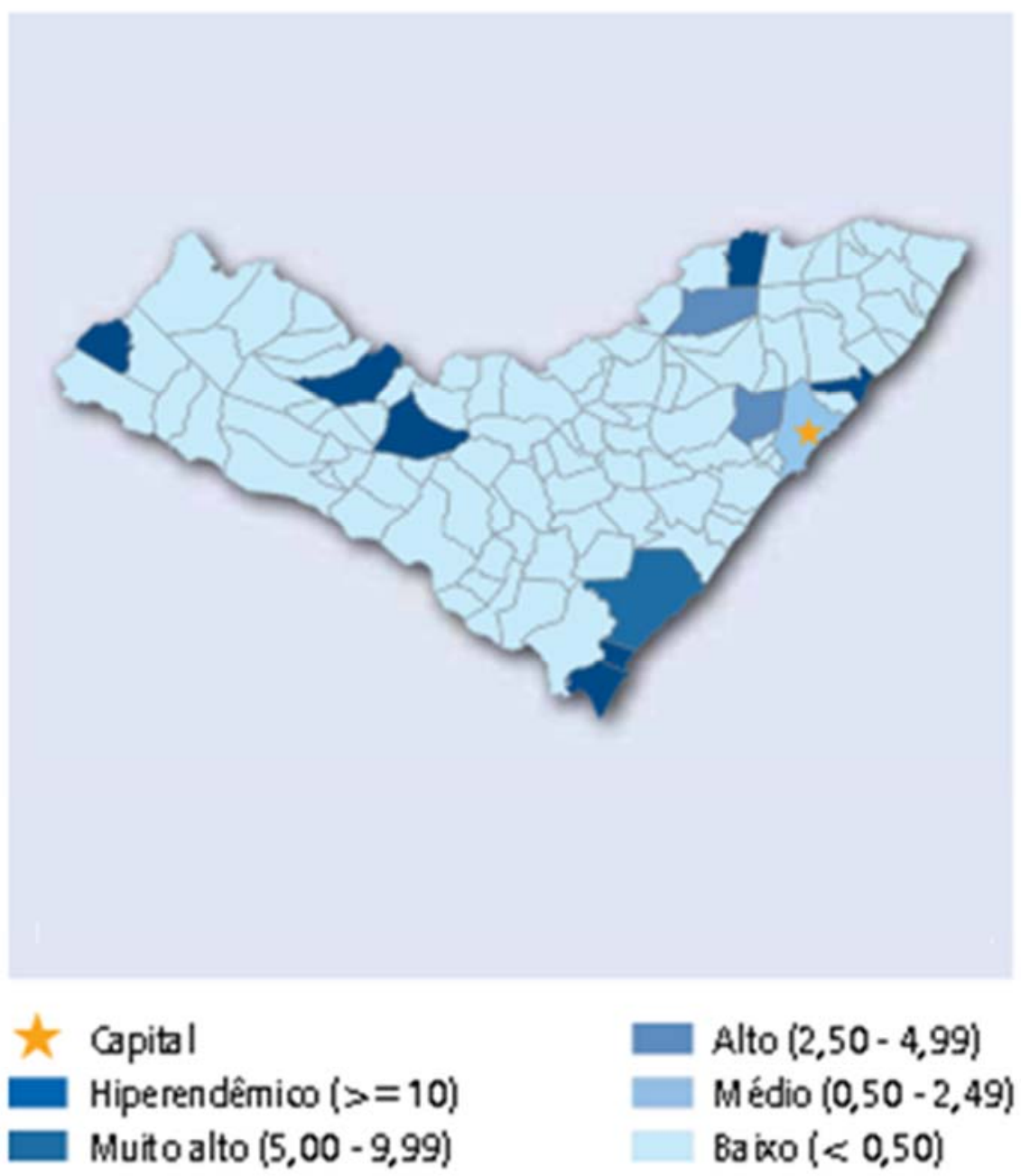

Distribuição dos coeficientes de detecção de hanseníase em menores de 15 anos por município de residência, Alagoas, 2008*.

Fonte: SINAN, SVS-MS. * 2008, dados preliminares. 


\section{ANEXO 2}

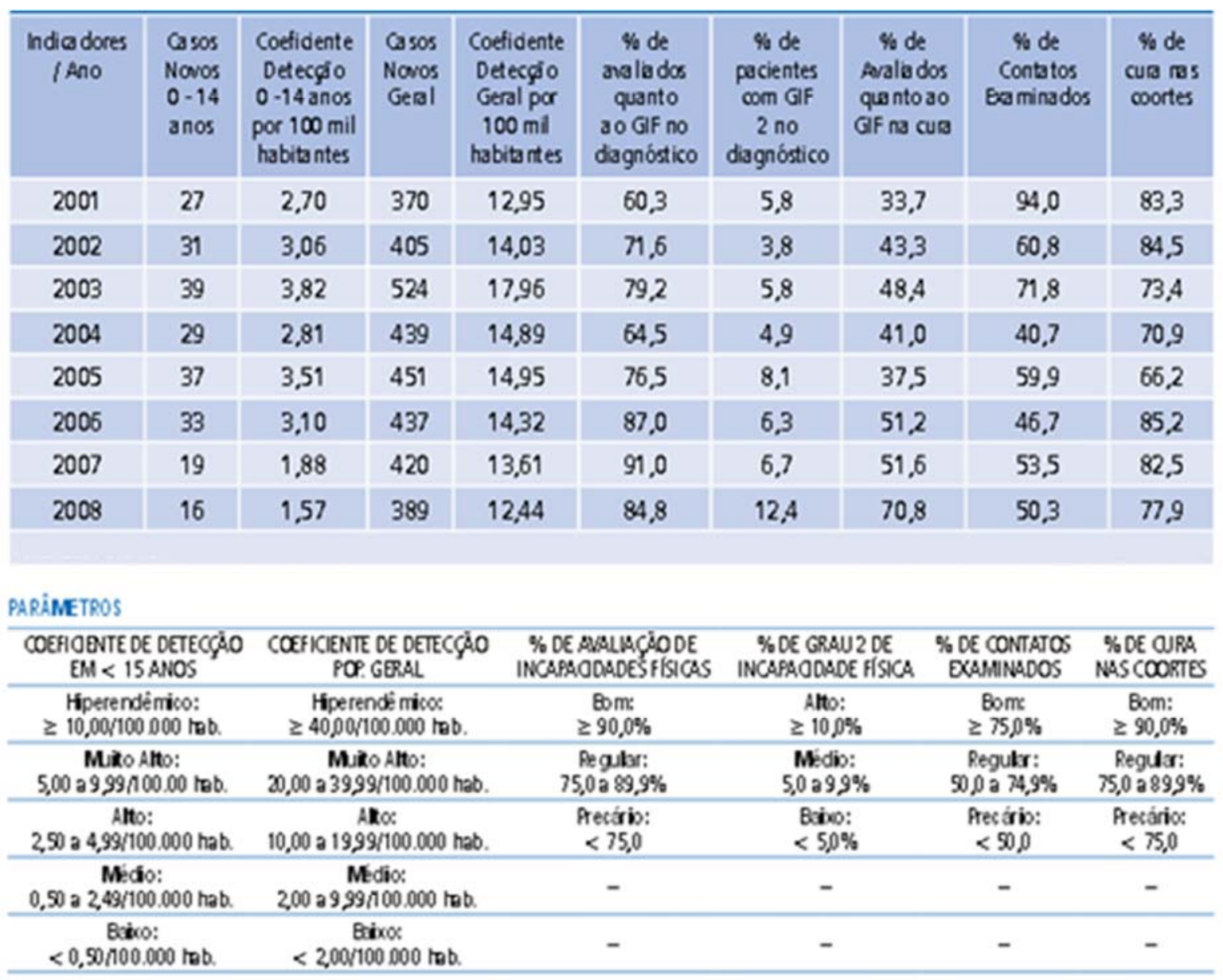

Indicadores epidemiológicos e operacionais de hanseníase, Alagoas, 2001 a 2008*. Fonte: SINAN/SVS-MS. *2008 - dados preliminares. 


\section{ANEXO 3}

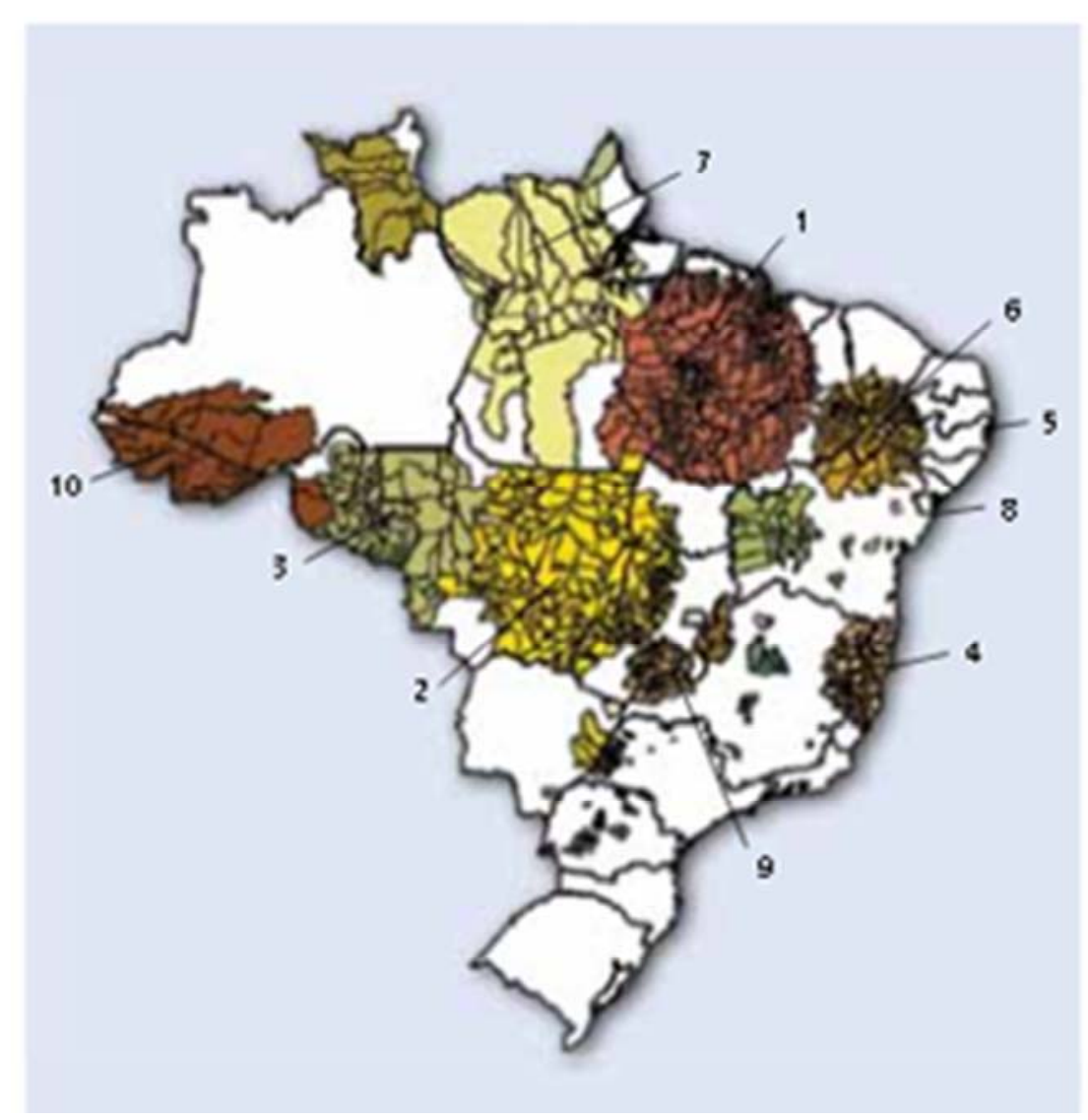

Clusters de casos novos de hanseníase, ordenados segundo o coeficiente de detecção no período de 2005 a 2007, Brasil.

Fonte: Penna, MLF - MS, 2008. 


\section{ANEXO 4}

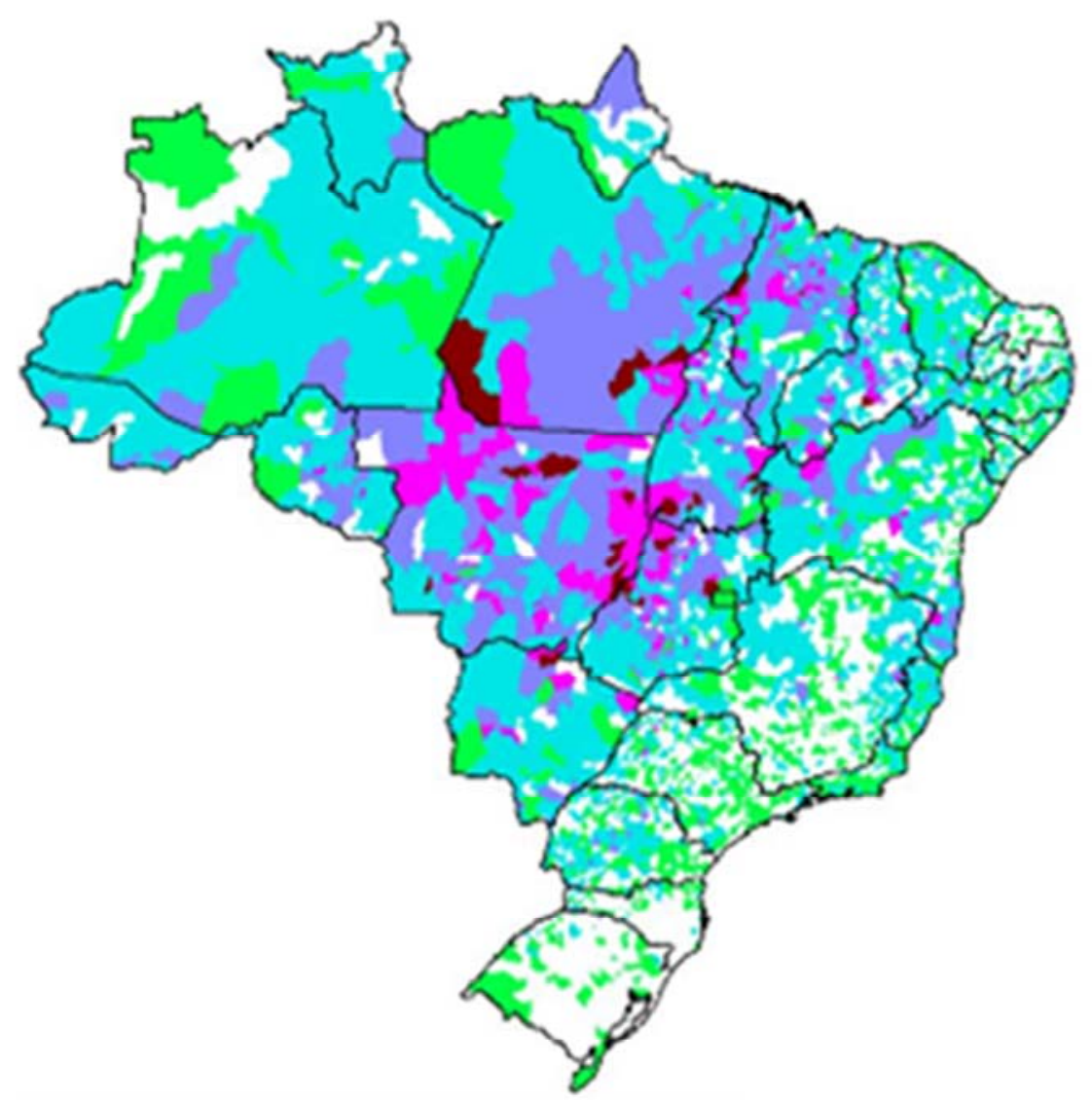

Coeficiente de prevaléncia por 10 mil habitantes

$\square$ Sem casos
$\square$ Baibo $<1,00$
$\square$ Medo 1,00 a 4,99
$\square$ Ato 5,00 a 9,99
$\square$ Muito Ato 10,00 a 19,99
Hiperendemico $=20,00$

Taxa de prevalência de hanseníase por 10 mil habitantes.

Fonte: Brasil, 2011. 


\section{Anexo 5}

\section{LEGISLAÇÕES}

\section{$\underline{\text { LEI N }^{\circ} 9.263, \text { DE } 12 \text { DE JANEIRO DE } 1996}$}

Regula o $\S 7^{\circ}$ do art. 226 da Constituição Federal, que trata do planejamento familiar, estabelece penalidades e dá outras providências.

O PRESIDENTE DA REPÚBLICA: Faço saber que o Congresso Nacional decreta e eu sanciono a seguinte Lei:

\section{CAPÍTULO I}

\section{DO PLANEJAMENTO FAMILIAR}

Art. $1^{\circ} \mathrm{O}$ planejamento familiar é direito de todo cidadão, observado o disposto nesta Lei.

Art. $2^{\circ}$ Para fins desta Lei, entende-se planejamento familiar como o conjunto de ações de regulação da fecundidade que garanta direitos iguais de constituição, limitação ou aumento da prole pela mulher, pelo homem ou pelo casal.

Parágrafo único - É proibida a utilização das ações a que se refere o caput para qualquer tipo de controle demográfico.

Art. $3^{\circ} \mathrm{O}$ planejamento familiar é parte integrante do conjunto de ações de atenção à mulher, ao homem ou ao casal, dentro de uma visão de atendimento global e integral à saúde.

Parágrafo único - As instâncias gestoras do Sistema Único de Saúde, em todos os seus níveis, na prestação das ações previstas no caput, obrigam-se a garantir, em toda a sua rede de serviços, no que respeita a atenção à mulher, ao homem ou ao casal, programa de atenção integral à saúde, em todos os seus ciclos vitais, que inclua, como atividades básicas, entre outras:

I - a assistência à concepção e contracepção;

II - $\mathrm{o}$ atendimento pré-natal;

III - a assistência ao parto, ao puerpério e ao neonato;

IV - o controle das doenças sexualmente transmissíveis; 
$\mathrm{V}$ - o controle e prevenção do câncer cervicouterino, do câncer de mama e do câncer de pênis.

Art. $4^{\circ} \mathrm{O}$ planejamento familiar orienta-se por ações preventivas e educativas e pela garantia de acesso igualitário a informações, meios, métodos e técnicas disponíveis para a regulação da fecundidade.

Parágrafo único - O Sistema Único de Saúde promoverá o treinamento de recursos humanos, com ênfase na capacitação do pessoal técnico, visando a promoção de ações de atendimento à saúde reprodutiva.

Art. $5^{\circ}$ - É dever do Estado, por meio do Sistema Único de Saúde, em associação, no que couber, às instâncias componentes do sistema educacional, promover condições e recursos informativos, educacionais, técnicos e científicos que assegurem o livre exercício do planejamento familiar.

Art. $6^{0}$ As ações de planejamento familiar serão exercidas pelas instituições públicas e privadas, filantrópicas ou não, nos termos desta Lei e das normas de funcionamento e mecanismos de fiscalização estabelecidos pelas instâncias gestoras do Sistema Único de Saúde.

Parágrafo único - Compete à direção nacional do Sistema Único de Saúde definir as normas gerais de planejamento familiar.

Art. $7^{\circ}$ - É permitida a participação direta ou indireta de empresas ou capitais estrangeiros nas ações e pesquisas de planejamento familiar, desde que autorizada, fiscalizada e controlada pelo órgão de direção nacional do Sistema Único de Saúde.

Art. $8^{\circ}$ A realização de experiências com seres humanos no campo da regulação da fecundidade somente será permitida se previamente autorizada, fiscalizada e controlada pela direção nacional do Sistema Único de Saúde e atendidos os critérios estabelecidos pela Organização Mundial de Saúde.

Art. $9^{\circ}$ Para o exercício do direito ao planejamento familiar, serão oferecidos todos os métodos e técnicas de concepção e contracepção cientificamente aceitos e que não coloquem em risco a vida e a saúde das pessoas, garantida a liberdade de opção.

Parágrafo único. A prescrição a que se refere o caput só poderá ocorrer mediante avaliação e acompanhamento clínico e com informação sobre os seus riscos, vantagens, desvantagens e eficácia. 
Art. 10. Somente é permitida a esterilização voluntária nas seguintes situações: (Artigo vetado e mantido pelo Congresso Nacional - Mensagem $\mathrm{n}^{\mathrm{o}}$ 928, de 19.8.1997 < sagem Veto/Mv928-97.htm>)

I - em homens e mulheres com capacidade civil plena e maiores de vinte e cinco anos de idade ou, pelo menos, com dois filhos vivos, desde que observado o prazo mínimo de sessenta dias entre a manifestação da vontade e o ato cirúrgico, período no qual será propiciado à pessoa interessada acesso a serviço de regulação da fecundidade, incluindo aconselhamento por equipe multidisciplinar, visando desencorajar a esterilização precoce;

II - risco à vida ou à saúde da mulher ou do futuro concepto, testemunhado em relatório escrito e assinado por dois médicos.

$\S 1^{\circ}$ É condição para que se realize a esterilização o registro de expressa manifestação da vontade em documento escrito e firmado, após a informação a respeito dos riscos da cirurgia, possíveis efeitos colaterais, dificuldades de sua reversão e opções de contracepção reversíveis existentes.

$\S 2^{\circ}$ É vedada a esterilização cirúrgica em mulher durante os períodos de parto ou aborto, exceto nos casos de comprovada necessidade, por cesarianas sucessivas anteriores.

$\S 3^{\circ}$ Não será considerada a manifestação de vontade, na forma do $\S 1^{\circ}$, expressa durante ocorrência de alterações na capacidade de discernimento por influência de álcool, drogas, estados emocionais alterados ou incapacidade mental temporária ou permanente.

$\S 4^{\circ}$ A esterilização cirúrgica como método contraceptivo somente será executada por meio da laqueadura tubária, vasectomia ou de outro método cientificamente aceito, sendo vedada por meio da histerectomia e ooforectomia.

$\S 5^{\circ} \mathrm{Na}$ vigência de sociedade conjugal, a esterilização depende do consentimento expresso de ambos os cônjuges.

$\S 6^{\circ}$ A esterilização cirúrgica em pessoas absolutamente incapazes somente poderá ocorrer mediante autorização judicial, regulamentada na forma da Lei.

Art. 11. Toda esterilização cirúrgica será objeto de notificação compulsória à direção do Sistema Único de Saúde. (Artigo vetado e mantido pelo Congresso Nacional) Mensagem $n^{\circ}$ 928, de 19.8.1997 < Mensagem Veto/Mv928-97.htm $>$ 
Art. 12. É vedada a indução ou instigamento individual ou coletivo à prática da esterilização cirúrgica.

Art. 13. É vedada a exigência de atestado de esterilização ou de teste de gravidez para quaisquer fins.

Art. 14. Cabe à instância gestora do Sistema Único de Saúde, guardado o seu nível de competência e atribuições, cadastrar, fiscalizar e controlar as instituições e serviços que realizam ações e pesquisas na área do planejamento familiar.

Parágrafo único. Só podem ser autorizadas a realizar esterilização cirúrgica as instituições que ofereçam todas as opções de meios e métodos de contracepção reversíveis. (Parágrafo vetado e mantido pelo Congresso Nacional) Mensagem $\mathrm{n}^{\mathrm{o}}$ 928, de 19.8.1997 $<$ Mensagem_Veto/Mv928-97.htm $>$

\section{CAPÍTULO II}

\section{DOS CRIMES E DAS PENALIDADES}

Art. 15. Realizar esterilização cirúrgica em desacordo com o estabelecido no art. 10 desta Lei. (Artigo vetado e mantido pelo Congresso Nacional) Mensagem $\mathrm{n}^{\mathrm{o}}$ 928, de 19.8.1997 $<\underline{\text { Mensagem Veto/Mv928-97.htm }>}$

Pena - reclusão, de dois a oito anos, e multa, se a prática não constitui crime mais grave.

Parágrafo único - A pena é aumentada de um terço se a esterilização for praticada:

I - durante os períodos de parto ou aborto, salvo o disposto no inciso II do art. 10 desta Lei. II - com manifestação da vontade do esterilizado expressa durante a ocorrência de alterações na capacidade de discernimento por influência de álcool, drogas, estados emocionais alterados ou incapacidade mental temporária ou permanente;

III - por meio de histerectomia e ooforectomia;

IV - em pessoa absolutamente incapaz, sem autorização judicial;

V - por meio de cesária indicada para fim exclusivo de esterilização.

Art. 16. Deixar o médico de notificar à autoridade sanitária as esterilizações cirúrgicas que realizar. 
Pena - detenção, de seis meses a dois anos, e multa.

Art. 17. Induzir ou instigar dolosamente a prática de esterilização cirúrgica.

Pena - reclusão, de um a dois anos.

Parágrafo único - Se o crime for cometido contra a coletividade, caracteriza-se como genocídio, aplicando-se o disposto na Lei $\mathrm{n}^{\circ} 2.889$, de $1^{\circ}$ de outubro de $1956<$ L2889.htm>.

Art. 18. Exigir atestado de esterilização para qualquer fim.

Pena - reclusão, de um a dois anos, e multa.

Art. 19. Aplica-se aos gestores e responsáveis por instituições que permitam a prática de qualquer dos atos ilícitos previstos nesta Lei o disposto no caput e nos $\S \S 1^{\circ}$ e $2^{\circ}$ do art. 29 do Decreto-lei $\mathrm{n}^{\circ}$ 2.848, de 7 de dezembro de $1940<$. ./Decreto-Lei/Del2848. htm> - Código Penal.

Art. 20. As instituições a que se refere o artigo anterior sofrerão as seguintes sanções, sem prejuízo das aplicáveis aos agentes do ilícito, aos co-autores ou aos partícipes:

I - se particular a instituição:

a) de duzentos a trezentos e sessenta dias-multa e, se reincidente, suspensão das atividades ou descredenciamento, sem direito a qualquer indenização ou cobertura de gastos ou investimentos efetuados;

b) proibição de estabelecer contratos ou convênios com entidades públicas e de se beneficiar de créditos oriundos de instituições governamentais ou daquelas em que o Estado é acionista; II - se pública a instituição, afastamento temporário ou definitivo dos agentes do ilícito, dos gestores e responsáveis dos cargos ou funções ocupados, sem prejuízo de outras penalidades.

Art. 21. Os agentes do ilícito e, se for o caso, as instituições a que pertençam ficam obrigados a reparar os danos morais e materiais decorrentes de esterilização não autorizada na forma desta Lei, observados, nesse caso, o disposto nos arts. 159, 1.518 e 1.521 e seu parágrafo único do Código Civil, combinados com o art. 63 do Código de Processo Penal.

\section{CAPÍTULO III}

\section{DAS DISPOSIÇÕES FINAIS}


Art. 22. Aplica-se subsidiariamente a esta Lei o disposto no Decreto-lei $\mathrm{n}^{\mathrm{o}} 2.848$, de 7 de dezembro de $1940<. . /$ Decreto-Lei/Del2848.htm>- Código Penal, e, em especial, nos seus arts. 29, caput, e $\S \S 1^{\circ}$ e $2^{\circ} ; 43$, caput e incisos I, II e III; 44, caput e incisos I e II e III e parágrafo único; 45, caput e incisos I e II; 46, caput e parágrafo único; 47, caput e incisos I, II e III; 48, caput e parágrafo único; 49, caput e $\S \S 1^{\circ}$ e $2^{\circ} ; 50$, caput, $\S 1^{\circ}$ e alíneas e $\S 2^{\circ} ; 51$, caput e $\S \S 1^{\mathrm{o}}$ e $2^{\mathrm{o}} ; 52 ; 56 ; 129$, caput e $\S 1^{\mathrm{o}}$, incisos I, II e III, $\S 2^{\circ}$, incisos I, III e IV e $\S 3^{\circ}$.

Art. 23. O Poder Executivo regulamentará esta Lei no prazo de noventa dias, a contar da data de sua publicação.

Art. 24. Esta Lei entra em vigor na data de sua publicação.

Art. 25. Revogam-se as disposições em contrário.

Brasília, 12 de janeiro de 1996; $175^{\circ}$ da Independência e $108^{\circ}$ da República. 


\section{APROVAÇÃO DO COMITÊ DE ÉTICA EM PESQUISA E ENSINO DO CENTRO UNIVERSITÁRIO CESMAC}

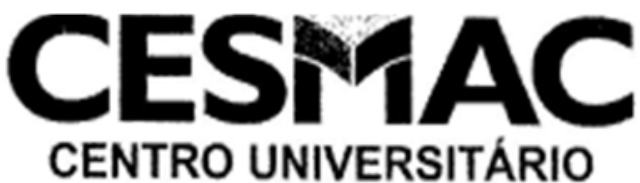

Comité de Ética em Pesquisa e Ensino do Centro Universitário Cesmac (COEPE)

Regietro $\pi^{0}$ 25000.196371/2011-70 - CONEP/CNS/SIPAR/MS - 10/11/2011

Maceib, 12 de julho de 2012.

PARECER CONSUBSTANCIADO

1) IDENTIFICACAOO:

Protocolo n': 1291/12 Título: Análise das açỏes de anticoncepçāo om mulheres em idade fértil com Hansoniase

Grupo III Área de conhecimento: Ciências da saúde Código: 4.04

Pesquisador Responsável: Clodis Neria Tavares

Instituiçăo Responsável: Universidade Federal de Alagoas

Data de Entrada: 19/03/2012 Analisado na 51 Reuniáo Extraordinaria

Data đa Reuniăo: 09/05/2012

\section{ii) SUMÁRIO GERAL DO PROTOCOLO:}

Segundo as estatisticas atuais, o número de mulheres em idade fértil, na faica otária de 10 a 49 anos, no período de 2006 a 2010, que foram notificadas com hanseniage em Alagoss b́ de aproximadamente 779 mulheres es om Macaió representa $37 \%$ dos casos do Estado, exístindo 288 mulheres em idade fórtil portadoras de hansentase. Considerase que a relevância do estudo ó refletida no risco destas mulheres engravidarem, quando as alteraçóes orgánicas

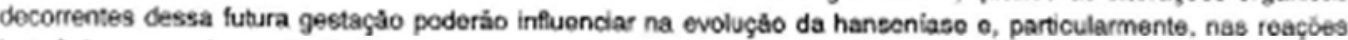
hansẻnicas, nos riscos obstétricos e para o concepto. Infere-se que hả necessidade do conhecimento da situaçảo dessa populaçăo em relaçáo ao planejamento familiar $\theta$ a disponiblidade dos mótodos contraceotivos. Náo existem dados a nivol nacional eobre o asaunto e os produtos resultantes deste trabalho poderáo fornecor subsidios para o plantjamento de açóbs e intervençóes que possibilitem as mulheres portadoras do hanseniase na uailizaçáo de proteçảo efetva no sentido da prevençáo das complicaçóes decorrentes das manifestaçdes reacionais. Diante do exposto, faz-se necessário conhecer a situaçato da mulher portadora de hanseniase nos servicos de planejamento familar, pois as açỏes junto a csse grupo ó um componente importante para assisténcia à saúde reprodutiva, com o objetivo de retardar ou evitar a gravidoz nảo planejada ou a gravidez de alto risco, prevenindo, assim, as reaçỏes hansênicas (tipo I e II). 0 objetivo geral deste trabalho é analisar as apcées de saúde dirigidas a anticoncepça de mutheres em idado fértil portadorae de Hanseniase. Trata-se de Estudo Transversal com abordagem quantitativa, a ser realizado nas Unidades Básicas de Saúdo (UBS) do município de Maceló-AL, onde a atençăo básica é composta de 65 Unidades de Saúde o 36 com Estratégia de Sajje da Família (ESF). Destas, 48 UBS estáo aptas a rocober casos de hanseniase e 28\% da populaçâo é ocberta pela Estratégia de Saúde da Familia (ESF). Dentre as unidades dc saúdo, 28 tem implantadas as acobes de dlagnóstico e tratamento da hanseniase além de dez unidades de reforéncia, que contarn ern sou quadro com dermatologista sanitário. Seráo incluidas nesse estudo as 28 UBS municipais e uma unidade de saúde de referència estedual que 6 o $2^{\circ}$ Centro de Saúdo, que atende priortariamente casos suspeitos de hanseníase que nåo foram elucidados na atençáo básica, como também portadores e ex-

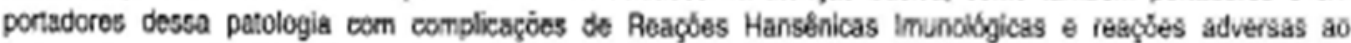
tratamento, como também diagnosticar casos em menores de 15 anos, recidivas e Hanseniase Neural Pura. Para o primeiro componente do estudo, a populaçăo será corstituida por 288 mulheres em idade fértil, com diagnóstico de hansenlase, registradas nas unidades saude, na taba etaria de 14 a 49 anos, que estavam em curso do fratamento c ou pós-alta, que foram notificadas no periodo do 2006-2011, residentes em Maceió e que acoitarem participar do estudo. Para o segundo componente, seráo incluidos os 168 profissionais de saúde (médicos e enfermeiros) das 28 UBS que atuam nas açees de controle da hanseniase. Iniciaimente será realizado um levantamento dos dados de mulheres em idade fértil na faixa etária selecionada com as variàveis deccritvas da peseos, tempo e lugar no SINAN. Em seguida as UBS selecionadas serúo visinadas pelas posquisadoras para realzar uma reuniáo com a equipe de saúde com o objetivo de apresentar a proposta da pesquisa e junto com os ACS visitar as residincias das multheres 
com a finalidade de convidá-las para a reuniảo na UBS. Se concordarem em participar da pesquisa, lerâo agendamentos prévios, sendo o local da realizaçáo das entrevistas, as UBS que realizam ou realizaram fratamentos de hanseniase. Para a coleta de dados utilizar-se-á prontuários das pacientes para levantamento de dados sobre a clínica đa doença e formulários construídos para a pesquisa, que seräo validados scgundo literatura por profissionais da Área de Hansenologia e Saúde da Mulher (Planojamento Familiar) do Estado de Alagoas. As variáveis de estudo sáo: idade, estado civil, escolaridade, naturalidade, município de residéncla, forma clinica, classificaçáo operacional, tempo de diagnóstico, modo de entrada, resultado de baciloscopia, data do inicio do tratamento, conhecimento acerca dos riscos de desonvolvimento das reaçoes hansénicas ao engravidar, durante $e$ após 0 tratamento. grau de incapacidade física no diagnóstico e varí́veis reforentes a históna reprodutiva, tais como: número de gravidez. número filhos, abortos, se apresentou sintomas da doença ou reaçấo hansĉnica antes, đurante a gravidez, no puerpério ou na lactaçáo. O instrumento para coleta de dados referente aos profissionais de saúde será composio de dados pessoais, $n^{\circ}$ de capacitaçỏes $\mathrm{cm}$ hansenologia e tempo de trabaho na área e planejamento familiar, dirocionamento nas ap̧os de anticoncepçâo de mulheres com hanseniase em idade férti. Os critérios para inclusáo das mulhores sáo: ser portadora ou ox-portadora de hanseniase; ter idade de 14 a 49 anos; ser residente em Maceió: - ostar om tratamento ou ter finalkzado o tratamento nos últimos cinco anos. Os critérios para inclusáo dos profissionais săo: ser médico ou enfermeiro; trabalhar na atençăo básica ou unidades de referência que tenham açbes de hanseniase implantadas; e trabalhar com açōes do hanseniase, no minimo, há seis moses. Serdo excluidas as mulheres que realizaram histerectomia e aquelas na faixa otária que já tiverom entrado na menopausa 0 meninas na laíxa etária de 10-13 anos. Entre os profissionais de saúde, serấo excluidos os que nấo atendem mulheres em idade fèrtil com hansoniase. A pęquisa sorá suspensa caso haja a retrada da autorizaçấ por parte da direçâo das unidades básicas de saúde, ou perda dos dados coletados e/cu rasuras dos questionários. Ou se os sujetos da pesquisa, por quaisquer motivos, desistirem de participar da mesma. Os riscos associados a este estudo estáo relacionadoos a náo interpretaçéo lđônea desta pesquisa, tanto pelas mulheres em idade térail portadores $\theta$ exportadoras de Hanseniase, uma vez que catas podem sentir-5e constrangidas diante dos questionamentos, corne também os profissionais de saúde podem tor resisténcia por julgarem que serảo avaliados. Para óminuir estes riscos, a pesquisadora agirá da forma mais clara possivel com os pesquisados, dando informaçóes relativas à pesquisa e mantendo sigilo durante a entrevista, identficando os pesquisados atravús do número do instrumento $\theta$ do prontuário. Os beneficios sáo informaçbes obtidas para a importância do planejamento familiar para a anticoncepçáo, evitando riscos gestacionais e para se concepto. Tais informaçōes seráo repassadas através de técricas de dinámica de grupo com metodologias ativas quern possam facilitar a compreensabo e entencimento da femática pelas mulheres, sendo esperado que as mesmas possam priorizar as açóes de planejamento familiar como prevençâo de uma gravidez de risco.

III) TCLE (linguagem adequada, descrição dos procedimentos, identificaçào dos riscos e desconfortos esperados, endereço do responsávol, ressarcimento, sigilo, liberdade de recusar ou retirar o consentimento, entre outros):

Apresentado com identificaçăo das diretrizes definidas na Resolução 196/96 CNS/MS.

IV) CONCLUSÃO DO PARECER

\section{APROVADO}

\section{V) CONSIDERAÇOES}

Ilna. Profe. MSc. Cledis Maria Tavares, lembre-se que, segundo a res. CNS 196/96.

- Sujeito da pesquisa lem a liberdade de recusar-se a participer ou de retirar seu consentimento em qualquer fase da pesquisa, sem pensização alguma e sem projuizo ao sou cuidedo o deve receber ópia do TCLE, na integra, por eic assinado, a nåo ser om estudo com autorização de declínio;

- V.S deve desenvolver a posquisa conforme delineada no protocolo aprovado a descontinuar o estudo somente após análise das razb́es da descontinuidade por este CEP, excoto quando perceber risco ou dano náo previsto ao sujehto parficipante ou quando constatar a superioridade de regime oferecido a um dos grupos da pesquise que requeiram açăo imediata: 
- O CEP deve ser imediatamente informado de todos os fatos relevantes que altorom o curso normal do estudo. É responsabiidade do pesquisador, assegurar medidas imediatas adequadas a evento adverso corrido e enviar notificaçáo a esto CEP:

- Eventuais modisicaçōes ou emendas ao protocolo devem ser apresentadas ao CEP de forma clara o sucinta, identificando a perte do protcoolo a ser modificada e suas justificativas;

- Seus relatórios parciais e final devem ser apresentados a este CEP, inicialmente em 07/08/2012 e ao término do estudo. A fata de ervio de, peio menos, o relatório final da pesquisa implicará em năo recebimento de um próximo protocolo de pesquisa de vossa autoria.

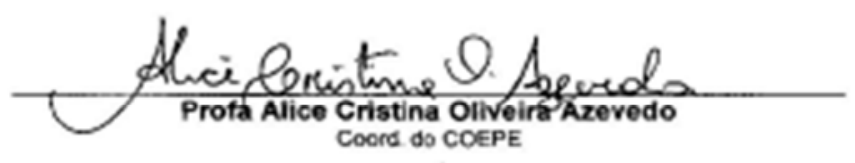

Atenciosamente, 
ANEXO 7

\section{AUTORIZAÇÃO DA SECRETARIA MUNICIPAL DE MACEIÓ-AL}

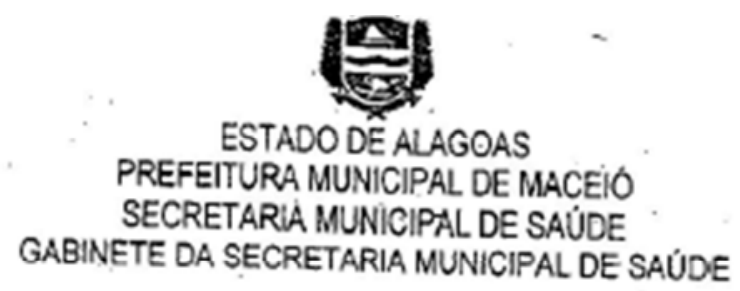

\section{AUTORIZAÇÃO}

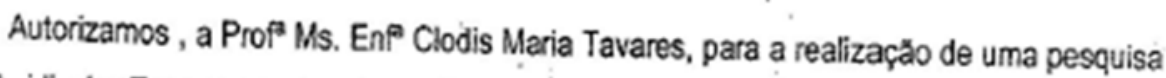
que subsidiarả a Tese de Doutorado em Ciências da Enfermagem pela Universidade Estadual de Sằo Paulo.(USP), "Análise das Açð̄es de Anticoncepçăo em mulheres em idade fértil com Hanseniase" que será realizada na Atençăo Básica de Saúde de Maceió. Com o objetivo de analisar as acōes de Saúde dirigidas a anticoncepçắo de mulheres em idade fértil portadoras de Hanseniase.

A referida pesquisa contará com o acompanhamento das respectivas Coordenaçōes desta Secretaria envolvidas. Assim como, a referida pesquisadora deverá apresentar a esta secretaria os resultados e discussões obtidos ao término do trabalho.

Maceió, 27 de Fevereiro 2012.

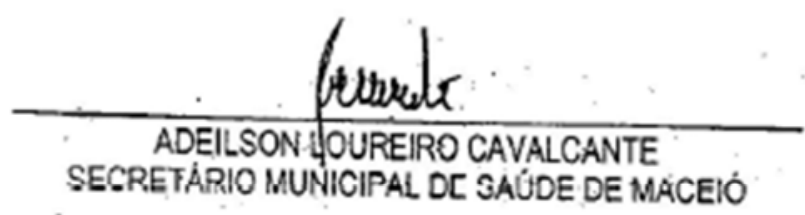

Rua Dias Cabral, n'569, Sala 411 Centro

MaceiOIAL- CEP 57.020-250, Fone: (DB2*)3315.6226

E-mail: codrhsms, al egmail.com 